NBER WORKING PAPER SERIES

\title{
MIGRATION AND INFORMAL INSURANCE: \\ EVIDENCE FROM A RANDOMIZED CONTROLLED TRIAL AND A STRUCTURAL MODEL
}

\author{
Costas Meghir \\ Ahmed Mushfiq Mobarak \\ Corina D. Mommaerts \\ Melanie Morten \\ Working Paper 26082 \\ http://www.nber.org/papers/w26082 \\ NATIONAL BUREAU OF ECONOMIC RESEARCH \\ 1050 Massachusetts Avenue \\ Cambridge, MA 02138 \\ July 2019, Revised January 2021
}

We thank the editor Dirk Krueger and four anonymous referees for helpful comments. We also thank Pascaline Dupas, Andrew Foster, John Kennan, Ethan Ligon, Fabrizio Perri, Mark Rosenzweig, Rob Townsend, and Alessandra Voena for comments. We are grateful to seminar participants at the 2014 IFS/CEAR Household Workshop, the 2015 SED meeting, the 2015 Barcelona Summer Workshop, the 8th International Conference on Migration and Development, the 2017 NBER Summer Institute, Princeton University, University of Namur, Paris School of Economics, Toulouse School of Economics, the University of Kansas, and the University of California, Berkeley. Costas Meghir thanks the Cowles Foundation and ISPS at Yale for financial support. Some of the computing for this project was performed on the Sherlock cluster. We would like to thank Stanford University and the Stanford Research Computing Center for providing computational resources and support that contributed to these research results. Any errors are our own. The views expressed herein are those of the authors and do not necessarily reflect the views of the National Bureau of Economic Research.

At least one co-author has disclosed additional relationships of potential relevance for this research. Further information is available online at http://www.nber.org/papers/w26082.ack

NBER working papers are circulated for discussion and comment purposes. They have not been peer-reviewed or been subject to the review by the NBER Board of Directors that accompanies official NBER publications.

(C) 2019 by Costas Meghir, Ahmed Mushfiq Mobarak, Corina D. Mommaerts, and Melanie Morten. All rights reserved. Short sections of text, not to exceed two paragraphs, may be quoted without explicit permission provided that full credit, including $\odot$ notice, is given to the source. 
Migration and Informal Insurance: Evidence from a Randomized Controlled Trial and a Structural Model

Costas Meghir, Ahmed Mushfiq Mobarak, Corina D. Mommaerts, and Melanie Morten

NBER Working Paper No. 26082

July 2019, Revised January 2021

JEL No. D12,D52,J6,O12,R23

\section{ABSTRACT}

We document that an experimental intervention offering transport subsidies for poor rural households to migrate seasonally in Bangladesh improved risk sharing. A theoretical model of endogenous migration and risk sharing shows that the effect of subsidizing migration depends on the underlying economic environment. If migration is risky, a temporary subsidy can induce an improvement in risk sharing and enable profitable migration. We estimate the model and find that the migration experiment increased welfare by $12.9 \%$. Counterfactual analysis suggests that a permanent, rather than temporary, decline in migration costs in the same environment would result in a reduction in risk sharing.

Costas Meghir

Department of Economics

Yale University

37 Hillhouse Avenue

New Haven, CT 06511

and IZA

and also NBER

c.meghir@yale.edu

Ahmed Mushfiq Mobarak

Yale School of Management

135 Prospect Street

Box 208200

New Haven, CT 06520

and NBER

ahmed.mobarak@yale.edu
Corina D. Mommaerts

Department of Economics

University of Wisconsin-Madison

1180 Observatory Drive

Madison, WI 53706

and NBER

cmommaerts@wisc.edu

Melanie Morten

Department of Economics

Stanford University

579 Serra Mall

Stanford, CA 94305

and NBER

memorten@stanford.edu

A randomized controlled trials registry entry is available at https://www.socialscienceregistry.org/trials/1165 


\section{Introduction}

Poverty is highly concentrated in rural areas. Four out of every five poor households in Asia are rural (Asian Development Bank, 2007), and many of these households rely on risky, weather-dependent agricultural activities. Rural livelihoods are therefore both volatile across years, and fluctuate across seasons with the crop cycle. To address this uncertainty, agrarian households smooth consumption and manage risk using two primary mechanisms: they share risk with other members of their community (Munshi and Rosenzweig, 2016; Ferrara, 2003), and they migrate to diversify income sources (Banerjee and Duflo, 2007). However, each of these mechanisms is imperfect. Informal risk sharing provides only partial insurance (Townsend, 1994; Ligon et al., 2002; Kinnan, 2020), and migration may be costly or itself risky (Bazzi, 2017; Beam et al., 2016). The two approaches may also interact with one another. The presence of a safety net at home might either facilitate or deter risky migration. New migration opportunities might either undermine informal insurance schemes by providing exit options or, conversely, produce spillover benefits for other members of the network through transfers and sharing of the extra migration income. Therefore to understand the overall welfare effects of encouraging migration, it is necessary to consider the effects of migration on risk sharing.

In this paper, we study the interaction between migration and social safety nets by examining how new migration opportunities affect the nature and extent of informal risk sharing within those villages. We have three main objectives. The first is to empirically estimate the causal effect of migration subsidies on risk sharing. We take advantage of the randomized controlled trial (RCT) described in Bryan et al. (2014) in which households 
in rural Bangladesh were randomly offered subsidies to migrate temporarily during the agricultural lean season. While existing evaluations of the program consider only the effects on direct beneficiaries (Bryan et al., 2014; Lagakos et al., 2018), we analyze the spillover effects on the entire risk-sharing network. The second objective is to interpret and explain our empirical findings using a model of endogenous risk sharing and endogenous migration, allowing for the complex set of interactions between the two. We build upon the model in Morten (2019) and show that migration subsidies can interact with the underlying risk environment to generate either positive or negative spillovers; this is an important insight because it demonstrates that the welfare effects of policy are heavily context dependent. We thus characterize key features of the environment and of preferences that can alter how these policies interact. Our third objective is to estimate this model using the experimental variation, use these estimates to quantify the welfare effects of migration subsidies that we implemented, and consider counterfactual policies of permanent migration subsidies and unconditional cash transfers.

The Bangladesh experiment provided very poor agrarian households money for the round-trip bus fare (worth USD 8.50) conditional on one member migrating temporarily. Bryan et al. (2014) present the effects of the experiment on direct beneficiaries. The subsidy offer led to a 22 percentage point increase in migration in the first year, household consumption increased by $30 \%$ for those induced to migrate, and migration rates remained 11 percentage points higher during the next lean season, one year after the one-time subsidy was removed. Our analysis goes beyond these direct benefits and considers the indirect spillover effects on households in the village that did not send migrants themselves. We document several types of experimental evidence that suggest 
that risk sharing improved in treatment villages. For both migrants and non-migrants, actual transfers between households increased, households in treatment villages became more likely to report that they receive help from family and friends in the village, and treatment reduced the effect of household income on household consumption by over seven percentage points (a reduction of $40 \%$ ). We also show that these results are not driven by an increase in self-insurance (savings) nor by an increase in measurement error. These changes in risk sharing imply that analyzing only the direct effects of the migration subsidies gives an incomplete picture of the overall welfare effects.

Next, in order to understand why subsidies for migration led to an improvement in risk sharing in this context, we develop a model in which both migration and risk sharing are endogenous and jointly determined. The model allows us to study the underlying economic mechanisms that link migration and risk sharing, which is important because our results are in contrast to Morten (2019), who found that in rural India, an increase in migration led to a crowding-out, rather than a crowding-in, of informal insurance. We reconcile these conflicting empirical results by showing that it is possible to get either crowd-in or crowd-out of risk sharing from the same theoretical model under different local conditions and preferences and also different assumptions about the permanence of the policy itself. Our model augments Morten (2019), which considers a model with limited commitment constraints on risk sharing (Kocherlakota, 1996; Ligon et al., 2002; Krueger and Perri, 2010) and an endogenous migration decision based on the net return to migrating (Harris and Todaro, 1970). To that we add the possibility that migrants develop contacts in the city, allowing them to better obtain jobs. This "asset" can lead to persistence in migration episodes. We model the migration subsidy in a flexible, agnostic 
way: alongside the USD 8.50 financial subsidy, we allow the experiment to change the utility value of migrating resulting from the encouragement offered by the experimental design and from the fact that increased migration allowed people to migrate with their friends. We estimate the value of this "utility subsidy" by matching the experimental responses of migration and risk sharing. ${ }^{1}$

As mentioned above, the model can explain why a migration subsidy can induce either an improvement or a decline in risk sharing in different contexts. In many settings, migration is a risky lottery: a household gives up some income in the village for a chance at income in the destination (Harris and Todaro, 1970). A migration subsidy increases the return to migrating, which may have two effects. On the one hand, increasing migration may increase the total resources available to the village, thus increasing the social return to the village of pooling income through risk sharing. On the other hand, the migration subsidy increases the private return to migrating, thus affecting the incentive to participating in risk sharing. For example, if it is very risky to migrate, the private return to migrating may be much lower than the social return because without insurance migration is simply too risky to undertake. In contrast, if it is relatively safe to migrate, then the migrant may not need the safety net provided by the network, and a migration subsidy may lead to crowding-out of informal risk sharing. We show, by simulating the model for different values of migration risk and subsidy levels, that we can indeed generate both positive and negative spillovers of a migration subsidy on risk sharing.

While the RCT allows us to estimate the effect of the subsidies on risk sharing directly,

\footnotetext{
${ }^{1} \mathrm{~A}$ later round of experiments in the same villages found that people are more likely to migrate when others in the village are offered subsidies, even if they themselves were not subsidy recipients (Akram et al., 2018).
} 
the issues discussed above demonstrate that a theoretical framework is essential to understand the underlying reasons behind our empirical result of improved risk sharing and how it may change in other contexts. We thus use the results from the RCT to estimate a model that allows us to identify the underlying parameters. By combining our model with experimental variation, we achieve cleaner identification by not having to rely only on observational data, as Morten (2019) did. The model itself provides a powerful toolkit for analyzing alternative policies, and the resulting combination adds to a nascent but growing literature that combines RCTs and structural models (see, for example, Attanasio et al. (2012); Todd and Wolpin (2006); Kaboski and Townsend (2011)). We estimate parameters that characterize income processes, migration costs, migration asset paths, and preferences to match experimental outcomes over three periods. Our model can replicate the dynamics and treatment effects of migration and risk sharing.

Using these estimates, we quantify the overall welfare effect of the migration subsidies and conduct counterfactual experiments to evaluate different policy levers. We estimate that the experiment led to an increase in welfare equivalent to a $12.9 \%$ permanent increase in consumption the year the experimental subsidies were disbursed, net of the subsidy itself. While some of this gain is due to increased resources from migration, the welfare gain is three times higher after accounting for the improvement in risk sharing compared to the gain without accounting for the improvement in risk sharing. We also show that alternative policies can have very different effects on risk sharing and welfare: an unconditional cash transfer leads to a slight improvement in risk sharing but a negligible effect on welfare, while a permanent conditional subsidy leads to a worsening of risk sharing but a positive welfare gain. 
Our analysis has two important implications for understanding policy impacts and the development process. First, it is crucial to account for spillover effects - which may be negative or positive - to understand the full welfare effect of any policy that addresses the income stream of households. This finding resonates with the growing literature estimating spillover effects from financial inclusion initiatives, which can also have either positive or negative interactions with risk-sharing (see, e.g., Angelucci and de Giorgi (2009) and Dupas et al. (2017)). Second, while in the current paper we focus on the causal effect of subsidizing migration on risk sharing, the fact that migration and risk sharing are jointly determined implies that any change to the ability of households to share risk may also affect migration. The underlying ability - whether through the economic environment or other policies - for households to share risk may thus itself influence whether households adopt new income-generating methods such as migration.

The paper continues by describing the data and experimental results on risk sharing in Sections 2 and 3. We then move to the model of endogenous risk sharing and migration in Section 4. We describe our estimation procedure in Section 5 and show, by simulating the model locally around our estimates, the key comparative statics driving the mechanisms in the model. We then consider model counterfactuals in Section 6 and conclude by discussing the broader implications of our findings for understanding the interaction between informal insurance and technology adoption. 


\section{Data}

The experiment randomly offered some households subsidies to temporarily emigrate from villages in a poor region of northern Bangladesh. This region is prone to a period of preharvest seasonal deprivation during September to December known as Monga, which was the original motivation for the experimental intervention. ${ }^{2}$ Bryan et al. (2014) provides additional details on the experiment and reports on the program evaluation, focusing on the direct beneficiaries. In this section, we describe the experiment and the data that is critical for understanding our analysis of the risk-sharing effects of this experiment.

The migration subsidy treatment was randomized at the village level. For all villages in our sample, a census was conducted to ascertain eligibility for the experiment, where eligibility was consistently defined as households who reported (a) having low levels of landholding and (b) that a household member had to skip at least one meal during the prior Monga season. In total, $56 \%$ of households satisfied both criteria. From the census, 19 households from each village were randomly selected from the group of eligible households to participate in the experiment and surveys, and these 19 households comprise our analysis sample. In treatment villages, all 19 households were offered the subsidy; in control villages none were offered the subsidy.

The migration subsidy was an offer of 600 Taka (USD 8.50) conditional on one person from the household migrating, with an additional 200 Taka given if the migrant reported to our enumerators in the destination. This amount is sufficient to cover the cost of a

\footnotetext{
${ }^{2}$ Income and consumption levels drop by roughly $50 \%$ and $25 \%$, respectively during this period (Khandker, 2012). Up to $60 \%$ of our sample respondents report missing meals during this period. This same phenomenon, colloquially known as the "hunger season," is prevalent in many poor agrarian societies around the world.
} 
return bus ticket and a few days food in the destination. The subsidy was offered in the form of a grant in 37 villages or a zero-interest loan in 31 additional villages. We follow Bryan et al. (2014) and combine these two into a 68-village "incentive" arm, and compare that against a 32-village "control arm" (composed of 16 villages where we provided general information about migration opportunities and 16 others where we did nothing).

The subsidies were distributed in August-September 2008. We will make use of three periods of data: (a) a pre-intervention survey conducted in July 2008, (b) effects during the intervention year, collected in 2008-2009, and (c) longer-run post-intervention data collected in 2011, approximately two-and-a-half years after the experiment. We rely heavily on 2011 data for our analysis of risk sharing because it is the only round to contain annual data on income, consumption, and migration. We provide a summary of the timing of the interventions and data collection in Appendix Table 2.

Table 1 shows summary statistics for the sample of households in 2011 that we use for estimation, which includes the 1900 households from the original experiment plus 627 new households from 33 randomly selected new villages in the same two districts using the same eligibility criteria. ${ }^{3}$ Statistics are shown separately for all households (column 1 ), households in control villages (column 2), and households in incentive villages (column 3). Our main measures of interest are income, consumption, and migration rates, but we also show summary statistics of other measures of consumption smoothing. For income and consumption, we exclude outliers by trimming the top and bottom percentiles as well as households whose migration or treatment status is missing. ${ }^{4}$

\footnotetext{
${ }^{3}$ In 2011, additional experiments were also run in the sample. Our primary analysis focuses on analyzing the longer-run effects of the original (2008) experiments. We discuss robustness tests addressing the
} 


\section{Table 1: Summary statistics (post-intervention)}

Note: Income, consumption, savings, and transfers are in Taka (approximately 75 Taka per USD in 2011). Income and consumption are annual and per capita.

\subsection{Income}

We use three measures of income in our analysis: home income, city income, and total income. Home income comprises income earned by the household in the rural village and consists of wage income, non-farm business income, agricultural income (crops and noncrops, valued at prices they would have obtained if they sold them), and miscellaneous income such as lottery winnings and interest income. We do not include transfers from other members of the community in income. City income is defined as earnings (both monetary and in the form of housing and food) during migration episodes, net of travel costs (such as train, bus, and rickshaw) to and from the migration destination. Total income is the sum of home income and city income. Each of these measures span the previous 12 months and are thus annual measures of income. ${ }^{5}$

Following Bryan et al. (2014), we convert these measures to per capita amounts by additional (2011) experiments in Section 3.

${ }^{4}$ For the original balance tables of the baseline sample in 2008, see Bryan et al. (2014). Since the focus of their paper was not risk sharing, we additionally plot the distributions of baseline income and consumption in Appendix Figure 4 and show that neither the difference in means nor the difference in distributions are statistically significant from zero between treatment and control households. Additionally, the baseline "treatment" effect from a risk-sharing regression (as described in Section 3) using baseline income and consumption results in a small and insignificant coefficient of 0.026 with standard error 0.028 . Our main sample trims the top and bottom 5\% of the data; we show in Appendix Table 7 that our results are robust to using more conservative trimming thresholds. Average income is 5\% higher and average consumption is $3 \%$ higher with a $1 \%$ trim.

${ }^{5}$ Specifically, to capture daily wage employment respondents were asked about the daily wage in cash in the past 12 months and the number of days worked, as well as in-kind payment with quantity and price. Salaried workers were asked how many months worked, the monthly cash salary, and other in-kind benefits converted to Taka. For non-agricultural enterprises, respondents were asked how many months it operated in the past 12 months, profits, and share kept by the household. For agricultural crop and noncrop production, the total of each crop produced in the past 12 months was asked, and the amount sold and money obtained minus cost. Migration income was ascertained over the last 4 months. Other income was also asked about the past 12 months. 
dividing by the household size, defined as all individuals reported to be living in the house for at least seven days at the time of the interview (which may or may not include migrants, depending on when they returned home). ${ }^{6}$ City income is around $20 \%$ of home income, and households in treatment villages have slightly higher home income and city income than households in control villages.

\subsection{Consumption}

Our measure of consumption closely follows Bryan et al. (2014) and consists of 215 food items and 63 non-food items. Some of these items have a weekly recall and others have a bi-weekly or monthly recall, so we convert these items to annual and per capita amounts in order to be consistent with our measure of income. Like income, consumption for households in treatment villages is higher than consumption for households in control villages. ${ }^{7}$

\subsection{Other summary statistics}

Households in our sample typically contain four members, and around $40 \%$ of households sent a migrant over the course of the year. $47 \%$ of households saved some amount during the year, but the amounts were very small (under 400 Taka). In contrast, many households gave or received transfers from other households in the community: 57\%

\footnotetext{
${ }^{6}$ In the next section we show that our main estimated treatment effect of income on consumption is robust to alternative household size definitions, including the current number of household members at the time of the interview and the number of household members who are living in the house for at least 14 days at the time of the interview.

${ }^{7}$ Total consumption is higher than total income, as is often found in rural household survey data collected in agrarian areas. The ratio of income to consumption, however, does not vary significantly between treatment and control households.
} 
received transfers, averaging 5,600 Taka, and 18\% gave transfers, averaging 2,800 Taka. ${ }^{8}$

Appendix Tables 3 and 4 give more information on the migration experience, based on surveys of incentivized migrants in the destination and survey data from both incentivized and nonincentivized migrants at endline. Based on the endline data, $65 \%$ of migrants migrated to a rural area. $54 \%$ of migrants worked in the agricultural sector, $24 \%$ worked as non-agricultural day laborers, $10 \%$ in the transportation sector, and $12 \%$ in other sectors. $56 \%$ of migrants reported earning less than they expected. Survey data from incentivized migrants in the destination shows that $98 \%$ of migrants found work, with $89 \%$ reporting that the wage was higher than their home wage. Migrants predominantly traveled in groups, with only $22 \%$ migrating alone. $70 \%$ of migrants split food costs and accommodation with their group members, and 73\% of migrants exchanged information about jobs with other members in their group.

\section{Effect of the experiment on risk sharing}

As Table 1 shows, households often engage in direct transfers between each other, presumably as a way to protect themselves against bad income realizations. In this section, we empirically investigate whether offering migration subsidies affects the functioning of risk-sharing networks. We take the risk-sharing network to be the village. By com-

\footnotetext{
${ }^{8}$ The summary statistics in Table 1 show that average transfers received by members in the sample are approximately six times larger than average transfers sent. The reason for this difference is that only the poorest households in the village (based on land holdings and on experiencing hunger the previous year) were eligible for the experiment and thus included in the dataset; we verify in Appendix $C$ that, as expected, net transfers out increase with income. We note that any imbalance in the total amount of income to be shared amongst eligible households does not affect the regressions within the observed data, as the village fixed effect controls for the total resources in the network. However, one caveat to our structural estimation is that we estimate the model using only data on eligible households.
} 
paring treatment villages to control villages, we conduct direct tests of the effect of the experiment on several measures of transfers and risk sharing.

\subsection{Effect on financial transfers}

We start by showing that actual transfers, as well as the household's self-reported willingness to ask for help, were affected by the migration subsidies. Table 2 regresses these measures on treatment to test whether the experiment changed these beliefs in the financial arrangements between villagers ("Willingness to help") and the transfers that occurred ("Actual transfers").

Each row in the first column is a separate regression of the effect of treatment on each outcome between community members (i.e., family, friends, and other villagers). The second column contains the mean of the variable among households in the control group. The top panel suggests that the experiment significantly increased the willingness of households to interact financially. For example, $57 \%$ of households in control villages report that community members would ask them for help, and treatment increases that by 11 percentage points. Not only are such intentions affected in villages where migration subsidies were offered, but actual amounts of transfers also increased as a result of treat-

ment. While there is no change detected in the probability of receiving a transfer, treatment increased the value of transfers received (among those who did receive) by 1,821 Taka off a base of 4,808 Taka, or $38 \%$. The results for transfers given are even stronger: a 3.6 percentage point increase in the propensity to give, and a 1,310 Taka $(65 \%)$ increase in the amount given, conditional on giving. Since we collect data on a set of people within 
the village who recently received external migration subsidies, it is perhaps sensible that the results on "transfers given" are larger than those on "transfers received."

Table 2: Treatment effect on transfers within the community

\begin{tabular}{lcc}
\hline & Treatment effect & Control mean \\
\hline Willingness to help & & \\
Community member would help you & 0.030 & 0.85 \\
& $(0.020)$ & 0.83 \\
... and you would ask for help & 0.025 & 0.57 \\
Community member would ask you for help & $0.109^{* * *}$ & 0.53 \\
... and you would help them & $(0.033)$ & \\
Actual transfers & $0.109^{* * *}$ & 0.57 \\
Receive any transfer from community member & $(0.032)$ & 4808 \\
Amount, if any transfer received (Tk) & -0.024 & \\
Give any transfer to community member & $(0.022)$ & 0.15 \\
Amount, if any transfer given (Tk) & $\left(621^{* * *}\right.$ & 2001 \\
\end{tabular}

Note: The sample includes households from the 2011 survey. Each cell is a separate regression of the effect of treatment on whether the source denoted in the row would behave as described. Each regression also controls for upazila (county). Standard errors, clustered by village, are in parentheses, and the mean of the control group is in square brackets. ${ }^{*} p<0.10,{ }^{* *} p<0.05$, *** $p<0.01$.

Perhaps the act of migration leads to migrants bringing back gifts for friends in the village, which could be why we observe the increase in "transfers given," but this does not signal a broader improvement in risk sharing. In Appendix Table 5 we repeat the analysis of transfers separately for households that sent a migrant in the past year and those that did not. ${ }^{9}$ The results show similar effects for both the migrant and non-migrant samples. Migration not only increased the willingness to share risk among particular

\footnotetext{
${ }^{9}$ Although this sample split is endogenous to the decision to migrate, we argue that it provides suggestive evidence of risk-sharing benefits spilling over to households in the village that did not receive the direct migration incentives provided by the experiment.
} 
households that were induced by the experiment to send a migrant but strengthened informal relationships within a village more broadly.

There are three takeaways from these results. First, there is a strong norm that households would provide and receive financial assistance among each other, as shown in the summary statistics of Table 1 . Second, the point estimates show that the migration experiment significantly increased the willingness of households to participate in these arrangements as well as actual transfers between households. Third, this increase is not limited to households that were induced to migrate: non-migrant households in treatment villages also reported an increase in the ability to use these informal arrangements.

\subsection{Effect on the exposure of consumption to income}

Since it is difficult for survey data to enumerate the full range of relevant gifts, transfers, and loans, or to determine whether these transfers were made in response to an income shock or otherwise, we now investigate the effect of the experiment on the extent to which income relates to consumption. We test two key ideas. First, we explore the exposure of consumption to income as a measure of informal insurance within the village. Second, we investigate whether the experiment changed this exposure.

We first consider the exposure of consumption to income in control villages by regressing log of per capita household consumption on three alternative measures of log of per capita household income using the following regression:

$$
\log C_{i v}=\gamma_{v}+\beta \log Y_{i v}+\epsilon_{i v}
$$


where $\log C_{i v}$ and $\log Y_{i v}$ are household $i$ 's $\log$ per-capita consumption and income, respectively, in village $v$. Village fixed effects $\gamma_{v}$ control for aggregate shocks to consumption. ${ }^{10}$ The main parameter of interest is $\beta$, which captures the exposure of consumption to income, conditional on differences in aggregate resources across villages.

Table 3: Exposure of consumption to income among control villages

\begin{tabular}{lccc}
\hline & \multicolumn{3}{c}{ Log consumption } \\
\cline { 2 - 4 } & $(1)$ & $(2)$ & $(3)$ \\
\hline Log total income & $0.165^{* * *}$ & & \\
& $(0.021)$ & & \\
Log village income & & $0.122^{* * *}$ & \\
& & $(0.018)$ & \\
Log migration income & & & $0.117^{* * *}$ \\
& & & $(0.032)$ \\
\hline Sample & Full & Full & Migrants \\
Observations & 911 & 946 & 350 \\
$R^{2}$ & 0.217 & 0.194 & 0.298 \\
\hline
\end{tabular}

Note: The sample includes households in control villages in the 2011 survey. The dependent variable is $\log$ of annual total per-capita consumption and the independent variable is log of annual per-capita total income. Each model also includes village fixed effects. Standard errors, clustered by village, are in parentheses. ${ }^{*} p<0.10,{ }^{* *} p<0.05,{ }^{* * *} p<0.01$

Table 3 reports the results of Equation (1) using total income (column 1), home income (column 2), and city income among migrant households (column 3) in the sample of control villages in the "post-intervention" period. In all cases, the income coefficient is significantly different from zero, consistent with the absence of full insurance, and its value below one is also consistent with the presence of a substantial degree of partial insurance in the non-treatment state.

The next sets of regressions leverage the experimental variation in the data to test

\footnotetext{
${ }^{10}$ Below, when we go on to consider the effect of the program on the exposure of consumption to income, we also include household fixed effects to control for permanent income differences and the results we obtain do not change significantly.
} 
whether a one-time exogenous decrease in migration costs via the experiment led to a change in the coefficient on log income in the consumption regression in a subsequent year. We augment Equation (1) to allow the transmission parameter $\beta$ to vary by whether the village is in the treatment sample:

$$
\log C_{i v}=\gamma_{v}+\beta_{0} \log Y_{i v}+\beta_{1}\left(\log Y_{i v} * T_{v}\right)+\epsilon_{i v}
$$

where $T_{v}$ is an indicator variable taking a value of 1 if the village is a treatment village. ${ }^{11}$ The main parameter of interest in this regression is $\beta_{1}$, which captures the effect of the migration treatment on the exposure of consumption to income.

Column (1) in Table 4 reports $\beta_{0}$ and $\beta_{1}$ using total per-capita income and consumption. We find a negative coefficient on the interaction between log income and the migration treatment, consistent with an improvement in risk sharing. Specifically, treatment reduced the effect of household income on household consumption by over seven percentage points. Compared to an exposure of consumption to income shocks of $16 \%$, the migration treatment cuts this exposure by around $40 \%$. These estimates are robust to the definition of household size and household composition (see Appendix Table 9) and are particularly large given that they are intent-to-treat estimates. ${ }^{12}$

\footnotetext{
${ }^{11}$ The treatment indicator captures villages randomized to receive migration subsidies in 2008 . As described in Footnote 3, additional experiments were implemented in 2011. We control for the additional round of treatments through the village fixed effects and additional interaction terms between log income and 2011 treatment arms. The 2011 treatments were implemented outside the Monga period (around April) and did not have any effects on the coefficient on log income. We also run these specifications using only households that did not receive any additional 2011 experiments (i.e., were "pure" control villages) in Appendix Table 8 . We find similar results.

${ }^{12}$ We report ITT rather than LATE (IV) estimates because treating one household may affect a neighbor's consumption through changes in demand for transfers - even absent sharing any extra migration income so the exclusion restriction for the IV would be violated.
} 
Table 4: Effect of migration incentives on the exposure of consumption to income

\begin{tabular}{|c|c|c|c|c|c|c|}
\hline & \multicolumn{4}{|c|}{ Round 4} & \multicolumn{2}{|c|}{ Diff in Diff } \\
\hline & $(1)$ & $(2)$ & (3) & (4) & (5) & (6) \\
\hline Log income (round 4) & $\begin{array}{c}0.157^{* * *} \\
(0.027)\end{array}$ & $\begin{array}{c}0.169^{* * *} \\
(0.028)\end{array}$ & $\begin{array}{c}0.130^{* * *} \\
(0.028)\end{array}$ & $\begin{array}{c}0.140^{* * *} \\
(0.029)\end{array}$ & $\begin{array}{c}0.112^{* *} \\
(0.054)\end{array}$ & $\begin{array}{c}0.109^{* *} \\
(0.046)\end{array}$ \\
\hline Treatment effect on log income & $\begin{array}{c}-0.073^{* * *} \\
(0.027)\end{array}$ & $\begin{array}{c}-0.066^{* *} \\
(0.027)\end{array}$ & $\begin{array}{c}-0.072^{* * *} \\
(0.027)\end{array}$ & $\begin{array}{c}-0.061^{* *} \\
(0.026)\end{array}$ & $\begin{array}{l}-0.077 \\
(0.061)\end{array}$ & $\begin{array}{c}-0.099^{* *} \\
(0.046)\end{array}$ \\
\hline Village-round FE & $x$ & $x$ & $x$ & $x$ & $x$ & $x$ \\
\hline Household FE & & & & & $x$ & $X$ \\
\hline Household head controls & & $X$ & & $x$ & & \\
\hline Resource controls & & & $X$ & $x$ & & \\
\hline Includes baseline & & & & & $X$ & $X$ \\
\hline Includes 2013 & & & & & & $x$ \\
\hline Observations & 1857 & 1857 & 1857 & 1857 & 2166 & 4371 \\
\hline R squared & 0.186 & 0.221 & 0.217 & 0.267 & 0.791 & 0.721 \\
\hline
\end{tabular}

Note: Table presents coefficients of the effect of log annual per capita income on log annual per capita consumption and the interaction with treatment ( $\beta_{0}$ and $\beta_{1}$ from Equation 2$)$. All models control for village fixed effects and all other interactions between treatment and log income as well as log income interacted with 2011 treatments. Column (2) additionally adds household head controls, column (3) adds household resource controls, and column (4) adds both household head and resource controls. Columns (5) and (6) show the result of difference-in-difference specifications, with the first coefficient shown being the interaction between log income and round 4, and the second coefficient shown being the interaction between treatment, log income, and a post-experiment indicator. Column (5) includes baseline data, and column (6) includes both baseline and 2013 data, and both include household fixed effects. ${ }^{*} p<0.10,{ }^{* *} p<0.05$, ${ }^{* * *}$ $p<0.01$ 
One concern with the interpretation of these estimates is that the cross-sectional coefficient on log income may be conflating a risk-sharing effect with a level difference in permanent income. Thus, Columns (2)-(6) of Table 4 report a variety of robustness checks to control for such differences. ${ }^{13}$ Columns (2)-(4) add observable characteristics to the specification, including household head controls (e.g., education) in column (2), household resource controls (e.g., characteristics of the house) in column (3), and both household head and resource controls in column (4). The coefficients on both $\beta_{0}$ and $\beta_{1}$ are very similar across specifications, with $\beta_{1}$ ranging from -0.061 to $-0.072 .{ }^{14}$ To allow for permanent income differences, columns (5) and (6) control for household fixed effects in an approach dating back to Townsend (1994) by leveraging baseline data (column 5) and additionally 2013 data (column 6). ${ }^{15}$ Using a difference-in-difference specification, ${ }^{16}$ these columns show similar results; we lose significance on the treatment effect when controlling for household fixed effects with just two observations per household, but it returns with three observations. Overall, the differences across columns in both $\beta_{0}$ and $\beta_{1}$ are not statistically distinguishable. In addition to these robustness checks, we note that these regressions should be interpreted in conjunction with the previous transfer evidence; both

\footnotetext{
${ }^{13}$ Additionally, we note that treatment was randomly allocated, so even if the cross-sectional coefficient on log income is biased (because both income and consumption may depend on permanent unobserved heterogeneity), the treatment effect does not necessarily suffer from bias. Appendix A.1 derives the conditions for the treatment effect to be unbiased in the presence of permanent unobserved heterogeneity. The key condition is that the treatment effect on log income is additive. Our empirical result that the treatment effect is stable with and without fixed effects is consistent with this theoretical result.

${ }^{14}$ Results are also similar if we focus only on villages that were included in the baseline experimental sample.

${ }^{15}$ A caveat with the 2013 data-and the reason we do not use it elsewhere in the paper- is that there are data quality concerns. Specifically, there was a significant amount of political strikes and strike-induced violence in 2013, which made data collection difficult and likely changed migration behavior considerably (see Akram et al. (2018) for more details).

${ }^{16}$ The treatment effect on log income in columns 5 and 6 is the interaction between log income, the treatment indicator, and the post-experiment indicator.
} 
provide evidence consistent with an improvement in risk sharing in treatment villages. In sum, using different methods, all of our results taken together point to an improvement in risk sharing in treatment villages as a result of the intervention.

Another potential concern with the results in Table 4 is that our ability to measure income for treatment households may be less accurate than for control households, either because migration income is inherently more difficult for the econometrician to capture, or because migration income is easier to hide both from other households and from the econometrician. ${ }^{17}$ If such measurement error were classical, either of these measurement issues may create an attenuation bias in treatment effect estimates. To investigate this, we repeat the analysis from Table 4 among households that did not send a migrant. ${ }^{18}$ We present results in Appendix Table 8. While this is an endogenously selected sample, our ability to measure their income should not vary by treatment, and hence, this exercise should help to address the measurement concerns. The results show that treatment also reduces the coefficient on log income for non-migrant households, suggesting that measurement concerns are not driving the treatment effects we observe in Table 4 . These estimates are consistent with the experiment changing the risk-sharing equilibrium be-

\footnotetext{
${ }^{17}$ Appendix Table 6 report the effects of various sub-treatments that could help discern the presence of hidden income (Townsend, 1982; Rogerson, 1985; Ligon, 1998; Kinnan, 2020). If migration makes it easier to hide income because some of the income is earned away from other villagers' watchful eyes, risk sharing can break down. To investigate the relevance of hidden income in our setting, we take advantage of sub-treatment variations in the experiment, where some of those receiving migration subsidy offers were additionally required to migrate in groups. Those group members were either assigned by the experimenters in one sub-treatment or self-formed by the migrants in another. Columns (2) and (3) show that the treatment effect on the correlation between own-income and own-consumption continues to be negative, even when migrants are required to travel in groups or to particular destinations. There is no statistically significant change in the treatment effect when one of these requirements is imposed. This result suggests that hidden income may not be a key constraint limiting risk sharing in this setting. Our model presented in the next Section, therefore, focuses on limited commitment (as opposed to hidden income) as the primary friction undermining risk sharing.

${ }^{18}$ In addition, we run reverse regressions of log income on log consumption in Appendix Table 10, and the ratios of the "forward" and reverse regression coefficients are very similar between treatment and control samples.
} 
tween all households in the network, not only the subset who were induced to migrate.

A final concern is that the coefficient $\beta$ could mechanically decrease if the variance of income increased as a result of the experiment. While the result mentioned above showing that the coefficient also decreased among non-migrants should alleviate this concern, a more structural measure of risk sharing is the difference in the consumption equivalents between autarky and participating in the network. We consider this alternative measure later in the paper and show that it is consistent with our measure of the exposure of consumption to income.

\subsection{Effects on savings}

A change in the exposure of consumption to income does not necessarily imply a change in risk sharing across households if the migration subsidy offers also increased the household's ability to save. These households could be using savings (as opposed to migration and sharing risk with other households) as an alternative consumption-smoothing mechanism (although this would not explain why we see an improvement in risk sharing even among non-migrant households). In Table 5, we test the effect of the experiment on the amount saved over the past 12 months. Columns (1) and (2) show that there is no significant effect of treatment on the amount saved, both among the full sample of households (column 1) and the sample of those that reported saving a non-zero amount (column 2).

Not only are the treatment effects small and indistinguishable from zero, but mean savings is also very small. For example, mean savings in the control group is 155 Taka, which is $1.6 \%$ of their total annual income of 9,502 Taka. ${ }^{19}$ This is consistent with the

\footnotetext{
${ }^{19}$ Additionally, Appendix Table 12 reports statistics of additional measures of savings against village
} 
Table 5: Treatment effect on savings per capita

\begin{tabular}{lcc}
\hline & \multicolumn{2}{c}{ Amount saved in last 12 months (Taka) } \\
\cline { 2 - 3 } & $(1)$ & $(2)$ \\
& Unconditional & Conditional on any \\
\hline Treatment & 33.4 & 5.4 \\
& $(21.0)$ & $(37.4)$ \\
\hline Mean amount saved, control group & 155.3 & 363.5 \\
Observations & 2359 & 1101 \\
$R^{2}$ & 0.01 & 0.02 \\
\hline
\end{tabular}

Note: The sample includes households from the 2011 survey. The dependent variable is the amount saved (in Taka) per capita in the previous year, including zeros (column 1) and excluding zeros (column 2). Both models control for upazila (county) and 2011 treatment arms. Standard errors, clustered by village, are in parentheses. ${ }^{*} p<0.10,{ }^{* *} p<0.05,{ }^{* * *} p<0.01$

fact that these households are extremely poor, and the marginal propensity to consume any extra migration income during this lean (hungry) season is very high. These null savings results, coupled with substantial reductions in the coefficient on log income in the consumption regressions and significant increases in financial transfers, all point to the experiment causing a substantial improvement in the willingness and ability to share risk in treatment villages. To understand why this happened, we next turn to a model of endogenous migration and risk sharing.

\section{Joint model of risk sharing and migration}

We consider a joint model of risk sharing and migration based on Morten (2019). Households make migration decisions taking into account the returns to migrating, including risk-sharing transfers. We assume that risk sharing is constrained by limited commitment frictions (Kocherlakota, 1996; Ligon et al., 2002; Krueger and Perri, 2010). Other frictions

income for control villages and shows that mean liquid and cash savings are around $5 \%$ of mean household income and $10 \%$ of the standard deviation of household income. 
could affect informal risk sharing, such as moral hazard or hidden income, but several pieces of indirect evidence suggest that they are likely not key constraints: the treatment effect is the same across treated households that had to travel in unassigned versus assigned groups and to unassigned versus assigned destinations (Appendix Table 6), and the treatment effect is similar across home income and migration income (Appendix Table 11), which we would not expect if migration income is easier to hide. ${ }^{20}$

We extend the limited commitment framework in Morten (2019) to allow for a migration asset, which we think of as a job connection in the destination. This asset can be accumulated (or lost) over time, based on the experiences of the migrant in the destination. This extension will allow the model to approximate the fact that migrants tend to return to the same employer - for example, Bryan et al. (2014) find that $60 \%$ of incentivized migrants return to work for the same employer - which in turn allows the model to explain why the one-time experiment led to persistent effects on migration. In this setting, therefore, migration serves two purposes. First, within a period, it potentially increases the income available to the household. Second, because it allows individuals to update their migration asset, it provides a dynamic payoff for the future.

We model risk sharing as between two households, denoted by $i=\{1,2\}$, with identical preferences. We assume that households cannot save, which is consistent with the empirical finding in Section 3 that savings are very low and did not respond to the experiment, and has the benefit of making the model more tractable. ${ }^{21}$ The timing of the model

\footnotetext{
${ }^{20}$ Additionally, while other work has argued that permanent migrants may indeed have incentives to hide their income from family members (Joseph et al., 2015; Baseler, 2018), 76\% of the temporary migrants in our setting migrate with someone else, $84 \%$ of temporary migrants worked with another person from the same village, and of those that did, they worked with on average 6 other migrants from the same village. Thus it may be harder to hide income in this setting.

${ }^{21}$ The role of savings, especially hidden savings, may be important, however we note that in a limited
} 
is as follows. There are two sub-periods: a before-migration period, when the village income state is realized and migration decisions are made, and an after-migration period, when migration outcomes are realized and transfers and consumption occur. We describe what happens in each sub-period below. Figure 1 summarizes the model timing.

Figure 1: Model timeline

\begin{tabular}{|c|c|c|}
\hline Model period & Activities & State of the world \\
\hline $\begin{array}{l}\text { Start of period } t- \\
\text { Before migration - }\end{array}$ & $\begin{array}{l}\text { Start-of-period job contacts }\left(A_{t}\right) \\
\text { Observe village state }\left(s_{t}\right) \\
\text { Migration decision }\left(j_{t}\right)\end{array}$ & $h_{t}=\left\{s_{t}, A_{t}\right\}$ \\
\hline After migration - & $\begin{array}{l}\text { Exogenous creation of job contacts }\left(\hat{A}_{t}\right) \\
\text { Observe migration state }\left(q_{t}\right) \\
\text { Make risk-sharing transfers } \\
\text { Consume } \\
\text { Return to village } \\
\text { Exogenous separation of job contacts }\left(A_{t+1}\right)\end{array}$ & $\hat{h}_{t}=\left\{h_{t}, j_{t}, q_{t}, \hat{A}_{t}\left(h_{t}, j_{t}\right)\right\}$ \\
\hline Start of period $t+1-$ & $\begin{array}{l}\text { Start-of-period job contacts }\left(A_{t+1}\right) \\
\text { Observe village state }\left(s_{t+1}\right)\end{array}$ & $h_{t+1}=\left\{s_{t+1}, A_{t+1}\right\}$ \\
\hline
\end{tabular}

At the start of period $t$ both households are in the village. Each household receives a village income, $e^{i}\left(s_{t}\right)$, where $s_{t}$ denotes the realization (from a set of finite possibilities) of the state in the village. Each household $i$, based on its past migration, either has $\left(a_{t}^{i}=1\right)$ or does not have $\left(a_{t}^{i}=0\right)$ an active job connection in the city at the start of the period. We denote the before-migration job contact assets of both households by the vector $A_{t}=$ $\left\{a_{t}^{1}, a_{t}^{2}\right\}$. The before-migration state is summarized by $h_{t}=\left\{s_{t}, A_{t}\right\}$.

Next, each household decides whether to migrate based on the expected return to commitment environment, agents will not use private savings when public storage is optimal (Abraham and Laczo, 2018). That is, the equilibrium of the limited commitment model excluding private savings (but with public savings) is the same as the equilibrium of the model including it. 
migrating. Each household either sends a migrant $\left(\mathbb{I}_{t}^{i}=1\right)$ or does not send a migrant $\left(\mathbb{I}_{t}^{i}=0\right)$; we summarize the migration outcome of both households by the vector $j_{t}=\left\{\mathbb{I}_{t}^{1}, \mathbb{I}_{t}^{2}\right\}$. Migration income is uncertain and is not observed until after the migration decision is made. ${ }^{22}$ Migration involves a financial cost, $d_{t}^{\text {fin }}$, which may be negative if migration is subsidized. In addition to financial concerns, migration also involves a utility $\operatorname{cost} d_{t}^{\text {utility }}{ }^{23}$ After migrating, migrants who migrated without a job contact match with a provider with an exogenous probability $\pi^{\text {get contact }}$; those who migrated with a contact already in hand keep it. Migrants then learn the state of the world in the destination, $q_{t}$, which is drawn from a finite set. We assume that the migration asset is specific to the individual and cannot be shared. ${ }^{24}$ The after-migration job contact vector is given by $\hat{A}_{t}\left(h_{t}, j_{t}\right)$. Net migration income depends on the state of the world and the job contact, less any net financial cost to migrate. Total household income depends therefore on the realization of the state of the world in the village, the migration decision, the realization of the state of the world in the destination, the realization of the migration asset, and the net financial migration cost. Letting $\hat{h}_{t}=\left\{h_{t}, j_{t}, q_{t}, \hat{A}_{t}\left(j_{t}, A_{t}\right)\right\}$, after-migration income

\footnotetext{
${ }^{22}$ The assumption that migrants do not know their income before they migrate is consistent with survey responses where $14 \%$ of migrants said they earned more than expected, $33 \%$ said they earned less than expected, and $62 \%$ said they earned same as expected (we note that this doesn't add up to $100 \%$ because there are sometimes multiple episodes per household). Additionally, Bryan et al. (2014) show that migration outcomes in 2008 predict remigration in 2009 only for the treatment (and not the control) group, consistent with the treatment group not having information about their ability at migration.

${ }^{23}$ We assume that all households face the same cost of migrating. An alternative way to write the problem would be to allow households to have different costs of migrating, as considered in Lagakos et al. (2018). In this case, the migration rule would additionally depend on the costs of migrating.

${ }^{24}$ The migration literature has emphasized the role of social networks in providing information (Massey et al., 2003; Munshi, 2003). Based on surveys with migrants in the destination, $72.3 \%$ of people report either giving or receiving information about jobs from people in their current travel group. However, when looking at actual remigration behavior, Bryan et al. (2014) find that previous migration was the only factor that predicts repeat migration and that the number of friends and/or relatives who migrated is not a significant predictor. One way to reconcile these two facts is to consider that information from migrants affects the probability of getting a job contact once in the destination, but this information is not transferable between migrants and nonmigrants. This therefore matches the modeling choice to make the migration asset individual-specific.
} 
for household $i$ is given by $\hat{y}^{i}\left(\hat{h}_{t}, d_{t}^{\text {fin }}\right) .{ }^{25}$

At the end of the period all migrants return to the village. At that point, a household is separated from their migration contact with a probability that depends on whether

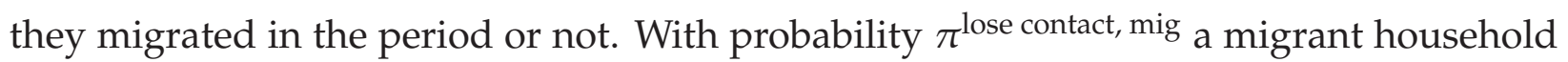
who had an active job contact loses it; with probability $\pi^{\text {lose contact, nonmig a nonmigrant }}$ household who had an active job contact loses it. The job contact assets of each household at the beginning of period $t+1$ are given by the vector $A_{t+1}\left(\hat{h}_{t}\right)$. The state of the world at the beginning of period $t+1$ is thus summarized by $h_{t+1}=\left\{s_{t+1}, A_{t+1}\right\}$. The mechanism design problem then repeats itself in the following period.

To determine the risk-sharing capabilities between households, it is useful to first describe the optimization problem if each household is independent (i.e., not part of a risksharing arrangement). Households solve maximization problems at two points in time that result in the before-migration value, $\Omega^{i}(h)$, and the after-migration value, $\widehat{\Omega^{i}}(\hat{h})$. The before-migration value is the expected utility at the time the household is deciding whether or not to migrate:

$$
\Omega^{i}(h)=\max _{\mathbb{I}^{i}} \sum_{\hat{h}} \pi_{\hat{h} \mid h, \mathbb{I}}\left[u\left(\hat{y}^{i}\left(\hat{h}, d^{\mathrm{fin}}\right)\right)-\mathbb{I}^{i}(\hat{h}) d^{\mathrm{utility}}+\beta \sum_{h^{\prime}} \pi_{h^{\prime} \mid \hat{h}^{2}} \Omega^{i}\left(h^{\prime}\right)\right]
$$

The after-migration value is the expected utility once the migration decision has been made and the household learns if it has a job contact, and then learns the state of the

\footnotetext{
${ }^{25}$ This general formulation allows for the case in which migrant households also receive some income from the village (for example, if other household members still work).
} 
world in the destination:

$$
\widehat{\Omega}^{i}(\hat{h})=u\left(\hat{y}^{i}\left(\hat{h}, d^{\text {fin }}\right)\right)-\mathbb{I}^{i}(\hat{h}) d^{\text {utility }}+\beta \sum_{h^{\prime}} \pi_{h^{\prime}} \hat{h}^{\Omega^{i}}\left(h^{\prime}\right)
$$

Equations 3 and 4 are important objects for determining the value of migration subsidies in an environment without spillovers as well as for determining the credible threat points in the full endogenous risk-sharing model.

We can now describe the full model, in which both risk sharing and migration are endogenously determined. The optimization problem involves migration choices of both households and the net transfer from household one to household two, $\tau$, to maximize total welfare. This problem is constrained by two sets of incentive compatibility constraints (one for each household at the before-migration stage, and one for each household at the after-migration stage), as well as a promise-keeping constraint that household one receives the utility promised to them. We follow the solution concept proposed in Ligon et al. (2002) by solving for the conditional Pareto frontier that maximizes the utility of household two given a promised level of utility to household one. Because households make choices at two points in time during a period, we define two Pareto frontiers: first, the frontier that maximizes the before-migration utility of household two, $V(h)$, given a state-dependent level of before-migration promised utility, $U(h)$, to household one. Second, the after-migration frontier maximizes the after-migration utility of household two, $\widehat{V}(\hat{h})$, conditional on the after-migration state $\hat{h}$.

We solve the model in two steps. Starting in the second sub-period, we solve for optimal transfers $\tau\left(\hat{h}, d^{\text {fin }}\right)$ and continuation utility $U\left(h^{\prime}\right)$ for all future states $h^{\prime}$ : 
$\widehat{V}(\hat{h}, \widehat{U}(\hat{h}))=\max _{\left\{\tau\left(\hat{h}, d^{\text {fin }}\right),\left\{U\left(h^{\prime}\right)\right\}_{\forall h^{\prime}}\right\}} u\left(\hat{y}^{2}\left(\hat{h}, d^{\text {fin }}\right)+\tau\left(\hat{h}, d^{\text {fin }}\right)\right)-\mathbb{I}^{2}(\hat{h}) d^{\text {utility }}+\beta \sum_{h^{\prime}} \pi_{h^{\prime} \mid \hat{h}} V\left(h^{\prime}, U\left(h^{\prime}\right)\right)$

subject to a promise-keeping constraint that household 1 receives their promised utility:

$$
\left(\widehat{\lambda}_{\hat{h}}\right): u\left(\hat{y}^{1}\left(\hat{h}, d^{\text {fin }}\right)-\tau\left(\hat{h}, d^{\text {fin }}\right)\right)-\mathbb{I}^{1}(\hat{h}) d^{\text {utility }}+\beta \sum_{h^{\prime}} \pi_{h^{\prime}} \hat{h} U\left(h^{\prime}\right) \geq \widehat{U}(\hat{h})
$$

and incentive compatibility constraints for the before-migration problem in the following period for both households:

$$
\begin{aligned}
& \left(\beta \pi_{h^{\prime} \mid \hat{h}} \phi_{\hat{h} h^{\prime}}^{1}\right): U\left(h^{\prime}\right) \geq \Omega^{1}\left(h^{\prime}\right) \quad \forall h^{\prime} \\
& \left(\beta \pi_{h^{\prime} \mid \hat{h}} \phi_{\hat{h} h^{\prime}}^{2}\right): \quad V\left(h^{\prime}, U\left(h^{\prime}\right)\right) \geq \Omega^{2}\left(h^{\prime}\right) \quad \forall h^{\prime}
\end{aligned}
$$

Then, given this optimized Pareto frontier, the planner solves for the optimal aftermigration utility promised to household one, $\widehat{U}(h)$ and the optimal migration outcome of the two households $j=\left\{\mathbb{I}^{1}, \mathbb{I}^{2}\right\}$.

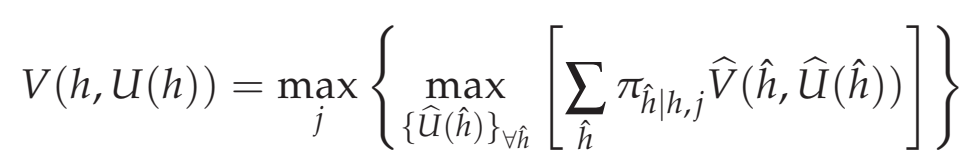

subject to satisfying a promise-keeping constraint that expected utility for household 1 for migration outcome $j$ is equal to their before-migration expected utility:

$$
\left(\lambda_{j}\right): \quad \sum_{\hat{h}} \pi_{\hat{h} \mid j} \widehat{U}(\hat{h}) \geq U(h) \quad \forall j
$$


and incentive compatibility constraints for the after-migration problem in the second sub-period for both households:

$$
\begin{aligned}
& \left(\pi_{\hat{h} \mid h, j} \alpha_{\hat{h}}^{1}\right): \widehat{U}(\hat{h}) \geq \widehat{\Omega}^{1}(\hat{h}) \quad \forall \hat{h} \\
& \left(\pi_{\hat{h} \mid h, j} \alpha_{\hat{h}}^{2}\right): \widehat{V}(\hat{h}, \widehat{U}(\hat{h})) \geq \widehat{\Omega}^{2}(\hat{h}) \quad \forall \hat{h}
\end{aligned}
$$

The first order conditions (which are given in Appendix A.2.1) imply that the Pareto weight follows a modified simple updating rule, as in Ligon et al. (2002) and Morten (2019). The updating rule has two steps; a before-migration update and an after-migration one. The history up to the end of period $t-1$ is given by $\hat{h}^{t-1}=\left\{\hat{h}_{0}, \hat{h}_{1}, \ldots, \hat{h}_{t-1}\right\}$. Given an initial before-migration Pareto weight $\lambda_{t}^{i}\left(h_{t}, \hat{h}^{t-1}\right)$, the after-migration Pareto weight is given by:

$$
\hat{\lambda}_{t}^{i}\left(\hat{h}_{t}, \hat{h}^{t-1}\right)= \begin{cases}\hat{\hat{\lambda}}_{\hat{h}}^{i}, & \text { if } \lambda_{t}^{i}\left(h_{t}, \hat{h}^{t-1}\right) \leq \underline{\hat{\lambda}}_{\hat{h}}^{i} \\ \lambda_{t}^{i}\left(h_{t}, \hat{h}^{t-1}\right) & \text { if } \lambda_{t}^{i}\left(h_{t}, \hat{h}^{t-1}\right) \in\left[\underline{\hat{\lambda}}_{\hat{h}}^{i}, \overline{\widehat{\lambda}}_{\hat{h}}^{i}\right] \\ \overline{\widehat{\lambda}}_{\hat{h}}^{i} & \text { if } \lambda_{t}^{i}\left(h_{t}, \hat{h}^{t-1}\right) \geq \overline{\widehat{\lambda}}_{\hat{h}}^{i}\end{cases}
$$

And the before-migration Pareto weight the following period is given by:

$$
\lambda_{t+1}^{i}\left(h_{t+1}, \hat{h}^{t}\right)= \begin{cases}\underline{\lambda}_{h^{\prime}}^{i}, & \text { if } \hat{\lambda}_{t}^{i}\left(\hat{h}_{t}, \hat{h}^{t-1}\right) \leq \underline{\lambda}_{h^{\prime}}^{i} \\ \widehat{\lambda}_{t}^{i}\left(\hat{h}_{t}, h^{t-1}\right), & \text { if } \hat{\lambda}_{t}^{i}\left(\hat{h}_{t}, \hat{h}^{t-1}\right) \in\left[\underline{\lambda}_{h^{\prime}}^{i}, \bar{\lambda}_{h^{\prime}}^{i}\right] \\ \bar{\lambda}_{h^{\prime}}^{i} & \text { if } \hat{\lambda}_{t}^{i}\left(\hat{h}_{t}, \hat{h}^{t-1}\right) \geq \bar{\lambda}_{h^{\prime}}^{i}\end{cases}
$$

While the model presented above applies to two households, we extend the theoretical 
model to $N$ households ${ }^{26}$ in Appendix A.2.2, following Ligon et al. (2002). To implement the $N$-household model we construct an aggregated "rest of village" household, giving that household income such that $y_{\text {rov }}=\bar{Y}-y_{i}$, where $\bar{Y}$ is the total resources of the village (accounting for migration and migration income earned). We then solve the limited commitment model assuming that there is household $i$ and the rest of the village. There is one additional step needed to implement the $\mathrm{N}$-household approximation. When we simulate the model we do not literally simulate only two households. We instead simulate $N$ households who each follow the policy rule we derive for the two-household case. We thus need to ensure the aggregate budget constraint is satisfied (the budget constraint is automatically satisfied with only two households). We only use the bound in the interval that corresponds to the incentive constraint for household $i$. We combine this lower bound with an additional first order condition, that the rate of growth of relative marginal utility for unconstrained households is equal, from the $\mathrm{N}$-person model. We thus estimate one additional parameter which scales the marginal utility of unconstrained households in order to satisfy the economy-wide budget constraint. ${ }^{27}$ We solve for the equilibrium policy functions, taking into account the before- and after- migration incentive constraints for all households and the budget account for the economy (which includes income earned from the endogenous migration decision), and solving the full

\footnotetext{
${ }^{26}$ We rule out coalitional deviations such as those studied by Genicot and Ray (2003) and Bold and Broer (2016).

${ }^{27}$ We estimate a scaling factor, $\zeta_{t}$, such that the Pareto weight becomes $\hat{\lambda}_{t}^{i}=\max \left(\zeta_{t} \hat{\lambda}_{t-1}^{i}, \underline{\hat{\lambda}}\right)$. We solve $\zeta_{t}$ to set total consumption equal to total income, i.e., $\sum_{i} c_{t}^{i}\left(\hat{h}^{t}, \hat{\lambda}_{t}^{i}\left(\zeta_{t}\right)\right)=\sum_{i} \hat{y}_{t}^{i}\left(\hat{h}^{t}\right)$. In the initial steady state, this requires solving for one $\zeta_{-1}$ to satisfy the budget constraint. Once we introduce the experiment into the model we need to solve for a sequence of $\zeta_{t}$ such that $\hat{\lambda}_{t}^{i}=\max \left(\zeta_{t} \hat{\lambda}_{t-1}^{i}, \underline{\hat{\lambda}}\right)$ and the invariant distribution of income is equal to the invariant distribution of consumption, for each $t$. We solve for one scaling parameter in the pre-experiment steady state $\zeta_{-1}$, one for the year of the experiment $\zeta_{0}$, and one for each year $t$ after the experiment $\left(\zeta_{1}, \zeta_{3}, \ldots, \zeta_{T}\right)$, until the economy has converged back to the equilibrium steady state (measured by $\zeta_{T}=\zeta_{-1}$ ). In practice, the economy converges back to the steady state 6 periods after the experiment.
} 
transition path of the economy after the implementation of the temporary subsidy (which is introduced in the next subsection). ${ }^{28}$ Solving the model is computationally intensive; we implement the estimation on a high-performance computer cluster. We discuss the computational algorithm in Appendix A.3 and provide evidence that the computational approximation works well.

\subsection{Introducing the experiment into the model}

We introduce the experiment into the model as an unanticipated shock. The experiment changes the financial cost of migrating, $d_{t}^{\text {fin }} \cdot{ }^{29}$ We also allow the experiment to change the utility cost of migrating, $d_{t}^{\text {utility }}$, for example, by either providing an endorsement effect or by generating a utility benefit of migrating with friends. In estimation, we fix the financial cost but are agnostic about whether the experiment led to an additional utility benefit and thus estimate this parameter based on the observed treatment effects.

The experiment changes the value of autarky, given by equation 3 (for before-migration) and equation 4 (for after-migration). The experiment thus affects the risk-sharing equilibrium through two channels. First, the experiment has a direct effect on the social planner's problem (given by Equation 5 and Equation 9). Second, the experiment indirectly changes the incentive compatibility constraints through its effect on the autarky value for

\footnotetext{
${ }^{28}$ To ensure that first order conditions hold, we smooth our objective function so that all migration states occur with positive probability.

${ }^{29}$ We are primarily exploiting the effects of the 2008 experiment which is the first time the villagers had engaged with migration subsidies. If households instead believed that the subsidies would continue then the risk-sharing effects may differ. Indeed, one of our counterfactuals in Section 6 asks exactly this question and studies the case where subsidies were permanent, instead of temporary. We find in that case that the risk-sharing effects would be negative instead of positive. An intermediate approach would be the one studied by Ligon and Schechter (2019), who introduce a probability that the experiment is played each period.
} 
households.

\section{Estimation}

The model described in Section 4 provides a framework to understand the mechanisms underlying the impacts of the migration subsidy experiment as well as to evaluate other potential counterfactual policies. To investigate how well the model captures economic behavior, we structurally estimate the model using moments based on the experimental variation. There are 13 model parameters, including: (a) the home income process (mean and standard deviation), (b) the city income process for migrants with a job contact (mean and standard deviation), (c) the migration contact process (probability of gaining or losing a contact, conditional on migrating or not), (d) migration costs (utility cost, opportunity cost, and utility subsidy), ${ }^{30}$ and (e) risk aversion and the discount factor. We estimate the model by simulated method of moments (McFadden, 1989; Pakes and Pollard, 1989) using an identity weight matrix. We next discuss the choice of moments and provide a heuristic discussion of identification.

\subsection{Identification}

We use the experimental intervention to help identify the model. The experiment both provides a genuine source of exogenous variation and allows us to account for the utility aspects of the experiment that would otherwise not be identifiable. ${ }^{31}$ To estimate the pa-

\footnotetext{
${ }^{30}$ We net out financial costs of migration from income, and so only estimate the utility cost of migrating.

${ }^{31}$ See Attanasio et al. (2012) for a discussion of the advantages of using experimental variation to identify structural models.
} 
rameters of our model, we construct moments from the data and match them to simulated moments from the model. Here we provide a heuristic discussion of identification based on how the chosen moments are informative about the parameters. We focus primarily on data collected after the experiment was conducted, combined with data on migration during the experiment to capture migration dynamics. It is important to note that each moment is related to many parameters and we do not imply that there is a one-to-one relationship between each parameter and a moment. Table 7 lists the full set of moments matched in estimation.

The first set of parameters are those that determine the home income distribution and the city income distribution for migrants with a contact. To focus on the role of uncertainty, we set the income distribution in the city for migrants without a contact to be equivalent to receiving zero income. To identify these distributions, we match means and standard deviations of the city income distribution for migrants, and means and standard deviations of home income for migrants and non-migrants separately. Note that these moments are not moments of the true underlying distribution; they are a selected and censored distribution due to endogenous migration decisions. Thus our simulated moments explicitly account for this endogeneity by modeling the selection and censoring. Specifically, we model censoring by assuming that migrants give up $\alpha \%$ of their home income $y$, where $\alpha$ is the estimated opportunity cost of migrating. For migrants, this means that mean observed income will be equal to $(1-\alpha) E(y \mid$ migrant $)$, and for non-migrants mean observed income will be equal to $E(y \mid$ non-migrant $)$, neither of which are necessarily equal to the mean of the underlying home income distribution $E(y)$. Thus, the observed home income distribution will differ from the true distribution because of the 
combination of (a) selection into migration, which will typically be households with low home income draws, and (b) censoring of home income of migrants due to the opportunity cost of migration. We therefore use the observed home income for both migrants and nonmigrants to jointly estimate the mean and variance of home income. The opportunity cost of migration is then identified as the residual - given the selection into migration that equalizes observed and true home income. ${ }^{32}$

Another set of parameters relate to the migration asset, which captures job contacts formed as a result of past migration episodes and leads to state dependence in migration. The parameters that characterize this asset include three probabilities: obtaining a $\operatorname{contact}\left(\pi^{\text {get contact }}\right)$, losing a previously formed contact if one migrates ( $\left.\pi^{\text {lose contact, mig }}\right)$, and losing a previously formed contact if one does not migrate ( $\left.\pi^{\text {lose contact, nomig }}\right)$. To identify these parameters, we construct moments that capture migration transitions conditional on earlier migration histories. More specifically, we construct eight moments from the data to identify these parameters: the mean migration rate in control villages; the treatment effect of the experiment on migration during the experiment and after the experiment; the share of people who do not migrate either during or after the experiment (both the control village mean and the treatment effect); and the share of people who migrate both during and after the experiment (again, both the control village mean and

\footnotetext{
${ }^{32} \mathrm{We}$ assume that households are not liquidity constrained. The limited commitment model assumes no savings and so there is no liquidity on hand other than current income. One could specify that a household needs to have enough current income to pay the migration cost, however, this would likely be inefficient: the equilibrium of the risk-sharing model would be that the network "lends" money to people to migrate as the network benefits the most if low-income households migrate. However, if households were constrained, it may affect the estimation of key parameters: for example, if poorer households were liquidity constrained and so did not migrate, actual migrants may be those with slightly higher incomes in the village than what we simulated, and so we may be underestimating the opportunity cost of migrating. It could also be that we overestimate the utility cost of migration by mistakenly attributing low migration rates to a high utility cost of migration rather than a constraint.
} 
the treatment effect). The experimental variation plays an important role here because it exogenously induces a number of people to migrate who did not have any previous migration history and thus helps identify the probability of obtaining a contact by observing the re-migration rate following the first migration episode.

Migration rates also play a key role in identifying the opportunity cost (i.e., the share of home income given up) of migrating $\left(\alpha^{y}\right)$ and the utility cost of migrating ( $\left.d^{\text {utility }}\right) .^{33}$ Moreover, the treatment effect on migration rates helps identify the utility subsidy in the experiment $\left(\Delta d^{\text {utility }}\right)$, conditional on changes in migration due to effect of treatment on the migration asset. The decline in the treatment effect over time suggests that the utility subsidy decays over time, so we estimate the fraction of the utility subsidy that is still present in the period after the experiment.

The remaining parameters are risk aversion and the discount factor. We identify them primarily using moments related to risk sharing, as these preference parameters help determine the level of risk sharing attainable in the economy. ${ }^{34}$ For example, the discount factor-or patience-is relevant to risk sharing because part of the return to risk sharing occurs in the future. We run the same consumption regressions on the simulated data as we ran in Section 3. We treat the coefficients from this auxiliary regression as summary measures of risk sharing (risk sharing (control) and risk sharing (treatment effect), respectively) and target these coefficients in the estimation.

\footnotetext{
${ }^{33}$ We directly net out the observed financial costs of migration from our measure of city income. Observed financial costs are the answer to the following survey question: "During your travel from your village to the migration destination, what was the total travel cost (include all costs related to travel such as bus/train, ricksaw etc)?"

${ }^{34}$ Of course, other parameters also determine risk sharing, such as migration rates and income distributions because migration is risky and therefore a high level of risk aversion would imply a lower rate of migration for a given income gain.
} 


\subsection{Estimation results}

Table 6 reports our parameter estimates. We compute standard errors by numerical approximation (see Appendix A.5 for details). The parameters determining the contact rate of migration are all in line with intuition. The estimates imply that, at the end of the period, $44 \%$ of migrants who hold an asset lose it and $66 \%$ of nomigrants who still had an active asset lose it, although estimated imprecisely. For migrants who leave without an asset, $79 \%$ would acquire one. We estimate that the opportunity cost of migrating is equal to $15 \%$ of village income. ${ }^{35}$ This is in addition to the direct cost of migration, which we observe. The size of the utility subsidy is estimated to be 0.08 utils (equivalent to $2.3 \%$ of total utility of 3.23). Note that although the intervention only occurred in one period, its impact on both migration and risk sharing is felt over future periods. We implement this by estimating the decay rate of the utility subsidy of 0.15 to match the dynamics in the data. Finally, we estimate a CRRA parameter of 1.9, showing moderate levels of risk aversion and not dissimilar to what is found on consumption studies in other countries (Blundell et al., 1994; Attanasio and Weber, 1995). In our main estimates, we set the discount factor to 0.7 and undertake robustness to this value in Appendix Table 14 .

In Table 7 we show how these parameter estimates match the targeted moments. Focusing on the treatment effects on migration and risk sharing, the model matches the decline in risk sharing as a result of the experiment reasonably well, predicting a decline of 5.5 percentage points in the risk sharing $\beta$ coefficient for the post-intervention period

\footnotetext{
${ }^{35}$ We estimate the opportunity cost to match the observed home income of migrants. The estimated opportunity cost is lower than the average migration trip length of 75 days (approximately 20\% of the year), but these two do not necessarily need to align, especially if people migrate in periods of the year when income is lower.
} 
Table 6: Parameter estimates

\begin{tabular}{lc}
\hline Preferences & 1.88 \\
CRRA parameter & $(0.037)$ \\
& 0.15 \\
Opportunity cost of migration & $(0.088)$ \\
& 0.075 \\
Utility cost of migrating & $(0.0051)$ \\
& 0.075 \\
Utility subsidy & $(0.025)$ \\
& 0.15 \\
Decay rate of utility subsidy & $(0.83)$ \\
& \\
Income processes & 2.23 \\
Mean home income & $(0.23)$ \\
& 0.58 \\
Std. home income & $(0.0040)$ \\
& 0.38 \\
Mean city income with contact & $(0.17)$ \\
& 0.78 \\
Std. city income with contact & $(0.074)$ \\
& \\
Dynamics & 0.79 \\
Prob. get contact & $(0.28)$ \\
& 0.44 \\
Prob. lose contact if migrate & $(0.85)$ \\
& 0.66 \\
Prob. lose contact if don't migrate & $(5.62)$ \\
\hline Model criterion & 1.715 \\
\hline Notes: The table shows parameter estimates and \\
standard errors. The parameter estimates arise from \\
estimating the model by simulated method of mo- \\
ments. The analytical standard errors are computed \\
by numerical differentiation. The mean level of util- \\
ity in control villages is 3.23. & \\
& \\
&
\end{tabular}


(compared with a seven percentage point decline in the data). The model also captures the treatment effect on migration during the RCT (35\% in the model compared with $22 \%$ in the data during the experiment, and 15\% compared with $9 \%$ after the experiment). The persistence of the migration effect is also captured well: we estimate an increase of $14 \%$ in the share of people migrating both during and after the experiment, close to the $15 \%$ rate in the data, and estimate a decrease of $16 \%$ in the share of people migrating neither during nor after the experiment, compared with $17 \%$ in the data. Overall, the model is capable of fitting the main patterns in the data, including the change in risk sharing and the dynamics of migration, even with such a parsimonious specification.

Table 7: Model fit

\begin{tabular}{lcc}
\hline & Data & Model \\
\hline Risk sharing (control) & 0.16 & 0.16 \\
Risk sharing (treatment effect) & -0.073 & -0.055 \\
Mean migration rate & 0.39 & 0.45 \\
Mig. treatment effect (during RCT) & 0.22 & 0.35 \\
Mig. treatment effect (after RCT) & 0.094 & 0.15 \\
Migrate neither during/after RCT (control) & 0.49 & 0.32 \\
Migrate during and after RCT (control) & 0.23 & 0.22 \\
Migrate neither during/after RCT (treatment effect) & -0.17 & -0.16 \\
Migrate during and after RCT (treatment effect) & 0.15 & 0.14 \\
Mean log home income (migrant) & 1.80 & 1.57 \\
Std. log home income (migrant) & 0.67 & 0.29 \\
Mean log home income (nonmigrant) & 2.13 & 2.63 \\
Std. log home income (nonmigrant) & 0.56 & 0.33 \\
Log std. mig. income (migrant) & 0.27 & 0.23 \\
Log mean mig. income (nonmigrant prior pd.) & 0.60 & 0.39 \\
Log mean mig. income (migrant prior pd.) & 0.73 & 0.51 \\
Model criterion & & 1.72 \\
\hline \hline
\end{tabular}

Notes: The table shows the targeted moments in the data (column (1)) and in the estimated model (column (2)). 


\subsubsection{Robustness checks of estimates}

We run several robustness checks of our estimates. In Appendix Table 13 we re-estimate the model without a utility effect of the experiment. We find that the models without the utility effect cannot match the risk-sharing level or treatment effect, a fact that is consistent with our discussion of what is driving the experimental results in the following section. In Appendix Table 14 we show the values of the function for different points of the discount factor grid. The fit of the model is best for a discount factor of 0.7 .

\subsection{Comparative statics}

In this section, we discuss the intuition about the key forces driving migration and risksharing outcomes - including the role of migration subsidies - and verify this intuition through showing local comparative statics around the estimated values of the model parameters. We show that migration subsidies can either crowd in risk sharing or crowd out risk sharing, depending on the underlying parameters and the nature of the subsidies.

The underlying intuition to understand the effect of a migration subsidy on income is that risky migration is effectively a lottery (Harris and Todaro, 1970): by paying a migration cost, the migrant gets a new income draw from a support that may include both very low incomes as well as very high ones. The option to migrate leads to a tradeoff for risk sharing. On the one hand, migration introduces an additional source of income that - in expectation - increases the total resources available to the network and thereby increases the gains from sharing risk. On the other hand, migration may change the private ability to smooth risk and thus change the incentive to share risk. The specific type of subsidy 
may also matter: a financial subsidy directly affects marginal utility (and hence the valuation of the income risk) whereas a utility subsidy does not change marginal utility (and hence does not affect the valuation of income risk).

To illustrate the mechanisms in the model, we simulate the effects of providing financial and utility subsidies on migration and risk sharing. We consider an increase in migration income variance around the estimated parameter values from Section 5.2.

Panel (a) of Figure 2 plots the baseline level of migration and risk sharing against the income risk of migrating. Panel (ai) shows that the baseline level of migration is higher (45\%) under limited commitment than under autarky $(0 \%)$. We do not find that the baseline migration rates vary greatly with income risk, reflecting both the migration cost (for the autarkic case) as well as the relatively low (14\%) opportunity cost (i.e., how much village income needs to be given up) of migrating. Panel (aii) shows the baseline risk sharing effect. As migration income becomes riskier, risk sharing improves. Panel (aiii) shows welfare, measured in consumption-equivalent units, of each regime. Because households value insurance, welfare in the limited commitment regime is about $4 \%$ higher than welfare under autarky; the gap between autarky and limited commitment welfare increases as risk sharing improves.

Next, we consider the effects of a financial, utility, and combined subsidy to migrate.

Computational Result 1. A financial subsidy leads to a larger difference between the welfare gain under autarky and the welfare gain under limited commitment when income is riskier

Panel (b) of Figure 2 plots the effect of a financial subsidy to migrate. Panel (bi) shows that the financial subsidy induces more autarkic migration when migration is riskier. This 
is because a financial subsidy, by giving a guaranteed income, provides a form of insurance. Insurance is generally more valuable when income risk is higher. The effect on migration under limited commitment is flat across the income risk: the network already provides insurance against the risk of migrating and so the financial subsidy is not as important in encouraging migration. Panel (bii) shows the estimated treatment effect on risk sharing. For low levels of income risk, a financial subsidy leads to an improvement in risk sharing (i.e., a reduction in the risk-sharing $\beta$ ). For high levels of income risk, risk sharing worsens. Panel (biii) shows the relative welfare effect of the policy. In autarky, the welfare gain of the subsidy is highest when income is riskier, reflecting the insurance benefit. With limited commitment, the welfare gain of the subsidy is lowest when income is riskier, reflecting the loss of insurance. ${ }^{36}$

Computational Result 2. A utility subsidy leads to a smaller difference between the welfare gain under autarky and the welfare gain under limited commitment when income is riskier

Panel (c) of Figure 2 plots the effect of a utility subsidy to migrate. Panel (ci) shows that the utility subsidy induces migration under autarky (from a baseline level of autarkic migration of zero). The migration effect under limited commitment also increases as income is riskier, despite the higher baseline rate. Panel (cii) shows that shows that there is a large overall improvement in risk sharing (i.e., a negative treatment effect on the risk-sharing $\beta$ ) across the range. The estimated improvement in risk sharing is largest when income is less risky. Panel (ciii) shows that welfare increase is larger under limited commitment than under autarky, reflecting the gain due to the large improvement in risk

\footnotetext{
${ }^{36}$ The overall decrease in welfare is due to two factors: first, the social planner is optimizing a Paretoweighted sum of individual weights, but the figure plots the (unweighted) welfare gain to the average individual; second, migration is costly and so the increased migration leads to an increase in costs.
} 
sharing. The gap between the welfare gain under autarky and the welfare gain under limited commitment narrows as the gain in risk sharing falls.

Finally, Panel (d) of Figure 2 plots the effect of a combined (financial and utility) subsidy to migrate. The combined subsidy follows the general pattern of the utility subsidy. This is because the model jointly matches both the income risk and risk-sharing effect of the experiment. Given the level of income risk in the economy, the estimated utility cost matches the improvement in risk sharing; the model estimates imply that the utility subsidy must be large, and thus the utility subsidy is an important driver of the experimental finding. We return to this point when discussing the experimental effects in the next section.

What explains these results? The main intuition to understand the differing slopes of migration subsidies on risk sharing is to understand when the private value to the individual of migrating increases relatively more than the public value to the network as a whole. For transparency, the comparative statics presented above considered a local change in the estimated variance. Because income is log-normally distributed, this thus conflates both an increase in the mean and an increase in the variance in income. We repeat the exercise in Appendix Figure 3 where we consider a mean-preserving increase in the riskiness of migration income. In the case of a mean-preserving spread there is a clear difference between a financial and a utility subsidy. If income is risky, then providing a financial subsidy provides self-insurance to an individual, increasing the autarkic value to the individual. A financial subsidy also increases the value of migrating under perfect risk sharing but because income risk is already perfectly pooled the financial subsidy does not provide an additional insurance benefit. Thus, the private return to migrating 
Figure 2: Comparative statics around income risk: utility and financial subsidies

(a) Control group

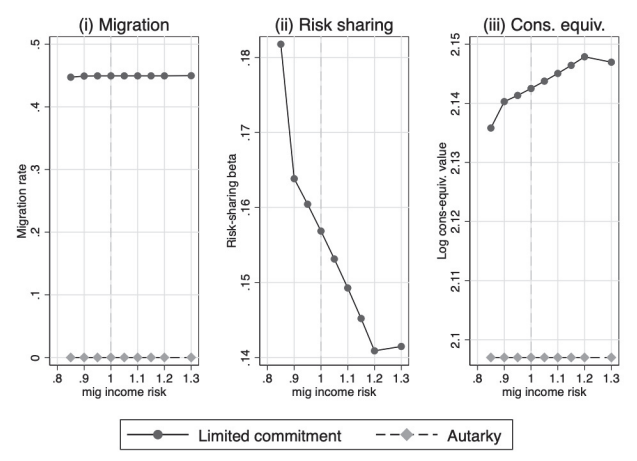

(c) Treatment effect: utility subsidy

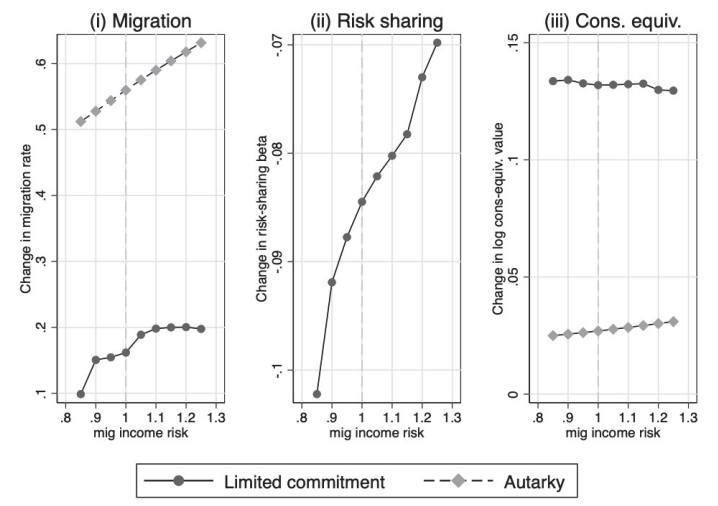

(b) Treatment effect: financial subsidy

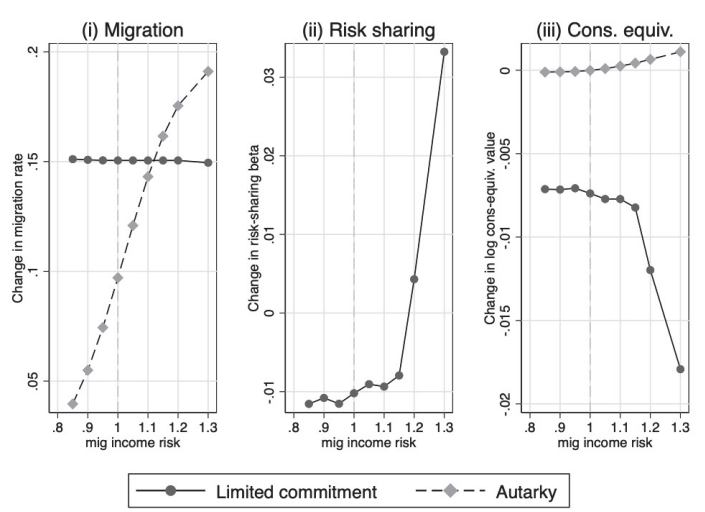

(d) Treatment effect: combined subsidy

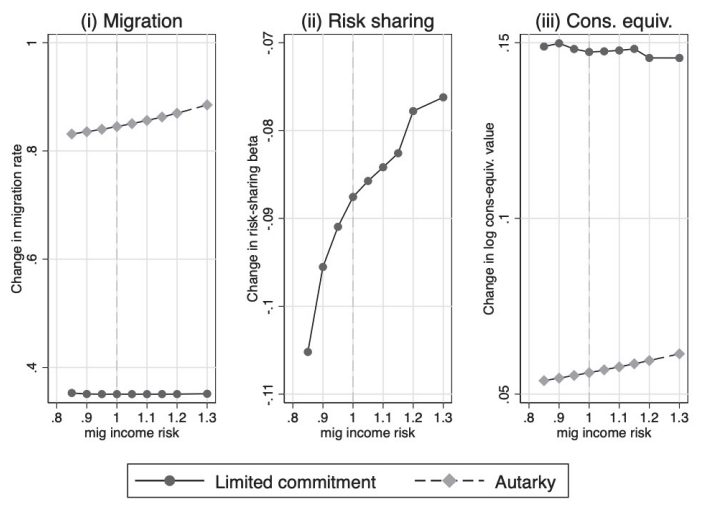

Note: Migration income risk is measured relative to the baseline estimate of the log-normal standard deviation (i.e., a value of 1 is the baseline estimate). 
increases more than the social return, tightening the incentive compatibility constraint and crowding out risk sharing. A utility subsidy has the opposite effect: because it does not alter marginal utility it does not provide additional insurance. When income is not risky, independent households are already willing to migrate, and so the utility subsidy simply provides additional utility. When income is very risky, an independent household is not willing to migrate and thus cannot benefit from the utility subsidy. At the same time, the household values having insurance from the network as it allows them to migrate. A utility subsidy does not put additional pressure on the incentive compatibility constraints and so risk sharing tends to improve. The simulated mean-preserving comparative statics match these predictions. We provide a further theoretical discussion of the difference between a financial and a utility subsidy in Appendix A.4.2.

\subsection{Simulating the experiment inside the model}

We now simulate the experiment to study the dynamic effects of the subsidy as well as to decompose the change in risk sharing into separate components attributable to the financial subsidy and to the change in utility costs of migration induced by the experiment (utility subsidy).

Figure 3 plots the time path of migration and risk sharing. ${ }^{37}$ Panel (a) shows the combined effect from the two subsidies (financial and utility). The left figure shows the migration response. Panels (b) and (c) show the effect of the financial and utility components of the experiment, respectively. In the post intervention period, we find that

\footnotetext{
${ }^{37}$ Appendix Figure 5 shows the same figure for alternative estimates where we do not include the migration asset or where we do not allow the model to affect utility.
} 
the financial component has approximately the same magnitude effect on encouraging migration (15.1 percentage points) as the utility shock (16.2 percentage points), but the financial shock leads to a much more modest improvement in risk sharing compared with the utility shock ( 0.6 percentage points compared with 5.5 percentage points).

To benchmark the magnitude of the estimated utility shock, note that the subsidy is equivalent to removing the migration cost entirely for the one period (and then decaying over time). Is this reasonable? While the utility cost effect of the experiment is unobservable, there is indirect evidence that the experiment did affect the cost of migrating. For example, follow up experiments in the same villages (Akram et al., 2018) found that the probability of migration for someone who themselves did not receive a subsidy was $9.6 \%$ higher if the person was in a village where approximately $70 \%$ of the residents were offered a subsidy to migrate compared with a control village. This result suggests that migration costs fall when more people migrate, which would be one channel for the utility cost effect we estimate.

Table 8 converts these results into welfare gains of the experiment in units of permanent consumption equivalents. The baseline experiment ("Temporary combined shock") led to an increase in welfare equivalent to a permanent $12.9 \%$ increase in consumption, net of the financial subsidy itself, the year the experimental subsidies were disbursed. In comparison, the estimated gain of the experiment without accounting for the risk-sharing response would be a consumption-equivalent gain of $3.4 \%$. In other words, welfare gains are three times higher when accounting for spillover effects of the experiment through risk sharing. ${ }^{38}$

\footnotetext{
${ }^{38}$ These results persisted in the subsequent period. In the post-experiment period, because of the persis-
} 
Figure 3: Effect of the experiment on migration and risk sharing

(a) Combined effect
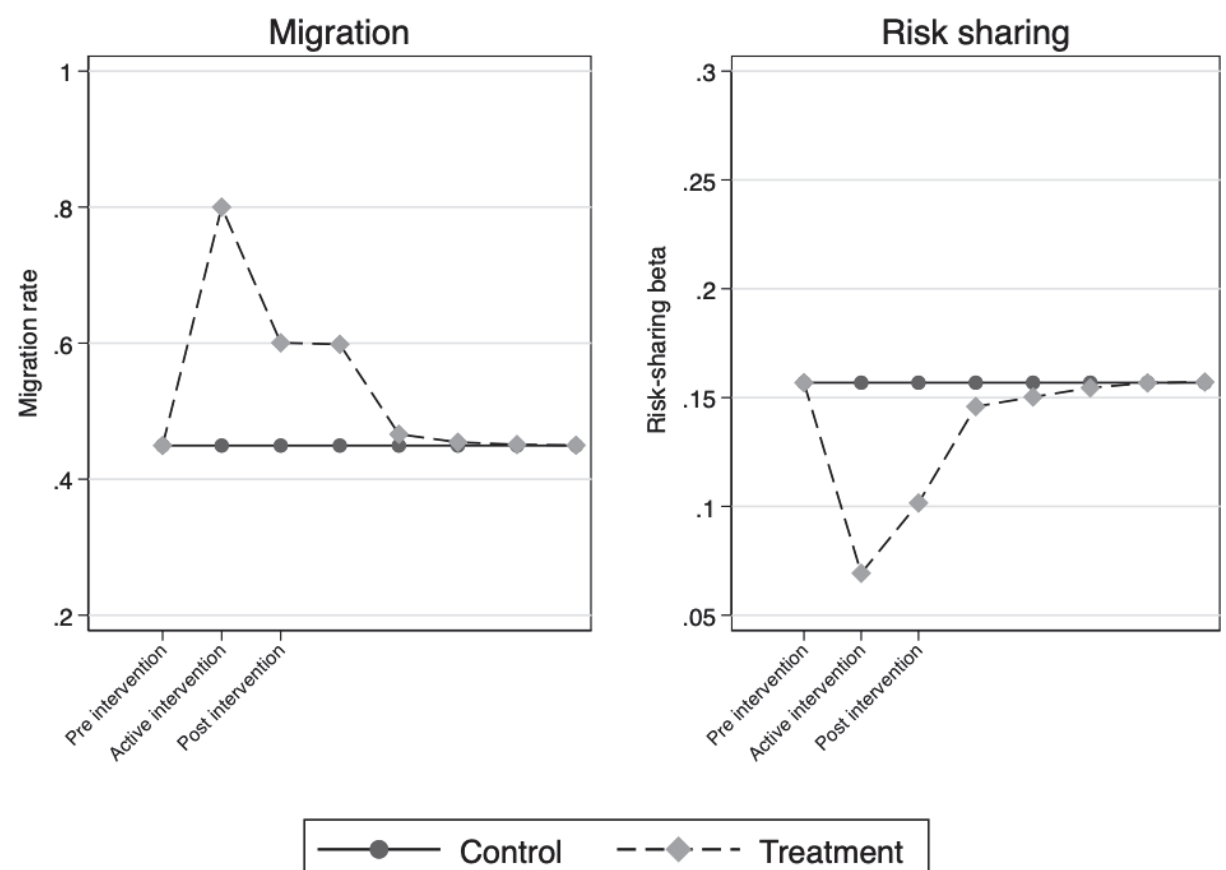

(b) Financial component

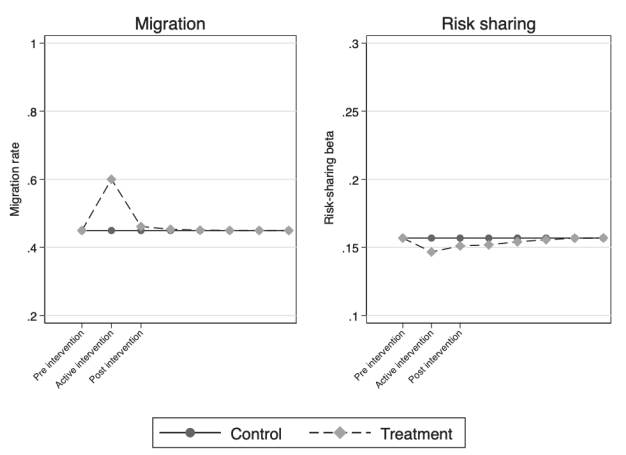

(c) Utility component

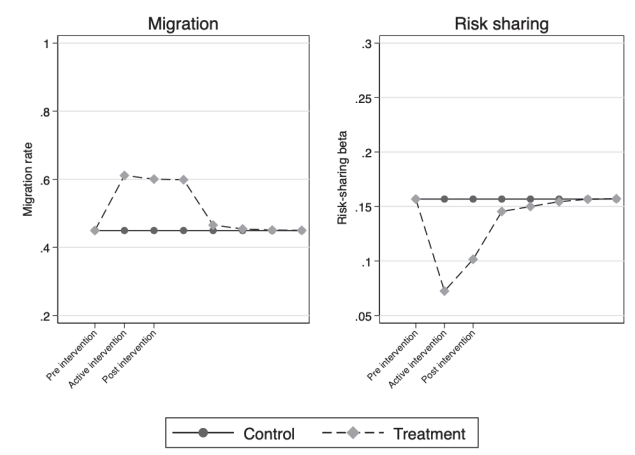


Table 8: Effect of the experiment on risk sharing and welfare

\begin{tabular}{lcccc}
\hline & \multicolumn{2}{c}{ Endogenous risk sharing } & & Autarky \\
\cline { 2 - 3 } \cline { 5 - 5 } & $(1)$ & $\begin{array}{c}(2) \\
\text { Cons-equiv }\end{array}$ & & $\begin{array}{c}(3) \\
\text { Cons-equiv } \\
\end{array}$ \\
& Risk sharing & $\begin{array}{c}\text { (Net of subsidy) } \\
\text { (Net of subsidy) }\end{array}$ \\
\hline Temporary combined shock & -0.0876 & 0.129 & & 0.0335 \\
Permanent combined shock & 0.0289 & 0.135 & & 0.0978 \\
Temporary CCT & -0.0102 & -0.0239 & & -0.00287 \\
Temporary UCT & -0.0125 & -0.00509 & & 0.00638 \\
\hline \hline
\end{tabular}

Notes: Table shows the welfare effects estimated in the active intervention period. Note that the risk-sharing moment targeted during estimation is risk sharing during the subsequent post intervention period. The measure of risk sharing is the percentage point change in the risksharing $\beta$; a negative number reflects an improvement in risk sharing. The consumption equivalent gain is the percent point increase after subtracting off the direct amount of the transfers.

In sum, our model of endogenous migration and risk sharing can replicate key features of the economic environment and experimental setting in rural Bangladesh. Using the model, we show that both the financial and utility components of the migration subsidies have important effects on migration, risk sharing, and welfare, and that ignoring the welfare effects stemming from risk-sharing improvements leads to an underestimate of the overall benefits of the subsidies. We next turn to alternative counterfactual policies as a way to further understand the economic forces that drive the codetermination of migration and risk sharing.

tent improvement in risk sharing, the welfare gains of the experiment were equivalent to a $8.9 \%$ permanent increase in consumption, compared to a $1.8 \%$ increase under autarky. These numbers are not presented in Table 8. 


\section{Counterfactuals}

In this section, we use our model to conduct two alternative policy experiments: first, the effect of a permanent subsidy rather than temporary subsidy; and second, an unconditional (rather than conditional) cash transfer. Both counterfactual policies have clear links to actual development policies. First, development agencies often pilot programs before deciding to roll them out and make them permanent. Understanding any differential effects between a short-term and a longer-term subsidy is thus important. Second, while many countries have enacted conditional cash transfer policies (for example, Progresa/Oportunidades in Mexico), a growing set of programs, notably GiveDirectly, provide unconditional cash transfers because they argue that the administrative costs of unconditional transfers are lower. We are thus interested in whether an unconditional transfer would yield different welfare effects than the conditional one.

Figure 4 shows the migration and risk sharing effects of a temporary subsidy (i.e., our main results) in Panel (a) and the effects of a permanent subsidy in Panel (b). We expect that the permanent subsidy may differ from the temporary subsidy for two reasons: first, the fact that the subsidy is permanent implies a permanent improvement in the outside option which could make risk sharing less important, and second, the fact that migration is persistent may imply that the average migrant improves their job contacts over time, reducing the risk of migration. We find that the permanent subsidy leads to the opposite effect - a crowding-out, rather than a crowding-in - than the temporary subsidy. ${ }^{39}$ In our context, making the subsidy permanent would lead to a permanent 2.9 percentage

\footnotetext{
${ }^{39}$ Appendix Figure 6 considers the decomposition of the permanent shock into the financial and utility components.
} 
point worsening in risk sharing. We estimate that a permanent subsidy would generate a $13.5 \%$ increase in welfare; this number is just $40 \%$ (viz., $300 \%$ for the temporary subsidy) higher than the equivalent value under autarky, reflecting the negative effect on welfare from the loss of insurance. This finding has an important implication for the validity of extrapolating from RCTs to alternative longer-term policies: in this case the experimental evidence, which is by nature short-lived, has the opposite implications for risk sharing than the permanent policy.

Figure 4: Temporary vs permanent subsidy

(a) Temporary subsidy

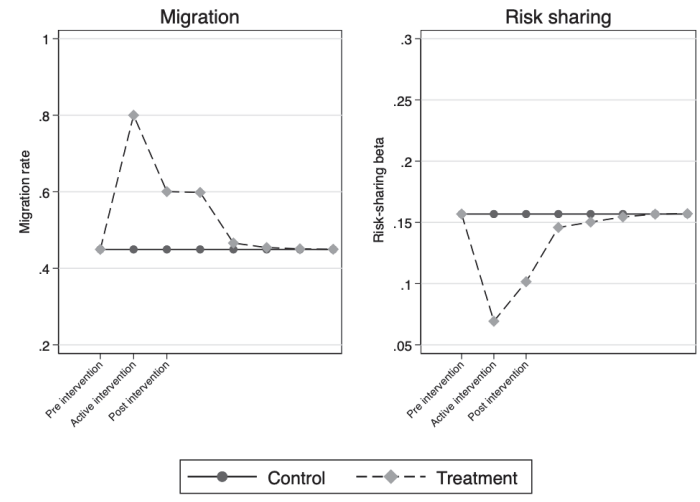

(b) Permanent subsidy

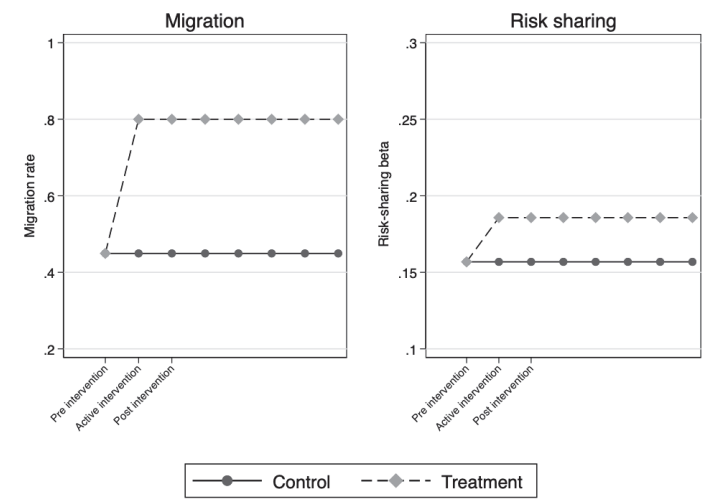

Note: Shock is both financial and utility shock.

We next consider an unconditional cash transfer (UCT) rather than a conditional cash transfer $(C C T$,$) in Figure 5. The UCT does not change migration and leads to a small$ improvement in risk sharing. Because everyone in the village receives the UCT, whereas only those who migrate receive a CCT, the UCT is a much larger income transfer. As such, the driving force in the risk-sharing effect is an income effect, compared with the driving force for the CCT coming through the income risk of migrating. Table 8 shows that, because the UCT does not cause any externalities through risk sharing, its welfare 
gain is essentially zero once the value of the subsidy is netted out.

Figure 5: One-time financial subsidy: conditional vs. unconditional

(a) Temporary conditional subsidy

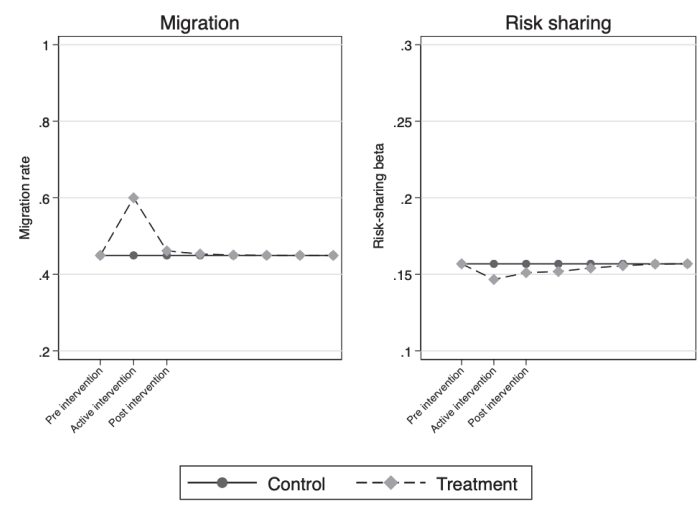

(b) Temporary unconditional subsidy

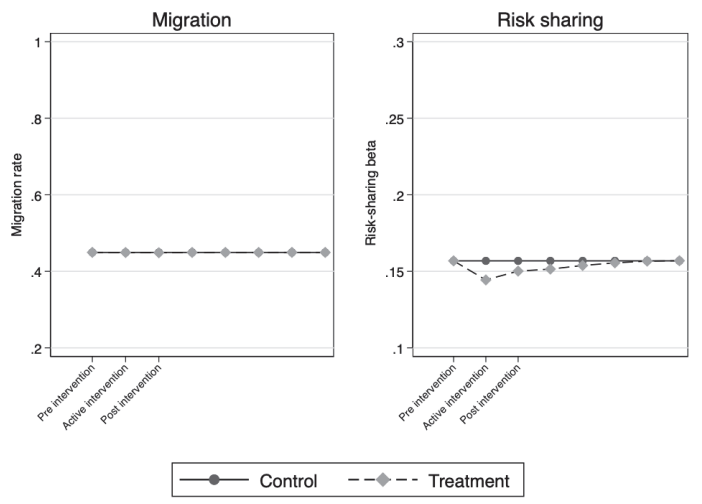

Note: The left panel shows the effect of an 800 Taka financial subsidy conditional on migrating. The right panel shows the effect of an unconditional 800 Taka financial subsidy. There is no utility subsidy in either case.

\section{Conclusion}

Our paper makes several contributions to our understanding of the trade-offs involved with experimentally introducing new income opportunities into a village. The experiment we use is described in Bryan et al. (2014): households in rural Bangladesh were randomly offered subsidies to migrate temporarily during the agricultural lean season. We focus on the interaction between migration and social safety nets and examine how new migration opportunities affect the nature and extent of informal risk sharing within villages. It is not obvious the direction these effects will take, as they depend on the nature of the intervention and the local context. Understanding the effects of facilitating migration also has broad relevance in many developing countries with high levels of agricultural risk. 
Our first contribution, based directly on the experimental results, is to show that the subsidy (i) increased transfers between households, (ii) increased the willingness of households to help others, and (iii) reduced the exposure of household consumption on household income, consistent with improved risk sharing. In order to understand this result, as well as the broader policy implications, we build a model that reveals the conditions under which risk sharing improves. Our model draws on Morten (2019), which includes limited commitment constraints on risk sharing (Kocherlakota, 1996; Ligon et al., 2002) and an endogenous migration decision based on the net return of migrating (Harris and Todaro, 1970), and adds a dynamic component making migration state-dependent.

We next show that the model can produce both improvements and declines in risk sharing. The key forces are the riskiness of the migration option and the expected value of city income. A risky migration option, which on average yields substantial returns, encourages risk sharing in exchange for the benefit of this potentially large return. On the other hand a relatively safe migration option, made easier by the intervention, discourages risk sharing because it also substantially improves the outside autarky option. Other factors also play a role, such as the relative size of financial and utility migration costs; our analysis points to many of these factors and how they interact.

We then fit our model to the experimental data to provide a framework to interpret the experimental findings and to evaluate the welfare effects of the program. The model fits the experimental treatment effects on migration and risk sharing reasonably well, providing a set of parameters that is consistent with improvements in the amount of insurance available. We use the model to conduct alternative policy experiments in which the subsidy is decomposed and made permanent, and show that a permanent utility subsidy 
leads to a permanent improvement in risk sharing while a permanent financial subsidy leads to a permanent decline in risk sharing. This result serves to illustrate how experimental evidence, which may involve only temporary interventions, may have very different impacts than longer-term policies.

These findings suggest a broader policy implication: the effectiveness of safety net programs and conditional transfers very much depends on how community networks operate and on the risk/return profile of the activities encouraged. In our experimental setting, the subsidy led to a positive spillover on risk sharing, generating larger welfare gains than in the absence of risk sharing. Nevertheless, we also show that in slightly different contexts, the opposite may occur. As a result, it is important to take into account these spillover effects when designing social protection programs. 


\section{References}

Abraham, Arpad and Sarolta Laczo, "Efficient Risk Sharing with Limited Commitment and Hidden Storage," Review of Economic Studies, 2018, 85 (3), 1389-1424.

Akram, Agha Ali, Shyamal Chowdhury, and Ahmed Mushfiq Mobarak, "Effects of Emigration on Rural Labor Markets," 2018.

Angelucci, Manuela and Giacomo de Giorgi, "Indirect Effects of an Aid Program: How do Cash Transfers Affect Ineligibles' Consumption?," American Economic Review, 2009, 99 (1), 486-508.

Asian Development Bank, "Rural Poverty Reduction and Inclusive Growth," Technical Report September 2007.

Attanasio, Orazio and Guglielmo Weber, "Is Consumption Growth Consistent with Intertemporal Optimization? Evidence from the Consumer Expenditure Survey," Journal of Political Economy, 1995, 103 (6), 1121-1157.

_ , Costas Meghir, and Ana Santiago, "Education Choices in Mexico: Using a Structural Model and a Randomized Experiment to Evaluate PROGRESA," Review of Economic Studies, 2012, 79 (1), 37-66.

Banerjee, Abhijit and Esther Duflo, "The Economic Lives of the Poor," Journal of Economic Perspectives, 2007, 21 (1), 141-167.

Baseler, Travis, "Hidden Income and the Perceived Returns to Migration: Experimental Evidence from Kenya," 2018.

Bazzi, Samuel, "Wealth Heterogeneity and the Income Elasticity of Migration," American Economic Journal: Applied Economics, 2017, 9 (2), 219-255.

Beam, Emily, David McKenzie, and Dean Yang, "Unilateral Facilitation Does Not Raise International Labor Migration from the Philippines," Economic Development and Cultural Change, 2016, 64 (2), 323-358.

Blundell, R., M. Browning, and C. Meghir, "Consumer Demand and the Life-Cycle Allocation of Household Expenditures," The Review of Economic Studies, 1994, 61 (1), 57-80.

Bold, Tessa and Tobias Broer, "Risk-Sharing in Village Economies Revisited," 2016, (June).

Bryan, Gharad, Shyamal Chowdhury, and Ahmed Mushfiq Mobarak, "Under-investment in a Profitable Technology : The Case of Seasonal Migration in Bangladesh," Econometrica, 2014, 82 (5), 1671-1748.

Chiappori, Pierre-Andre, K Samphantharak, Sam Schulhofer-Wohl, and Robert M Townsend, "Heterogeneity and Risk Sharing in Village Economies," Quantitative Economics, 2014, 5 (1), 1-27. 
Dupas, Pascaline, Anthony Keats, and Jonathan Robinson, "The Effect of Savings Accounts on Interpersonal Financial Relationships: Evidence from a Field Experiment in Rural Kenya," Economic Journal, 2017, (2015), 1-38.

Ferrara, Eliana La, "Kin Groups and Reciprocity: A Model of Credit Transactions in Ghana," The American Economic Review, 2003, 93 (5), 1730-1751.

Genicot, Garance and Debraj Ray, "Group Formation in Risk-Sharing Arrangements," The Review of Economic Studies, 2003, 70 (1), 87-113.

Hansen, Bruce E, “Econometrics,” 2016.

Harris, John and Michael Todaro, "Migration, Unemployment and Develpment: A TwoSector Analysis," The American Economic Review, 1970, 60 (1), 126-142.

Joseph, Thomas, Yaw Nyarko, and Shing yi Wang, "Asymmetric Information and Remittances: Evidence from Matched Administrative Data," NBER Working Paper, 2015.

Kaboski, Joseph P and Robert M Townsend, "A Structural Evaluation of a Large-Scale Quasi-Experimental Microfinance Initiative," Econometrica, 2011, 79 (5), 1357-1406.

Khandker, Shahidur R., "Seasonality of Income and Poverty in Bangladesh," Journal of Development Economics, mar 2012, 97 (2), 244-256.

Kinnan, Cynthia, "Distinguishing Barriers to Insurance in Thai Villages," Journal of Human Resources (forthcoming), 2020.

Kocherlakota, N, "Implications of Efficient Risk Sharing without Commitment," Review of Economic Studies, 1996, 63 (4), 595-609.

Krueger, Dirk and Fabrizio Perri, "Public versus Private Risk Sharing," Journal of Economic Theory, 2010, 146 (3), 920-956.

Lagakos, David, Mushfiq Mobarak, and Michael Waugh, "The Welfare Effects of Encouraging Rural-Urban Migration," NBER Working Paper, 2018.

Ligon, Ethan, "Risk sharing and information in village economies," Review of Economic Studies, 1998.

- and Laura Schechter, "Structural Experimentation to Distinguish between Models of Risk Sharing with Frictions in Rural Paraguay," Economic Development and Cultural Change, 2019.

_ , Jonathan Thomas, and Tim Worrall, "Informal Insurance Arrangements with Limited Commitment: Theory and Evidence from Village Economies," The Review of Economic Studies, 2002, 69 (1), 209-244.

Massey, Douglas, Jorge Durand, and Nolan Malone, Beyond Smoke and Mirrors: Mexican Immigration in an Era of Economic Integration, Russell Sage Foundation, 2003. 
Mazzocco, M and S Saini, "Testing Efficient Risk Sharing with Heterogeneous Risk Preferences," American Economic Review, 2012, 102 (1), 428-468.

McFadden, Daniel, "A Method of Simulated Moments for Estimation of Discrete Response Models Without Numerical Integration," Econometrica, 1989, 57 (5), 995-1026.

Morten, Melanie, "Temporary Migration and Endogenous Risk Sharing in Village India," Journal of Political Economy, 2019, 127 (1), 1-46.

Munshi, K, "Networks in the Modern Economy: Mexican Migrants in the US Labor Market," Quarterly Journal of Economics, 2003, 118 (2), 549-597.

Munshi, Kaivan and Mark Rosenzweig, "Networks and Misallocation: Insurance, Migration, and the Rural-Urban Wage Gap," American Economic Review, 2016, 106 (1), 46-98.

Pakes, A and D Pollard, "Simulation and the Asymptotics of Optimization Estimators," Econometrica, 1989, 57 (5), 1027-1057.

Rogerson, William, “Repeated Moral Hazard," Econometrica, 1985, 53 (1), 69-76.

Todd, Petra and Kenneth Wolpin, "Assessing the Impact of a School Subsidy Program in Mexico: Using a Social Experiment to Validate a Dynamic Behavioral Model of Child Schooling and Fertility," American Economic Review, 2006, 96 (5), 1384-1417.

Townsend, Robert M, "Optimal Multiperiod Contracts and the Gain from Enduring Relationships under Private Information," The Journal of Political Economy, 1982.

_ , "Risk and Insurance in Village India," Econometrica, 1994, 62 (3), 539-591. 


\section{Appendix}

\section{Table of Contents}

A Theoretical appendix $\quad 55$

A.1 Deriving the bias in cross-sectional risk sharing regressions . . . . . . . 55

A.2 Model extensions . . . . . . . . . . . . . . . . . . . . . . 59

A.3 Computational algorithm . . . . . . . . . . . . . . 63

A.4 Properties of migration decision . . . . . . . . . . . . . . . . 66

A.5 Standard errors . . . . . . . . . . . . . . . . . . 74

$\begin{array}{ll}\text { B Empirical appendix } & 75\end{array}$

B.1 Magnitude of transfers in and transfers out $\ldots \ldots \ldots \ldots$

B.2 Appendix Tables . . . . . . . . . . . . . . . . . 77

B.3 Appendix Figures . . . . . . . . . . . . . . . . . . . 89 


\section{A Theoretical appendix}

\section{A.1 Deriving the bias in cross-sectional risk sharing regressions}

In this appendix we derive the bias of the treatment effect of the risk sharing coefficient in a cross-sectional Townsend-style regression. We follow Chiappori et al. (2014) in deriving the risk-sharing test from first principles. We assume that household $i$ has CRRA preferences over consumption with a coefficient of relative risk aversion of $\sigma_{i}$, which may be heterogeneous across households. In each period $t$, the social planner problem maximizes the sum of utilities of all households in the village, weighted by household pareto weights $\lambda_{i}$, subject to a budget constraint that total income is equal to total consumption:

$$
\max _{c_{i t}, \forall i} \sum_{i} \lambda_{i} \frac{c_{i t}^{1-\sigma_{i}}}{1-\sigma_{i}} \text { such that } \sum_{i} c_{i t}=\sum_{i} y_{i t}
$$

The first order conditions yield the following relationship for consumption, where $\bar{\lambda}_{t}$ is the Pareto multiplier on the village budget constraint:

$$
\log c_{i t}=\frac{\log \lambda_{i}}{\sigma_{i}}-\frac{\bar{\lambda}_{t}}{\sigma_{i}}
$$

This forms the basis of the standard Townsend test for risk sharing:

$$
\begin{aligned}
\log c_{i t} & =\frac{\log \lambda_{i}}{\sigma_{i}}-\frac{\bar{\lambda}_{t}}{\sigma_{i}}+\alpha \times \log y_{i t} \\
& =u_{i}+x_{i t}+\alpha \times \log y_{i t}
\end{aligned}
$$

where we use $u_{i}$ and $x_{i t}$ as shorthands, and $\alpha=0$ under full risk sharing. We follow most of the literature in assuming homogeneous risk preferences (i.e., $\sigma_{i}=\sigma$ so $x_{i t}=x_{t}$ ). ${ }^{40}$ The standard approach to estimating this equation is to add village-time fixed effects to control for $x_{t}$ and household fixed effects to control for unobserved household heterogeneity $u_{i}$.

Neglecting household fixed effects can introduce bias in $\hat{\alpha}$ if $u_{i}$ is correlated with individual income. We show, however, that the effect of a randomized treatment on this risk-sharing coefficient is not necessarily biased under certain conditions. Denoting the treatment $T$, the new equation (purged of village-time effects and suppressing the $t$ subscript because we only use a cross-section) is:

$$
\log c_{i}=u_{i}+\gamma T+\alpha \times \log y_{i}+\beta \times T \times \log y_{i}
$$

and the corresponding estimating equation is:

$$
c=\alpha y+\gamma T+\beta y T+\delta u+\varepsilon
$$

where $c$ is $\log$ consumption, $y$ is log income, $u$ is an individual heterogeneity term that can capture an individual's pareto weight, and $T$ is treatment, which might be correlated

\footnotetext{
${ }^{40}$ Interesting exceptions are Chiappori et al. (2014) and Mazzocco and Saini (2012).
} 
with $y$ but is otherwise uncorrelated with all other terms. We are interested in whether $\beta$ is biased when $u$ is unobserved and cannot be controlled.

The standard OLS formula for the coefficients of Equation (15) gives:

$$
\left[\begin{array}{c}
\hat{\alpha} \\
\hat{\gamma} \\
\hat{\beta}
\end{array}\right]=\left(\frac{1}{N} \Sigma\left[\begin{array}{c}
y \\
T \\
y T
\end{array}\right]\left[\begin{array}{lll}
y & T & y T
\end{array}\right]\right)^{-1} \frac{1}{N} \Sigma\left[\begin{array}{c}
y \\
T \\
y T
\end{array}\right](\alpha y+\gamma T+\beta y T+\delta u+\varepsilon)
$$

The concern is the effect of $\delta u$ on $\hat{\beta}$ in this equation, so we concentrate on that term (if zero, then the bias of $\hat{\beta}$ is zero):

$$
\left(\frac{1}{N} \Sigma\left[\begin{array}{c}
y \\
T \\
y T
\end{array}\right]\left[\begin{array}{lll}
y & T & y T
\end{array}\right]\right)^{-1} \frac{1}{N} \Sigma\left[\begin{array}{c}
y \\
T \\
y T
\end{array}\right](\delta u)
$$

The matrix that needs to be inverted is:

$$
\frac{1}{N} \Sigma\left[\begin{array}{c}
y \\
T \\
y T
\end{array}\right]\left[\begin{array}{lll}
y & T & y T
\end{array}\right]=\left[\begin{array}{ccc}
\operatorname{var}(y) & \operatorname{cov}(y, T) & \operatorname{cov}(y, y T) \\
\operatorname{cov}(y, T) & \operatorname{var}(T) & \operatorname{cov}(T, y T) \\
\operatorname{cov}(y, y T) & \operatorname{cov}(T, y T) & \operatorname{var}(y T)
\end{array}\right]
$$

Inverting this matrix, whose determinant is $D$, and plugging the inverted matrix into the main equation gives:

$$
\frac{\delta}{D}\left[\begin{array}{ccc}
\ldots & \ldots & \ldots \\
\ldots & \ldots & \ldots \\
\operatorname{cov}(y, T) \operatorname{cov}(T, y T)-\operatorname{var}(T) \operatorname{cov}(y, y T) & \ldots & \operatorname{var}(T) \operatorname{var}(y)-\operatorname{cov}(y, T)^{2}
\end{array}\right]\left[\begin{array}{c}
\operatorname{cov}(y, u) \\
0 \\
\operatorname{cov}(y T, u)
\end{array}\right]
$$

where we have omitted the first two rows because they do not matter for the bias of $\beta$ and the bottom middle column because it gets multiplied by $\operatorname{cov}(T, u)$, which is zero because the treatment is randomized.

To solve the bias of $\beta$, we must specify $y$. We next go through several examples:

\section{A.1.1 Bias when treatment and income are uncorrelated}

We begin with $y=u+\eta$. Remembering that $T$ is independent of all unobserved components $(u, \epsilon$ and $\eta)$ in this case, the various covariance terms are:

$$
\begin{aligned}
\operatorname{cov}(y, T) & =0 \\
\operatorname{cov}(T, y T) & =\operatorname{var}(T) E(u+\eta) \\
\operatorname{cov}(y, y T) & =E(T) \operatorname{var}(u+\eta) \\
\operatorname{var}(y) & =\operatorname{var}(u+\eta) \\
\operatorname{cov}(y, u) & =\operatorname{var}(u) \\
\operatorname{cov}(y T, u) & =\operatorname{var}(u) E(T)
\end{aligned}
$$


Plugging these in and letting $\delta^{*}=\frac{\delta}{D}$ gives:

$$
\begin{aligned}
\text { Bias } & =\delta^{*}[-E(T) \operatorname{var}(T) \operatorname{var}(u+\eta) \operatorname{var}(u)+\operatorname{var}(T) \operatorname{var}(u+\eta) \operatorname{var}(u) E(T)] \\
& =\delta^{*}[0] \\
& =0
\end{aligned}
$$

So $E \hat{\beta}=\beta$ (it is unbiased) when $y=u+\eta$ and $u$ is omitted, implying an unbiased estimate of the effect of treatment on the degree of risk sharing.

\section{A.1.2 Bias when treatment affects income in an additive fashion}

Now let the treatment affect income such that $y=u+\eta+\phi T$. The various covariance terms become:

$$
\begin{aligned}
\operatorname{cov}(y, T) & =\phi \operatorname{var}(T) \\
\operatorname{cov}(T, y T) & =\operatorname{var}(T)[\phi+E(u+\eta)] \\
\operatorname{cov}(y, y T) & =\phi \operatorname{var}(T)[\phi+E(u+\eta)]+E(T) \operatorname{var}(u+\eta) \\
\operatorname{var}(y) & =\operatorname{var}(u+\eta)+\phi^{2} \operatorname{var}(T) \\
\operatorname{cov}(y, u) & =\operatorname{var}(u) \\
\operatorname{cov}(y T, u) & =\operatorname{var}(u) E(T)
\end{aligned}
$$

Plugging these in gives:

$$
\begin{aligned}
\text { Bias }= & \delta^{*}\left[\operatorname{var}(u)\left(\phi \operatorname{var}(T)^{2}[\phi+E(u+\eta)]-\phi \operatorname{var}(T)^{2}[\phi+E(u+\eta)]-\operatorname{var}(T) E(T) \operatorname{var}(u+\eta)\right)\right. \\
& \left.+\operatorname{var}(u) E(T) \operatorname{var}(T)\left(\operatorname{var}(u+\eta)+\phi^{2} \operatorname{var}(T)-\phi^{2} \operatorname{var}(T)\right)\right] \\
= & \delta^{*}[-\operatorname{var}(u) \operatorname{var}(T) E(T) \operatorname{var}(u+\eta)+\operatorname{var}(u) E(T) \operatorname{var}(T) \operatorname{var}(u+\eta)] \\
= & \delta^{*}[0] \\
= & 0
\end{aligned}
$$

So $E \hat{\beta}=\beta$ (it is unbiased) when $y=u+\eta+\phi T$ and $u$ is omitted, implying an unbiased estimate of the effect of treatment on the degree of risk sharing.

\section{A.1.3 Bias when treatment affects income in a multiplicative fashion}

Now suppose $y=\phi T u+\eta$. The various covariance terms become:

$$
\begin{aligned}
\operatorname{cov}(y, T) & =\phi E(u) \operatorname{var}(T) \\
\operatorname{cov}(T, y T) & =[\phi E(u)+E(n)] \operatorname{var}(T) \\
\operatorname{cov}(y, y T) & =\phi^{2} \operatorname{var}(u T)+E(T) \operatorname{var}(\eta)+\phi E(\eta) E(u) \operatorname{var}(T) \\
\operatorname{var}(y) & =\phi^{2} \operatorname{var}(u T)+\operatorname{var} \eta \\
\operatorname{cov}(y, u) & =\phi \operatorname{var}(u) E(T) \\
\operatorname{cov}(y T, u) & =\phi E(T) \operatorname{var}(u)
\end{aligned}
$$


Plugging these in gives:

$$
\begin{aligned}
\text { Bias }= & \delta^{*}\left[\phi E ( T ) \operatorname { v a r } ( u ) \left(\phi^{2} E(u)^{2} \operatorname{var}(T)^{2}-\phi^{2} \operatorname{var}(T) \operatorname{var}(u T)-\operatorname{var}(T) \operatorname{var}(\eta) E(T)\right.\right. \\
& \left.\left.+\phi^{2} \operatorname{var}(T) \operatorname{var}(u T)+\operatorname{var}(T) \operatorname{var}(\eta)-\phi^{2} E(u)^{2} \operatorname{var}(T)^{2}\right)\right] \\
= & \delta^{*} \phi \operatorname{var}(u) \operatorname{var}(\eta) \operatorname{var}(T) E(T)(1-E(T)) \\
= & \delta^{*} \phi \operatorname{var}(u) \operatorname{var}(\eta) \operatorname{var}(T)^{2}
\end{aligned}
$$

So the treatment effect on risk sharing is biased in this case. Thus, when treatment affects income in a log-additive way, then there is no bias, but if the proportional effect of treatment varies with the level of income then there is bias resulting from the omission of controls for permanent income (fixed effects). The bias will in general depend on the extent of departure from proportionality. While admittedly a strong condition, in practice, simulations show that small departures from proportionality only cause small biases. 


\section{A.2 Model extensions}

This subsection (i) derives the first order conditions for the two household model, and (ii) extends the model to $N$ households.

\section{A.2.1 First order conditions for two-household model}

\section{After-migration problem}

The after-migration problem is the following:

$\widehat{V}(\hat{h}, \widehat{U}(\hat{h}))=\max _{\left\{\tau,\left\{U\left(h^{\prime}\right)\right\}_{\forall h^{\prime}}\right\}} u\left(\hat{y}^{2}\left(\hat{h}, d^{\text {fin }}\right)+\tau\left(\hat{h}, d^{\text {fin }}\right)\right)-\mathbb{I}^{2}(\hat{h}) d^{\text {utility }}+\beta \sum_{h^{\prime}} \pi_{h^{\prime} \mid \hat{h}} V\left(h^{\prime}, U\left(h^{\prime}\right)\right)$

subject to a promise-keeping constraint for household 1:

$$
\left(\widehat{\lambda}_{\hat{h}}\right): \quad u\left(y^{1}\left(\hat{h}, d^{\text {fin }}\right)-\tau\left(\hat{h}, d^{\text {fin }}\right)\right)-\mathbb{I}^{i}(\hat{h}) d^{\text {utility }}+\beta \sum_{h^{\prime}} \pi_{h^{\prime} \mid \hat{h}} U\left(h^{\prime}\right) \geq \widehat{U}(\hat{h})
$$

an incentive compatibility constraint for household 1 (multiplying the multiplier by $\widehat{\lambda}_{\hat{h}^{\prime}} \beta \pi_{h^{\prime} \mid \hat{h}}$ ):

$$
\left(\widehat{\lambda}_{\hat{h}} \beta \pi_{h^{\prime} \mid \hat{h}} \phi_{h^{\prime}, \hat{h}}^{1}\right): \quad U\left(h^{\prime}\right) \geq \Omega^{1}\left(h^{\prime}\right) \quad \forall h^{\prime} ;
$$

and an incentive compatibility constraint for household 2 (multiplying the multiplier by $\left.\beta \pi_{h^{\prime} \mid \hat{h}}\right)$ :

$$
\left(\beta \pi_{h^{\prime} \mid \hat{h}} \phi_{h^{\prime}, \hat{h}}^{2}\right): \quad V\left(h^{\prime}, U\left(h^{\prime}\right)\right) \geq \Omega^{2}\left(h^{\prime}\right) \quad \forall h^{\prime}
$$

The first order conditions yield:

$$
\begin{aligned}
\frac{u_{1}\left(c^{2}(\hat{h})\right)}{u_{1}\left(c^{1}(\hat{h})\right)} & =\widehat{\lambda}_{\hat{h}} \\
V_{2}\left(h^{\prime}, U\left(h^{\prime}\right)\right) & =\widehat{\lambda}_{\hat{h}} \frac{\left(1+\phi_{h^{\prime}, \hat{h}}^{1}\right)}{\left(1+\phi_{h^{\prime}, \hat{h}}^{2}\right)}
\end{aligned}
$$

and the envelope condition yields:

$$
\widehat{V}_{2}(\hat{h}, \widehat{U}(\hat{h}))=\widehat{\lambda}_{\hat{h}}
$$

\section{Before-migration problem}

The before-migration problem is:

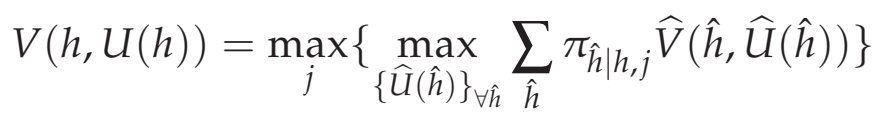

subject to a promise-keeping constraint that needs to hold for each migration outcome $j$ :

$$
\left(\lambda_{j}\right): \quad \sum_{\hat{h}} \pi_{\hat{h} \mid h, j} \widehat{U}(\hat{h}) \geq U(h) \quad \forall j ;
$$


an incentive compatibility constraint for household 1 (multiplying the multiplier by $\lambda_{j} \pi_{\hat{h} \mid h, j}$ ):

$$
\left(\lambda_{j} \pi_{\hat{h} \mid h, j} \alpha_{\hat{h}}^{1}\right): \quad \widehat{U}(\hat{h}) \geq \widehat{\Omega}^{1}(\hat{h}) \quad \forall \hat{h} ;
$$

and an incentive compatibility constraint for household 2 (multiplying the multiplier by $\left.\pi_{\hat{h} \mid h, j}\right):$

$$
\left(\pi_{\hat{h} \mid h, j} \alpha_{\hat{h}}^{2}\right): \quad \widehat{V}(\hat{h}, U(\hat{h})) \geq \widehat{\Omega}^{2}(\hat{h}) \quad \forall \hat{h}
$$

The first order condition yields:

$$
\widehat{V}_{2}(\hat{h}, U(\hat{h}))=-\lambda_{j} \frac{\left(1+\alpha_{\hat{h}}^{1}\right)}{\left(1+\alpha_{\hat{h}}^{2}\right)} \quad \forall \hat{h}
$$

and the envelope condition yields:

$$
V_{2}(h, U(h))=-\lambda_{j} \quad \forall j
$$

\section{Updating rules}

This section derives the updating rule for the Pareto weight. Consider an initial beforemigration Pareto weight of $\lambda_{t}$.

Equations 30, 25, and 23 imply that:

$$
\hat{\lambda}_{t}=\frac{u_{1}\left(c_{t}^{2}\left(\hat{h}_{t}\right)\right)}{u_{1}\left(c_{t}^{1}\left(\hat{h}_{t}\right)\right)}=-\lambda_{t} \frac{\left(1+\alpha_{\hat{h}_{t}}^{1}\right)}{\left(1+\alpha_{\hat{h}_{t}}^{2}\right)}
$$

Then, equation 24 implies that:

$$
\lambda_{t+1}=V_{2}\left(h_{t+1}, U\left(h_{t+1}\right)\right)=\hat{\lambda}_{t} \frac{\left(1+\phi_{h_{t+1}, \hat{h}_{t}}^{1}\right)}{\left(1+\phi_{h_{t+1}, \hat{h}_{t}}^{2}\right)}
$$

And so equations 30, 25, and 23 imply that:

$$
\hat{\lambda}_{t+1}=\frac{u_{1}\left(c_{t+1}^{2}\left(\hat{h}_{t+1}\right)\right)}{u_{1}\left(c_{t+1}^{1}\left(\hat{h}_{t+1}\right)\right)}=-\lambda_{t+1} \frac{\left(1+\alpha_{\hat{h}_{t+1}}^{1}\right)}{\left(1+\alpha_{\hat{h}_{t+1}}^{2}\right)}
$$

Notice that this implies that the change in the ratio of marginal utilities is given by

$$
\frac{u_{1}\left(c^{2}\left(\hat{h}_{t+1}\right)\right) / u_{1}\left(c^{1}\left(\hat{h}_{t+1}\right)\right)}{u_{1}\left(c^{2}\left(\hat{h}_{t}\right)\right) / u_{1}\left(c^{1}\left(\hat{h}_{t}\right)\right)}=\frac{\hat{\lambda}_{t+1}}{\hat{\lambda}_{t}}=\frac{\left(1+\phi_{h_{t+1}, \hat{h}_{t}}^{1}\right)\left(1+\alpha_{h_{t+1}}^{1}\right)}{\left(1+\phi_{h_{t+1}, \hat{h}_{t}}^{2}\right)\left(1+\alpha_{h_{t+1}}^{2}\right)}
$$

If neither household is constrained $\left(\alpha_{h_{t+1}}^{1}=\alpha_{h_{t+1}}^{2}=\phi_{h_{t+1}, \hat{h}_{t}}^{1}=\phi_{h_{t+1}, \hat{h}_{t}}^{2}=0\right)$ then the rate of growth of relative marginal utility is zero. Otherwise, the change in marginal utility adjusts towards whichever household has the binding participation constraints.

Consumption is derived from the after-migration first order conditions as follows: 


$$
\begin{aligned}
& \frac{u_{1}\left(c^{1}\right)}{u_{1}\left(c^{2}\right)}=\lambda \\
& c_{1}+c_{2}=Y
\end{aligned}
$$

and implies that consumption is given by:

$$
\begin{aligned}
& c_{1}=\frac{\lambda^{\frac{-1}{\gamma}}}{1+\lambda^{\frac{-1}{\gamma}}} Y \\
& c_{2}=\frac{1}{1+\lambda^{\frac{-1}{\gamma}}} Y
\end{aligned}
$$

\section{A.2.2 Extension to $N$ household case}

The model presented in the paper consists of two households. Here we extend the model to $N$ households. Now, the Pareto frontier traces out the utility to household $N$, given promised utility to households $1, \ldots, N-1$.

The after-migration problem is:

$$
\begin{array}{r}
\widehat{V}\left(\hat{h}, \widehat{U}_{1}(\hat{h}), \widehat{U}_{2}(\hat{h}), \ldots, \widehat{U}_{N-1}(\hat{h})\right)=\max _{\left\{\left\{\tau_{i,},\left\{U_{i}\left(h^{\prime}\right)\right\}_{\forall h^{\prime}}\right\}_{\forall i=1, \ldots, N-1}\right\}} u\left(\hat{y}^{N}\left(\hat{h}, d^{\text {fin }}\right)+\sum_{i=1}^{N-1} \tau_{i}\left(\hat{h}, d^{\text {fin }}\right)\right) \\
-\mathbb{I}^{N}(\hat{h}) d^{\text {utility }}+\beta \sum_{h^{\prime}} \pi_{h^{\prime} \mid \hat{h}} V\left(h^{\prime}, U_{1}\left(h^{\prime}\right), U_{2}\left(h^{\prime}\right), \ldots, U_{N-1}\left(h^{\prime}\right)\right)
\end{array}
$$

subject to promise-keeping constraints for each household $i=1, \ldots, N-1$ :

$\left(\widehat{\lambda}_{\hat{h}}^{i}\right): \quad u\left(y^{i}\left(\hat{h}, d^{\text {fin }}\right)-\tau_{i}\left(\hat{h}, d^{\text {fin }}\right)\right)-\mathbb{I}^{i}(\hat{h}) d^{\text {utility }}+\beta \sum_{h^{\prime}} \pi_{h^{\prime} \mid} U_{i}\left(h^{\prime}\right) \geq \widehat{U}_{i}(\hat{h}), \forall i=1, \ldots, N-1 ;$

incentive compatibility constraints for each household $i=1, \ldots, N-1$ (multiplying the multiplier by $\left.\widehat{\lambda}_{\hat{h}}^{i} \beta \pi_{h^{\prime} \mid \hat{h}}\right)$ :

$$
\left(\widehat{\lambda}_{\hat{h}}^{i} \beta \pi_{h^{\prime} \mid \hat{h}} \phi_{h^{\prime}, \hat{h}}^{i}\right): \quad U_{i}\left(h^{\prime}\right) \geq \Omega^{i}\left(h^{\prime}\right) \quad \forall h^{\prime}, \forall i=1, \ldots, N-1 ;
$$

and an incentive compatibility constraint for household $N$ (multiplying the multiplier by $\left.\beta \pi_{h^{\prime} \mid \hat{h}}\right)$ :

$$
\left(\beta \pi_{h^{\prime} \mid \hat{h}} \phi_{h^{\prime}, \hat{h}}^{N}\right): \quad V\left(h^{\prime}, U\left(h^{\prime}\right)\right) \geq \Omega^{N}\left(h^{\prime}\right) \quad \forall h^{\prime}
$$

The before-migration problem is:

$V\left(h, U_{1}(h), U_{2}(h), \ldots, U_{N-1}(h)\right)=\max _{j}\left\{\max _{\left\{\widehat{U}_{i}(\hat{h})\right\}_{\forall \hat{h}, \forall i=1, \ldots, N-1}} \sum_{\hat{h}} \pi_{\hat{h} \mid h, j} \widehat{V}\left(\hat{h}, \widehat{U}_{1}(\hat{h}), \widehat{U}_{2}(\hat{h}), \ldots \widehat{U}_{N-1}(\hat{h})\right)\right\}$ 
subject to a promise-keeping constraint for each household $i=1, \ldots, N-1$ :

$$
\left(\lambda_{j}^{i}\right): \sum_{\hat{h}} \pi_{\hat{h} \mid h, j} \widehat{U}(\hat{h}) \geq U(h) \forall j, \forall i=1, \ldots, N-1 ;
$$

incentive compatibility constraints for each household $i=1, \ldots, N-1$ (multiplying the multiplier by $\left.\lambda_{j}^{i} \pi_{\hat{h} \mid h, j}\right)$ :

$$
\left(\lambda_{j}^{i} \pi_{\hat{h} \mid h, j} \alpha_{\hat{h}}^{i}\right): \quad \widehat{U}_{i}(\hat{h}) \geq \widehat{\Omega}^{i}(\hat{h}) \quad \forall \hat{h}, \forall i=1, \ldots, N-1 ;
$$

and an incentive compatibility constraint for household $N$ (multiplying the multiplier by $\left.\pi_{\hat{h} \mid h, j}\right):$

$$
\left(\pi_{\hat{h} \mid h, j} \alpha_{\hat{h}}^{N}\right): \quad \widehat{V}\left(\hat{h}, U_{1}(\hat{h}), U_{2}(\hat{h}), \ldots, U_{N-1}(\hat{h})\right) \geq \widehat{\Omega}^{N}(\hat{h}) \quad \forall \hat{h}
$$

Similar to the two household model, the rate of growth of marginal utility for any two households $i$ and $g$ is given by:

$$
\frac{u_{1}\left(c^{g}\left(\hat{h}_{t+1}\right)\right) / u_{1}\left(c^{i}\left(\hat{h}_{t+1}\right)\right)}{u_{1}\left(c^{g}\left(\hat{h}_{t}\right)\right) / u_{1}\left(c^{i}\left(\hat{h}_{t}\right)\right)}=\frac{\hat{\lambda}_{t+1}}{\hat{\lambda}_{t}}=\frac{\left(1+\phi_{h_{t+1}, \hat{h}_{t}}^{i}\right)\left(1+\alpha_{h_{t+1}}^{i}\right)}{\left(1+\phi_{h_{t+1}, \hat{h}_{t}}^{g}\right)\left(1+\alpha_{h_{t+1}}^{g}\right)}
$$

If neither household is constrained $\left(\alpha_{h_{t+1}}^{i}=\alpha_{h_{t+1}}^{g}=\phi_{h_{t+1}, \hat{h}_{t}}^{i}=\phi_{h_{t+1}, \hat{h}_{t}}^{g}=0\right)$ then the rate of growth of relative marginal utility is constant (but unknown) for the two households. This equation therefore gives one more equation that, together with the budget constraint that total income equals total consumption, allows us to estimate the level of utility. To do this we estimate scaling factors, $\zeta_{t}$, where $t$ indexes the time period relative to the one-off experiment, such that total consumption is equal to total income. That is, we find $\zeta_{t}$ such that $\hat{\lambda}_{t}^{i}=\max \left(\zeta_{t} \hat{\lambda}_{t-1}^{i}, \underline{\hat{\lambda}}\right)$ and the invariant distribution of income is equal to the invariant distribution of consumption (i.e., $\left.\sum_{i} c_{t}^{i}\left(\hat{h}^{t}, \hat{\lambda}_{t}^{i}\left(\zeta_{t}\right)\right)=\sum_{i} \hat{y}_{t}^{i}\left(\hat{h}^{t}\right)\right)$. We solve for one scaling parameter in the pre-experiment steady state $\zeta_{-1}$, one for the year of the experiment $\zeta_{0}$, and one for each year $t$ after the experiment $\left(\zeta_{1}, \zeta_{3}, \ldots, \zeta_{T}\right)$, until the economy has converged back to the equilibrium steady state (measured by $\zeta_{T}=\zeta_{-1}$ ).

Consumption is derived from the after-migration first order conditions as follows. If preferences are Gorman-aggregable, then the following system of equations:

$$
\begin{aligned}
\frac{u_{1}\left(c^{i}\right)}{u_{1}\left(c^{N}\right)} & =\lambda^{i}, \forall i=1, \ldots, N-1 \\
\sum c^{i} & =Y
\end{aligned}
$$

imply that consumption is given by:

$$
c^{i}= \begin{cases}\frac{\left(\lambda^{i}\right)^{\frac{-1}{\gamma}}}{1+\sum_{i \neq N}\left(\lambda^{i}\right)^{\frac{-1}{\gamma}}} Y, & \text { if } i \neq N \\ \frac{1}{1+\sum_{i \neq N}\left(\lambda^{i}\right)^{\frac{-1}{\gamma}}} Y, & \text { if } i=N\end{cases}
$$

Thus, the aggregate "rest of village" household is given by

$$
c^{r o v}=\sum_{i \neq N}=\frac{\sum_{i \neq N}\left(\lambda^{i}\right)^{\frac{-1}{\gamma}}}{1+\sum_{i \neq N}\left(\lambda^{i}\right)^{\frac{-1}{\gamma}}} Y
$$




\section{A.3 Computational algorithm}

We solve the problem using a similar algorithm to that in Morten (2019). We solve the algorithm assuming that there are two households: an individual household and the "rest of the village" household. We solve by value function iteration for two grids: the beforemigration grid and the after-migration grid. Relative to Morten (2019), we additionally consider both a migration asset as well as a temporary experiment shock. This introduces two additional state variables-the asset and the time relative to the experiment-into the algorithm.

The before-migration grid has the following state variables: $\{\lambda, s, A, t\}$ where $\lambda$ is the before-migration Pareto weight; $\mathrm{s}$ is the state of the world in the village; $A$ is beforemigration assets, and $t$ measures time relative to the temporary shock: $t=-1,0,1, \ldots, T$ where $T$ is large enough so that the economy has returned to the steady-state equilibrium (in practice, this occurs by $T=7$ ).

The after-migration grid has the following state variables: $\{\hat{\lambda}, s, q, j, \hat{A}, t\}$ where $\hat{\lambda}$ is the after-migration Pareto weight, $\mathrm{s}$ is the state of the world in the village, $q$ is the state of world in the destination, $j$ indexes the migration decision, $\hat{A}$ is after-migration assets, and $t$ measures time relative to the temporary shock.

The algorithm loops through five steps to solve the problem. First, holding the scaling factor and the distribution of agents across the state space constant, it solves for the optimal order for agents to migrate under perfect risk sharing. Second, iterating through each possible migration outcome (in the given order of migration), it solves for the optimal lower and upper bounds of the before-migration and after-migration Pareto weights. Third, it chooses the migration decision that maximizes total welfare. Fourth, it updates the distribution of agents across the state space, accounting for the updated migration rule and interval bounds, and iterates until it finds a fixed point for total income (which is affected by migration) in the economy. Fifth, it solves for a fixed point of the scaling factors such that the economy-wide budget constraint is satisfied and then iterates until a fixed point of the scaling factors is found.

The algorithm requires the following steps. Let $i$ index the before-migration grid point $\left\{\lambda_{i}, s_{i}, A_{i}, t_{i}\right\}$ and $\hat{i}$ index the after-migration grid point $\left\{\hat{\lambda}_{\hat{i}}, s_{\hat{i}}, q_{\hat{i}}, j_{\hat{i}}, \hat{A}_{\hat{i}}, t_{\hat{i}}\right\}$.

1. Choose an initial before-migration distribution of agents across the state space $\Pi_{0}=$ $\{\lambda, s, A, t\}$. We set $\Pi_{0}=\left\{\Pi_{01}, \Pi_{02}, \ldots, \Pi_{0 T}\right\}$, with $\Pi_{0 t}=\frac{1}{\text { number elements }(\lambda, s, A)}$.

2. Solve the algorithm under perfect risk sharing to find the before-migration value function under perfect risk sharing and the order of migration (see Appendix A.4.1).

(a) Compute the return to agent $i$ migrating: income gain ${ }^{i}=e^{i}(s)-\mathbb{E} m^{i}(q, A)$

(b) Guess an initial sort order for agents to migrate: $\mathcal{D}_{0}=f\left(\right.$ income gain $\left.^{i}, A_{i}, \lambda_{i}\right)$

(c) Consider each migration possibility from $j=0$ (i.e., no agent migrates) to $j=N$ (i.e., all agents migrate), imposing the sort order $\mathcal{D}_{0}$

i. Compute the total resources in the economy under migration rule $j$ based on village income and the expected income gain

ii. Assign consumption based on the Pareto weight $\lambda_{i}$ 
iii. Compute total welfare $W_{j}=\sum_{i} \lambda_{i}\left(u\left(c_{i}\right)-\mathbb{I}_{j} d^{\text {utility cost }}\right)$

(d) Compute the change in total welfare as one additional person migrates: $\Delta W_{j}=$ $W_{j+1}-W_{j}$

(e) Order agents in terms of decreasing marginal change in welfare from migrating: $\mathcal{D}_{1}=f\left(\Delta W_{j}\right)$

(f) Compare sort order $\mathcal{D}_{0}$ and $\mathcal{D}_{1}$. Iterate Steps 2c to 2e until the sort order has converged.

3. Choose an initial scaling vector $Z$. We set $Z_{0}=\left\{\zeta_{0}, \zeta_{1}, \ldots, \zeta_{T}\right\}=1$.

4. Solve the limited commitment algorithm

(a) Choose an initial before-migration value function $V_{0}$. A good choice is $V_{0}=\max \left(W^{\text {perfect }}(\lambda, s, A, t), \Omega(\lambda, s, A, t)\right)$.

(b) For each migration outcome $j=1, \ldots, \mathrm{T}+1$ given by the sort order $\mathcal{D}^{\text {perfect: }}$

i. Compute the total resources in the economy under migration rule $j$ based on village income and the expected income gain. Assign income to the rest-of-village (ROV) household such that $y_{j}^{i}+y_{j}^{R O V, i}=Y_{j}$.

ii. Compute the after-migration value functions $\hat{V}_{0, j}^{i}=f(\hat{\lambda}, s, q, j, \hat{A}, t)$ and $\hat{V}_{0, j}^{R O V, i}=f(\hat{\lambda}, s, q, j, \hat{A}, t)$, assigning consumption based on the after-migration

Pareto weight $\hat{\lambda}_{i}$, and the future continuation value $V_{0, j}^{i}(\lambda, s, A, t)$ and $V_{0, j}^{R O V, i}(\lambda, s, A, t)$.

iii. Impose after-migration incentive constraints
A. Find $\underline{\hat{\lambda}}$ s.t. $\hat{V}_{0, j}^{i}(\underline{\hat{\lambda}}, s, q, j, \hat{A}, t)=\hat{\Omega}^{i}(s, q, j, \hat{A}, t)$
B. Find $\overline{\hat{\lambda}}$ s.t. $\hat{V}_{0, j}^{\mathrm{ROV}, \mathrm{i}}(\overline{\hat{\lambda}}, s, q, j, \hat{A}, t)=\hat{\Omega}^{R O V}(s, q, j, \hat{A}, t)$
C. Impose the IC constraints by updating the Pareto weight: $\hat{\lambda}_{1}=\min \left(\max \left(\zeta_{t} \underline{\hat{\lambda}}, \underline{\hat{\lambda}}\right), \overline{\hat{\lambda}}\right)$
D. Update $\hat{V}_{1, j}^{i}(\hat{\lambda}, s, q, j, \hat{A}, t)=\hat{V}_{0, j}^{i}\left(\hat{\lambda}_{1}, s, q, j, \hat{A}, t\right)$ and $\hat{V}_{1, j}^{R O V, i}(\hat{\lambda}, s, q, j, \hat{A}, t)=$ $\hat{V}_{0, j}^{R O V, i}\left(\hat{\lambda}_{1}, s, q, j, \hat{A}, t\right)$

iv. Compute the before-migration expected value, applying the migration rule

$$
j: V_{0, j}^{i}=f(\hat{\lambda}, s, q, j, \hat{A}, t) ; V_{0, j}^{R O V, i}=f(\hat{\lambda}, s, q, j, \hat{A}, t)
$$

v. Impose the before-migration incentive constraints
A. Find $\underline{\lambda}$ s.t. $V_{0, j}^{i}(\underline{\lambda}, s, q, j, \hat{A}, t)=\Omega^{i}(s, q, j, \hat{A}, t)$
B. Find $\bar{\lambda}$ s.t. $V_{0, j}^{R O V, i}(\bar{\lambda}, s, q, j, \hat{A}, t)=\Omega^{R O V, i}(s, q, j, \hat{A}, t)$
C. Find the updated Pareto weight that satisfies both constraints: $\lambda_{1}=$ $\min (\max (\underline{\lambda}, \underline{\lambda}), \bar{\lambda})$
D. Update the value functions: $V_{1, j}^{i}(\lambda, s, A, t)=V_{0, j}^{i}\left(\lambda_{1}, s, A, t\right)$ and $V_{1, j}^{R O V}(\lambda, s, A, t)=$ $V_{0, j}^{\mathrm{ROV}, \mathrm{i}}\left(\lambda_{1}, s, A, t\right)$

(c) Iterate Steps $4(\mathrm{~b}) \mathrm{i}$ to $4(\mathrm{~b}) \mathrm{vD}$ until the before-migration value function has converged i.e., $\left|V_{1 j}^{i}-V_{0 j}^{i}\right|<\epsilon$ for some small $\epsilon$. 
(d) Compute total welfare for migration decision $j$ by $W_{j}=\sum_{i}\left(\lambda_{i} V_{1 j}^{i}+V_{1 j}^{R O V}\right)$

(e) Choose $j$ that maximizes total welfare and save total resources $Y_{1}=Y_{j}$

5. Compute the new distribution of agents across the state space, imposing the migration policy function and the before-migration and after-migration intervals

6. Repeat Steps 4(b)i to 4 e until total resources $Y_{1}$ has converged. This implies that the migration decision has reached a fixed point.

7. Find the values of the scaling factors that solve the budget constraint: solve $Z_{1}=$ $\left\{\zeta_{-1}^{*}, \zeta_{0}^{*}, \ldots, \zeta_{T}^{*}\right\}$ such that excess demand is equal to zero for each $t$.

8. Update $Z_{0}$ and iterate Steps 4-7 until $\left|Z_{1}-Z_{0}\right|<\epsilon$ for some small $\epsilon$.

\section{A.3.1 Checking $N$ household approximation}

Our "rest of village" approach is based on the approach in Ligon et al. (2002). As described by the algorithm, we then solve the limited commitment model assuming that there is household $i$ and the rest of the village. This means that we are assuming that the multiplier on the incentive compatibility constraint is equal to the sum of the $N-1$ individual constraints. This is a large assumption, and so it is natural to ask how close the computational approximation is. Fortunately, the approximation appears to work well. For a version of the model without aggregate shocks and without endogenous migration, it is possible to solve the model for a continuum of agents, following Krueger and Perri (2010). The tables below (replicated from the appendix in Morten (2019)) compare the model solution to the continuum case with the "rest of village" approximation. The number of households in the table refers to how many average households the rest of village is assumed to incorporate (this essentially sets the "size" of the rest of the village relative to one household). As the table shows, the approximation between solving the model with the continuum and the discrete method is fairly close on several measures of income and consumption. 
Appendix Figure 1: Table from Morten (2019)

Appendix Table 27: Comparison of discrete approximation to continuum

\begin{tabular}{lccccc}
\hline & Continuum & \multicolumn{4}{c}{ Discrete } \\
& $(1)$ & $(2)$ & $(3)$ & $(4)$ & $(5)$ \\
& & $4 \mathrm{HH}$ & $10 \mathrm{HH}$ & $30 \mathrm{HH}$ & $50 \mathrm{HH}$ \\
\hline Mean income & 1.500 & 1.500 & 1.500 & 1.500 & 1.500 \\
Mean consumption & 1.500 & 1.500 & 1.500 & 1.500 & 1.500 \\
Min consumption & 1.073 & 1.099 & 1.099 & 1.099 & 1.099 \\
Max consumption & 1.765 & 1.807 & 1.790 & 1.694 & 1.631 \\
Standard deviation consumption & 0.160 & 0.315 & 0.301 & 0.222 & 0.163 \\
Correlation income, consumption & 0.808 & 0.976 & 0.964 & 0.876 & 0.806 \\
Risk sharing beta & 0.324 & 0.767 & 0.726 & 0.486 & 0.328 \\
\hline
\end{tabular}

Notes: Table compares the limited commitment solution calculated two different methods. 


\section{A.4 Properties of migration decision}

This section examines the migration decision. First, we derive the migration rule under perfect risk sharing to show how the policy rule depends on both the Pareto weight and the gain from migrating. Next, we show the how the properties of the transfer (i.e., whether it is financial or utility) interact with the value of the subsidy and the autarky migration decision.

\section{A.4.1 Optimal migration under perfect risk sharing}

This section derives the migration rule under perfect risk sharing.

If household $i$ is in the village, they earn $e_{i}$. If they migrate, they earn $\mathbb{E} m_{i}$ and need to pay the utility cost $d$. The social planner chooses migration (II) and consumption $c$ for each household by maximizing:

$$
\max _{\left\{\mathbb{I}_{i}, c_{i}\right\}_{i=1, \ldots, N}} \sum_{i} \lambda_{i}\left[u\left(c_{i}\right)-\mathbb{I}_{i} d\right]
$$

such that $\sum_{i} c_{i}=\sum_{i}\left(\left(1-\mathbb{I}_{i}\right) e_{i}+\mathbb{I} m_{i}\right)$

Notice that because of the utility cost of migrating, this problem is not equivalent to simply (i) maximizing total resources and (ii) dividing them based on Pareto weights - it is particularly costly to the social planner to send households with a large Pareto weight to migrate. The optimal migration rule will be a function of the returns to migrating and the Pareto weight.

Conditional on migration decisions, total resources are given by $Y$. The FOC imply that each household receives a share $\alpha_{i}\left(\lambda_{i}\right)$ of total resources:

$$
\begin{aligned}
\lambda_{i} u^{\prime}\left(c_{i}\right) & =\lambda_{j} u^{\prime}\left(c_{j}\right), \forall i, j \\
\frac{u^{\prime}\left(c_{i}\right)}{u^{\prime}\left(c_{j}\right)} & =\frac{\lambda_{j}}{\lambda_{i}} \\
\left(\frac{c_{i}}{c_{j}}\right)^{-\gamma} & =\frac{\lambda_{j}}{\lambda_{i}} \\
c_{i} & =c_{j}\left(\frac{\lambda_{j}}{\lambda_{i}}\right)^{\frac{-1}{\gamma}}=\tilde{\lambda}_{i}^{\frac{1}{\gamma}} c_{j}
\end{aligned}
$$

And, then, imposing the budget constraint: 


$$
\begin{array}{r}
\sum_{i} c_{i}=Y \\
c_{j}\left(1+\sum_{i \neq j} \tilde{\lambda}_{i}^{\frac{1}{\gamma}}\right)=Y \\
c_{j}=\frac{1}{1+\sum_{i \neq j} \tilde{\lambda}_{i}^{\frac{1}{\gamma}}} Y \\
\rightarrow c_{i}=\underbrace{\frac{\tilde{\lambda}_{i}^{\frac{1}{\gamma}}}{1+\sum_{i \neq j} \tilde{\lambda}_{i}^{\frac{1}{\gamma}}}}_{\alpha_{i}} Y
\end{array}
$$

(and, note, $\tilde{\lambda}_{i}=\left[\frac{\alpha_{i}}{1-\alpha_{i}}\right]^{\gamma}$ ).

Which households should migrate? Conditional on $N-1$ migration decisions, the total resources, assuming that total income from the other $N-1$ households is $\bar{y}$, is:

$$
\begin{array}{r}
Y_{\text {no mig }}=y_{i}+\bar{Y} \\
Y_{\text {mig }}=m_{i}+\bar{Y}
\end{array}
$$

The return to the network of $i$ migrating is proportional to the gain in income of migrating:

$$
\begin{aligned}
& \sum_{i} \lambda_{i}\left[u\left(\alpha_{i} Y_{\text {mig }}\right)-u\left(\alpha_{i} Y_{\text {nomig }}\right)\right] \\
\approx & \sum_{i} \lambda_{i} \alpha_{i} u^{\prime}\left(\alpha_{i} Y_{\text {no mig }}\right) \Delta Y_{\text {mig-no mig }}
\end{aligned}
$$

The cost to the network of $i$ migrating is:

$$
-\lambda_{i} d
$$

So it is optimal for $i$ to migrate, holding everything else constant, if:

$$
\sum_{i} \lambda_{i} \alpha_{i} u^{\prime}\left(\alpha_{i} Y_{\text {no mig }}\right) \Delta Y_{\text {mig-no mig }}>\lambda_{i} d
$$

Notice that if $\lambda_{i}=1 \forall i$, this implies that $\alpha_{i}=\frac{1}{N}$, and we get that migration is optimal if the marginal benefit exceeds the marginal cost:

$$
u^{\prime}\left(\frac{Y_{\text {no mig }}}{N}\right) \Delta Y_{\text {mig-no mig }}>\frac{d}{N}
$$


Notice that to compute this we need to know total resources of all other households. Without any constraints, we should consider $2^{N}$ permutations of which agent migrates, which is infeasible. Instead, we note that migration will depend on the return, $\Delta Y_{\text {mig-no mig, }}$ and the cost which is proportional to $\lambda_{i}$. We want to find the correct order that people would migrate so we can consider the net return of the next agent to migrate holding all others constant, which only has dimension $N$, which is feasible. We can do this by (i) guessing a migration order, based on return and Pareto weight, (ii) assuming this is the correct order, compute total resources sequentially and then the net return to migrating, (iii) check the order we guessed is correct, (iv) if not, update the proposed order of migration and compute again until we have the order correct. 


\section{A.4.2 Value of subsidies: perfect risk sharing compared to autarky}

This appendix derives some results regarding the welfare gain of a financial subsidy compared to a utility subsidy. We then use these results to develop intuition for when a migration subsidy will lead to a crowding-out of risk sharing and when it will lead to a crowding-in. We consider two extremes: perfect risk sharing, where all income is equally pooled and so consumption is equivalent to mean income, and autarky, where households consume their own income.

The key insight is that a financial subsidy acts as insurance and so it provides a larger welfare gain if income is risky compared to if income is less risky. A utility subsidy does not provide insurance. It thus provides a relatively lower benefit when income is risky compared with when income is less risky. In comparison, if all income is equally pooled, neither the welfare value of the financial subsidy nor the utility subsidy depend on income.

Consider a migration income process, $y_{m} \sim F\left(\mu_{m}, \sigma_{m}\right)$. Define implicitly three certainty equivalent values of migrating - no subsidy, financial subsidy, and utility subsidy, respectively - by:

$$
\begin{aligned}
u(c e) & =E u\left(y_{m}\right) \\
u\left(c e^{\mathrm{fin}}\right) & =E u\left(y_{m}+d^{\mathrm{fin}}\right) \\
u\left(c e^{\mathrm{utility}}\right) & =E u\left(y_{m}\right)+d^{\mathrm{utility}}
\end{aligned}
$$

Define the change in utility as the new utility minus the no-subsidy utility:

$$
\begin{aligned}
\Delta c e^{\mathrm{fin}} & =c e^{\mathrm{fin}}-c e \\
\Delta c e^{\mathrm{utility}} & =c e^{\mathrm{utility}}-c e
\end{aligned}
$$

Consider a mean-preserving change in the distribution arising from increasing the standard deviation of the income distribution. If utility is concave, then the following statements are true:

1. $\frac{\partial c e}{\partial \sigma_{m}}<0$ i.e., a riskier income stream has a lower certainty equivalent value.

2. $\frac{\partial \Delta c e^{\text {fin }}}{\partial \sigma_{m}}>0$ i.e., the increase in the certainty equivalent value of a financial transfer increases in the riskiness of migration income. This is because a financial transfer is more valuable when income is lower, which, for a mean-preserving spread, occurs when the variance of income is larger.

3. $\frac{\partial \Delta c \text { utility }^{\text {to }}}{\partial \sigma_{m}}<0$ i.e., the increase in the certainty equivalent value of a utility subsidy decreases in the riskiness of migration income. This is because a riskier income process has a lower $c e$, and given utility curvature, a smaller consumption increase is required to generate the same utility gain. 
Appendix Figure 2 gives a numerical example to illustrate the difference between a financial and a utility shock. Panel (a) plots the utility of the migration gamble in gray, where the standard deviation is given by the $x$-axis. As expected, the value of the gamble is decreasing in income risk. The dashed line shows the value of the gamble when there is a financial shock. Panel (b) plots the implied gain in consumption equivalent units. The consumption equivalent gain is increasing in income risk. Panel (c) and (d) repeat the exercise for a utility shock. In panel (c), the utility shock leads to a parallel shift in utility. Panel (d) shows that the consumption-equivalent value of the utility shock decreases with income risk.

Instead, if income was fully pooled, households consume expected income. Define the (equivalent) expected income of migrating under three scenarios - no subsidy, financial subsidy, and utility subsidy, respectively - by:

$$
\begin{aligned}
E_{y} & =E_{m} y_{m} \\
E_{y}^{\text {fin }} & =E_{m} y_{m}+d^{\text {fin }} \\
u\left(E_{y}^{\text {utility }}\right) & =u\left(E_{y}\right)+d^{\text {utility }}
\end{aligned}
$$

Define the change in expected income as the new (equivalent) expected income minus the no-subsidy expected income:

$$
\begin{aligned}
\Delta E_{y}^{\mathrm{fin}} & =E_{y}^{\mathrm{fin}}-E_{y} \quad\left(=d^{\mathrm{fin}}\right) \\
\Delta E_{y}^{\mathrm{utility}} & =E_{y}^{\text {utility }}-E_{y}
\end{aligned}
$$

Both $\Delta E_{y}^{\text {fin }}$ and $\Delta E_{y}^{\text {utility }}$ are independent of income risk.

The solid magenta line in Appendix Figure 2 illustrates the change in equivalent expected income under perfect risk sharing for a financial shock (Panel (b)) and a utility shock (Panel (d)) for the case of a normally-distributed income variable and log utility. As expected, these quantities do not depend on income risk.

When households are independent, migration decisions are made based on the certainty equivalent value of migration. If households instead were fully pooling income risk, migration decisions would be made based on expected income. A financial subsidy will have a larger effect on the certainty equivalent value of migrating relative to the expected income when income is riskier. In this case, we may expect the incentive effect to be tighter and hence risk sharing to reduce. On the other hand, a utility subsidy will have a smaller effect on the certainty equivalent value of migrating when income is riskier. This may lead to a looser incentive effect and an improvement in risk sharing.

Appendix Figure 3 shows the local derivatives around the point estimates when we consider a mean-preserving change in the income variance, compared to the example. In Figure 2 in the paper we considered a local change in the estimated variance. Because income is log-normally distributed, this thus conflated both an increase in the mean and an increase in the variance in income. In comparison, when we hold the mean effect constant we see comparative statics that align exactly with the intuition above. 
Appendix Figure 2: Motivating figure: financial and utility shocks

(a) Level effects: financial subsidy

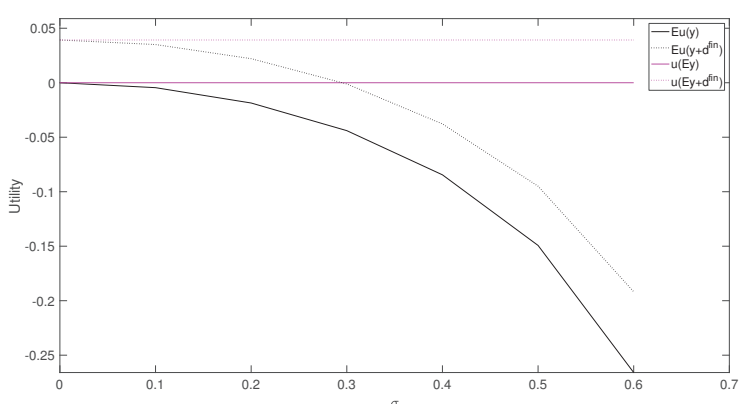

(c) Level effects: utility subsidy

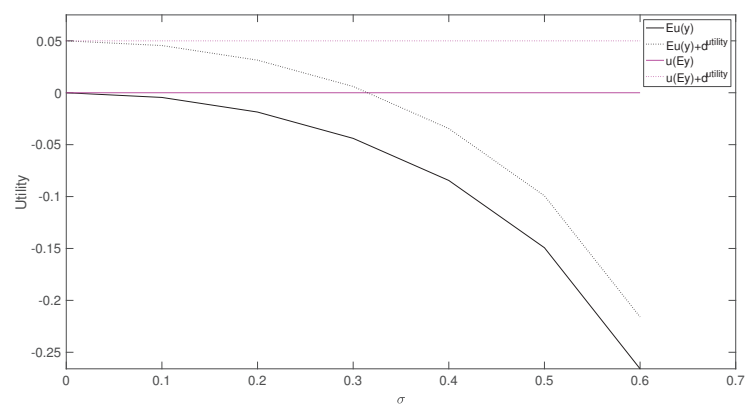

(b) Certainty equivalent gain (financial)

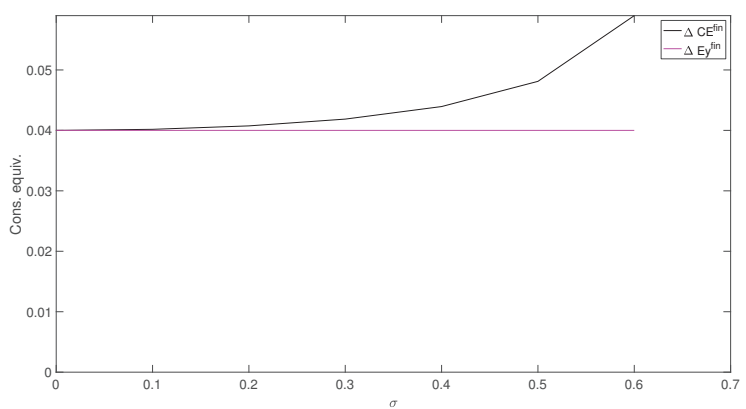

(d) Certainty equivalent gain (utility)

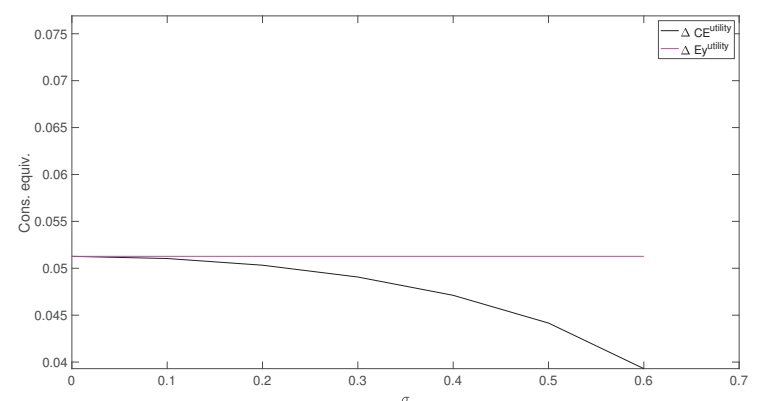

Note: Simulations assuming income is normally distributed with $\mu=1$ and $\sigma$ given by the value on the $\mathrm{x}$ axis and $\log$ utility. The financial shock is equal to 0.04 . The utility shock is equal to 0.05 . 
Computational Result 3. The derivative of the change in risk sharing is increasing in the meanpreserving riskiness of migration income with a financial subsidy

Panel (b) of Appendix Figure 3 plots the effect of a financial subsidy to migrate. Panel (bi) shows that the financial subsidy induces migration under autarky, but only for low levels of income risk. Migration under limited commitment increases by $15 \%$, independent of income risk. Panel (bii) shows that risk sharing improves overall (i.e., the estimated effect on beta is negative). The improvement in risk sharing is largest when income is least risky, although the magnitude is very small in all cases. Panel (biii) shows that welfare increases slightly under autarky, and there is a very small decrease in estimated welfare (because the utility cost of migrating may not be fully compensated) under limited commitment.

Computational Result 4. The derivative of the change in risk sharing is decreasing in the meanpreserving riskiness of migration income with a utility subsidy

Panel (c) of Appendix Figure 3 plots the effect of a utility subsidy to migrate. Panel (ci) shows that the utility subsidy induces migration under autarky, with the largest effect when income is least-risky. The migration effect under limited commitment is relatively flat, although slightly higher when income is less risky. Panel (cii) shows that shows that risk sharing improves overall (i.e., the estimated effect on beta is negative). In comparison to the financial subsidy, the improvement in risk sharing is largest when income is the most risky. Panel (ciii) shows that welfare increase is larger under limited commitment than under autarky; the gap is larger the riskier income is. 
Appendix Figure 3: Comparative statics around income risk: utility and financial subsidies (rescaling mean)

(a) Control group

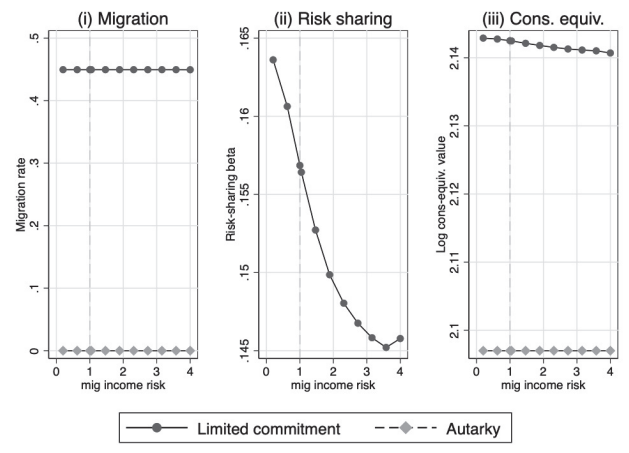

(c) Treatment effect: utility subsidy

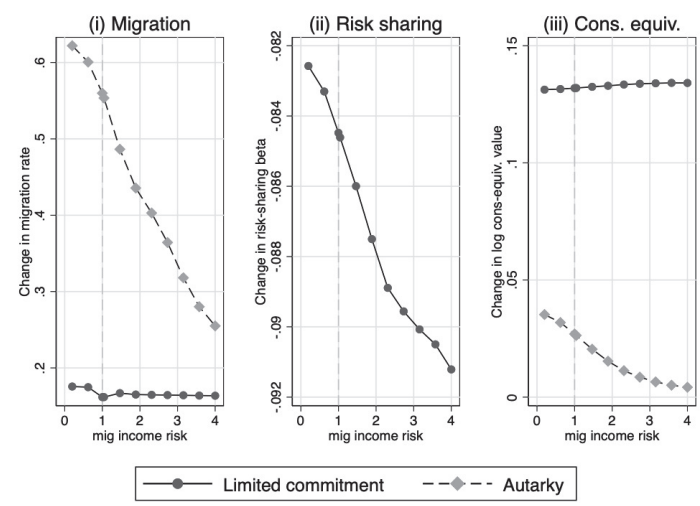

(b) Treatment effect: financial subsidy
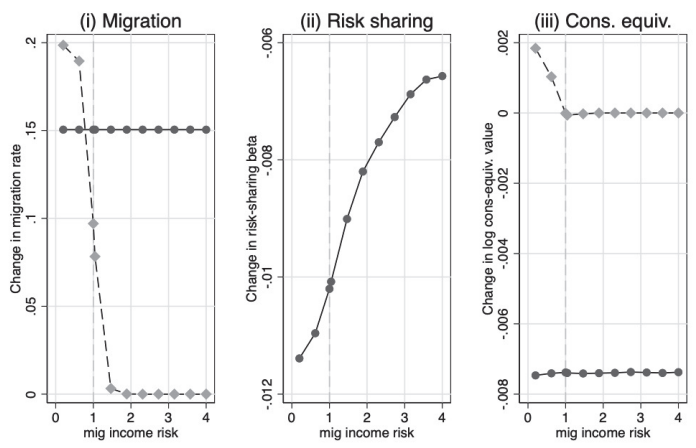

$\longrightarrow$ Limited commitment $\quad----$ Autarky

(d) Treatment effect: combined subsidy

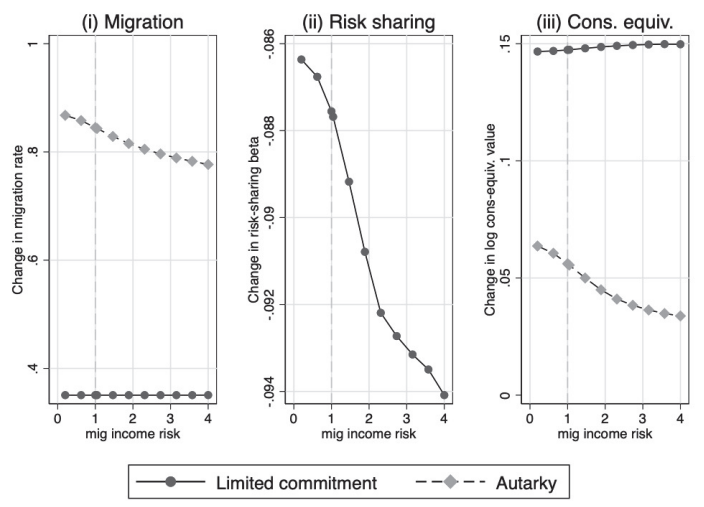

Note: Migration income risk is measured relative to the baseline estimates (i.e., a value of 1 is the baseline estimate). The log-normal distribution is rescaled so that the mean is constant as the risk increases. 


\section{A.5 Standard errors}

To compute standard errors we numerically approximate the variance-covariance matrix. Following the notation in Hansen (2016), the SMM estimator minimizes the weighted deviations of the simulated moment conditions, $\bar{g}_{i}(\beta), \forall i=1, \ldots, l$. The moment vector has dimension $(l \times 1)$ and the parameter vector, $\beta$, has dimension $(k \times 1)$.

The SMM estimator minimizes:

$$
\beta_{S M M}=\operatorname{argmin}_{\beta} \bar{g}(\beta)^{\prime} W \bar{g}(\beta)
$$

where $W$ is a weight matrix of dimension $l \times l$. The variance-covariance matrix is given by:

$$
V_{\beta}=\left(Q^{\prime} W Q\right)^{-1}\left(Q^{\prime} W \Omega W Q\right)\left(Q^{\prime} W Q\right)^{-1}
$$

The matrix $\mathrm{Q}$ is a $l \times k$ gradient matrix of the derivatives of each simulated moment to each parameter:

$$
\widehat{Q}=\mathbb{E} \frac{\partial}{\partial \beta^{\prime}} \bar{g}(\beta)
$$

We estimate $Q$ by numerical differentiation, taking step sizes of $1 \%$ of the estimated value. Because our problem is discrete, we smooth the objective function by a smoothing param-

eter $\lambda=1 e^{-4}$ so that it is possible to compute the numerical derivatives. We approximate $\Omega$ by the sample analog of the simulated moments:

$$
\widehat{\Omega}=\mathbb{E} \bar{g}(\beta) \bar{g}(\beta)^{\prime}
$$




\section{B Empirical appendix}

This appendix provides additional details on empirical issues. We start by discussing transfers and additional results from migrant surveys. We then include supplementary tables and figures discussed in the text.

\section{B.1 Magnitude of transfers in and transfers out}

The summary statistics in Table 1 show that average transfers received by members in the sample is larger than the total transfers given by the sample. The reason for this difference is that only the poorest households in the village (based on land holdings and on experiencing hunger the previous year) were eligible for the experiment. Data was only collected on eligible households, not on the wealthier ineligible households. Thus, if there were transfers between eligible and noneligible households we should expect giving to be smaller than receipts in our sample.

We show in Appendix Table 1 that, as expected, households that are richer transfer more than households that are poorer. The first four rows show mean income in column 1 and net giving (transfers given minus transfers received) as a percent of income in column 2, by income quartile in the data. Net transfers in as a fraction of income decreases monotonically with income: the poorest income quartile has $64 \%$ of income coming from net transfers in, while the richest income quartile has 19\% of income coming from net transfers in. We then construct linear predictions of these patterns in columns 3 and 4 , and extrapolate to the missing top 3/7ths of the income distribution in rows 5 through 7 . Once we do this exercise, we estimate that, at the village level, net giving would be 1723 Taka, suggesting that this linear approximation of transfers over the income distribution can explain the transfer imbalance fairly well.

We note that any imbalance in the total amount of income to be shared amongst eligible households does not affect the Townsend regressions within the observed data, as the village fixed effect is controlling for the total resources in the network. However, this is potentially a concern for the structural estimation, as we impose that total income is equal to total consumption when solving the model. Unfortunately, given the data we have, we are not able to adjust for this in the structural estimation. 


\section{Appendix Table 1: Extrapolated net giving}

\begin{tabular}{|c|c|c|c|c|c|}
\hline \multirow[b]{2}{*}{ Income group } & \multicolumn{2}{|c|}{ Data } & \multicolumn{3}{|c|}{ Linear prediction } \\
\hline & Mean income & $\begin{array}{c}\text { Net giving } \\
\text { (\% of income) }\end{array}$ & Mean income & $\begin{array}{c}\text { Net giving } \\
\text { (\% of income) }\end{array}$ & $\begin{array}{c}\text { Net giving } \\
\text { (level) }\end{array}$ \\
\hline \multicolumn{6}{|c|}{ Data: income quartile } \\
\hline 1 & 4176 & -0.64 & 3678 & -0.57 & -2103 \\
\hline 2 & 7349 & -0.35 & 7560 & -0.43 & -3216 \\
\hline 3 & 10372 & -0.23 & 11443 & -0.28 & -3191 \\
\hline 4 & 16111 & -0.19 & 15326 & -0.13 & -2029 \\
\hline \multicolumn{6}{|c|}{ Extrapolated/missing income groups } \\
\hline 5 & & & 19209 & 0.01 & 271 \\
\hline 6 & & & 23091 & 0.16 & 3708 \\
\hline 7 & & & 26974 & 0.31 & 8282 \\
\hline Overall net giving & & & & & 1723 \\
\hline
\end{tabular}

Note: Our data (control villages) consists of the bottom 4/7ths of the income distribution of villages, and thus the first four rows and first two columns show mean income and mean net giving (transfers given minus received) as a percent of income. The third and fourth columns report a linear prediction of the first two columns, and the fifth through seventh rows extrapolate to the rest of the village. The final column multiplies the fifth and sixth columns to get net giving, and the final row sums this column. 


\section{B.2 Appendix Tables}

\section{Appendix Table 2: Experimental design and data collection timeline}

\begin{tabular}{|c|c|c|c|c|c|c|c|c|c|}
\hline \multirow[t]{2}{*}{ Round } & \multirow[t]{2}{*}{ Date } & \multirow[t]{2}{*}{ Obs } & \multicolumn{4}{|c|}{ Data } & \multirow[t]{2}{*}{ Model period } & \multicolumn{2}{|c|}{ Experiments } \\
\hline & & & Migration & Income & Consumption & Townsend test? & & Main & Additional \\
\hline 1 & $\begin{array}{l}\text { July } 2008 \\
\text { Planting }\end{array}$ & $\begin{array}{c}1900 \mathrm{HH} \\
100 \text { villages }\end{array}$ & $x$ & 12 months & $\begin{array}{c}\text { Varies } \\
(1 \mathrm{wk}-12 \mathrm{mo}) \\
\end{array}$ & Robustness & Pre & $x$ & $x$ \\
\hline 2 & $\begin{array}{l}\text { Nov } 2008 \\
\text { Monga }\end{array}$ & $\begin{array}{c}1900 \mathrm{HH} \\
100 \text { villages }\end{array}$ & $\checkmark$ & 4 months & $\begin{array}{c}\text { Varies } \\
(1 \mathrm{wk}-4 \mathrm{mo})\end{array}$ & $x$ & Active & $\checkmark$ & $x$ \\
\hline 3 & $\begin{array}{l}\text { Nov } 2009 \\
\text { Monga }\end{array}$ & $\begin{array}{c}1900 \mathrm{HH} \\
100 \text { villages }\end{array}$ & $\checkmark$ & $x$ & $\begin{array}{c}\text { Varies } \\
(1 \mathrm{wk}-12 \mathrm{mo})\end{array}$ & $x$ & $x$ & $x$ & $x$ \\
\hline 4 & $\begin{array}{l}\text { July } 2011 \\
\text { Planting }\end{array}$ & $\begin{array}{c}2527 \mathrm{HH} \\
133 \text { villages }\end{array}$ & $\checkmark$ & 12 months & $\begin{array}{c}\text { Varies } \\
\text { (1 wk - } 12 \mathrm{mo})\end{array}$ & $\checkmark$ & Post & $x$ & $\checkmark$ \\
\hline 5 & $\begin{array}{l}\text { Dec } 2013 \\
\text { Monga }\end{array}$ & $\begin{array}{c}2527 \mathrm{HH} \\
133 \text { villages }\end{array}$ & $\checkmark$ & 12 months & $\begin{array}{c}\text { Varies } \\
(1 \mathrm{wk}-3 \mathrm{mo})\end{array}$ & Robustness & $x$ & $x$ & $\checkmark$ \\
\hline
\end{tabular}

Note: The row in bold (Round 4) is the data round primarily used in the analysis in the paper.

Experiments in Round 2 were: Cash, credit, info, control.

Experiments in Round 4 were: Rain insurance, price insurance, credit, conditional credit, job leads, control. Experiments in Round 5 were: Credit, job leads, control.

Consumption recall periods varied by category: Food: 1 week, or 2 weeks if didn't consume in past 1 week; fuel/transport expenses: 1 week; utility bills/rent/health expenses/personal items/entertainment: 1 month; clothing/furniture/events/education/durable purchases: 12 months in rounds 1, 3, and 4, 4 months in round 2 , and 3 months in round 5. 


\section{Appendix Table 3: Migration experiences (destination data)}

\begin{tabular}{|c|c|c|c|c|c|}
\hline & Mean & Std. Div & Min & Max & Obvs. \\
\hline Did you find a job at destination? & 0.979 & 0.143 & 0.0 & 1.0 & 145 \\
\hline Do you think the income/wage is more than your area? & 0.890 & 0.314 & 0.0 & 1.0 & 145 \\
\hline Did anyone from your travel group help in getting the job? & 0.338 & 0.475 & 0.0 & 1.0 & 145 \\
\hline Did anyone else known to you help in getting the job? & 0.234 & 0.425 & 0.0 & 1.0 & 145 \\
\hline Did anyone from your travel group or someone else help you in getting the job? & 0.545 & 0.500 & 0.0 & 1.0 & 145 \\
\hline Did you migrate alone? & 0.228 & 0.421 & 0.0 & 1.0 & 145 \\
\hline Did you expend other costs jointly with your group member? & 0.330 & 0.472 & 0.0 & 1.0 & 112 \\
\hline Did you expend costs for food jointly with your group member? & 0.703 & 0.463 & 0.0 & 1.0 & 37 \\
\hline Did you expend travel costs jointly with your group member? & 0.811 & 0.397 & 0.0 & 1.0 & 37 \\
\hline Did you expend other costs jointly with your group member (specify)? & 0.622 & 0.492 & 0.0 & 1.0 & 37 \\
\hline Are you currently sharing accommodations with a member of your travel group? & 0.705 & 0.458 & 0.0 & 1.0 & 112 \\
\hline Did you only give job information to someone in your travel group? & 0.152 & 0.360 & 0.0 & 1.0 & 112 \\
\hline Did you both give and receive job information from someone in your travel group? & 0.464 & 0.501 & 0.0 & 1.0 & 112 \\
\hline Did you neither give nor receive job info from someone in your travel group? & 0.277 & 0.449 & 0.0 & 1.0 & 112 \\
\hline How many times did you eat in the last week? & 20.510 & 1.768 & 7.0 & 21.0 & 145 \\
\hline How many times did you have a full meal during the last week? & 17.959 & 3.603 & 5.0 & 21.0 & 145 \\
\hline How many times did you have a meal with meat during the last week? & 7.972 & 4.278 & 0.0 & 21.0 & 145 \\
\hline How many times did you have a meal with rice during the last week? & 19.138 & 3.499 & 3.0 & 21.0 & 145 \\
\hline How much did you spend on food in total during the last week? & 16.943 & 26.170 & 0.0 & 95.7 & 145 \\
\hline How much did you receive from your employer for food during the last week? & 101.437 & 37.048 & 0.0 & 262.9 & 145 \\
\hline How much did you spend on accommodation during the last week? & 0.901 & 2.630 & 0.0 & 15.0 & 145 \\
\hline How much did you spend on other expenditure during the last week? & 8.453 & 8.035 & 0.0 & 69.3 & 145 \\
\hline How much did you receive as charity during the last week? & 0.116 & 0.921 & 0.0 & 10.0 & 145 \\
\hline Did you only receive job information from someone in your travel group? & 0.107 & 0.311 & 0.0 & 1.0 & 112 \\
\hline
\end{tabular}

\footnotetext{
Statistics taken from the 2008 destination survey. Monetary values are in Taka.
} 
Appendix Table 4: Migration experiences (endline data)

\begin{tabular}{|c|c|c|c|}
\hline Variable & $\begin{array}{c}(1) \\
\text { Not Incentivized } \\
\text { Mean/SE }\end{array}$ & $\begin{array}{c}(2) \\
\text { Incentivized } \\
\text { Mean/SE }\end{array}$ & $\begin{array}{l}\text { T-test } \\
\text { Difference } \\
(1)-(2)\end{array}$ \\
\hline Did you migrate to a rural area? & $\begin{array}{c}0.652 \\
(0.031)\end{array}$ & $\begin{array}{c}0.661 \\
(0.027)\end{array}$ & -0.008 \\
\hline When you migrated, did you migrate alone? & $\begin{array}{c}0.266 \\
(0.040)\end{array}$ & $\begin{array}{c}0.258 \\
(0.023)\end{array}$ & 0.009 \\
\hline Did you migrate with the same person last year? & $\begin{array}{c}0.429 \\
(0.054)\end{array}$ & $\begin{array}{c}0.481 \\
(0.027)\end{array}$ & -0.051 \\
\hline Did you work in the agricultural sector? & $\begin{array}{c}0.538 \\
(0.034)\end{array}$ & $\begin{array}{c}0.609 \\
(0.030)\end{array}$ & -0.071 \\
\hline Did you work in the transportation sector? & $\begin{array}{c}0.103 \\
(0.034)\end{array}$ & $\begin{array}{c}0.090 \\
(0.014)\end{array}$ & 0.013 \\
\hline Did you work as a non-ag. day laborer? & $\begin{array}{c}0.239 \\
(0.038)\end{array}$ & $\begin{array}{c}0.178 \\
(0.023)\end{array}$ & 0.061 \\
\hline Did you work in a different sector? & $\begin{array}{c}0.120 \\
(0.024)\end{array}$ & $\begin{array}{c}0.123 \\
(0.018)\end{array}$ & -0.003 \\
\hline Did you earn more than expected? & $\begin{array}{c}0.147 \\
(0.028)\end{array}$ & $\begin{array}{c}0.219 \\
(0.024)\end{array}$ & $-0.072^{*}$ \\
\hline Did you earn less than expected? & $\begin{array}{c}0.560 \\
(0.035)\end{array}$ & $\begin{array}{c}0.491 \\
(0.028)\end{array}$ & 0.069 \\
\hline Did you earn the same as expected? & $\begin{array}{c}0.293 \\
(0.033)\end{array}$ & $\begin{array}{c}0.290 \\
(0.023)\end{array}$ & 0.003 \\
\hline How much did you earn in cash? & $\begin{array}{l}3448.995 \\
(294.937)\end{array}$ & $\begin{array}{l}3370.511 \\
(207.954)\end{array}$ & 78.483 \\
\hline How much did you earn in non-monetary support? & $\begin{array}{c}845.163 \\
(112.789)\end{array}$ & $\begin{array}{l}1007.192 \\
(87.802)\end{array}$ & -162.029 \\
\hline How much money did you send back home? & $\begin{array}{c}976.902 \\
(225.667)\end{array}$ & $\begin{array}{c}660.644 \\
(83.199)\end{array}$ & 316.258 \\
\hline What were the savings from migration? & $\begin{array}{l}1554.685 \\
(116.222)\end{array}$ & $\begin{array}{l}1883.278 \\
(101.400)\end{array}$ & $-328.593^{* *}$ \\
\hline $\mathrm{N}$ & 184 & 489 & \\
\hline Clusters & 31 & 68 & \\
\hline
\end{tabular}

Notes: Taken from 2008 endline survey The value displayed for $\mathrm{t}$-tests are the differences in the means across the groups. Standard errors are clustered at variable village. ${ }^{* * *}, * *$, and ${ }^{*}$ indicate significance at the 1, 5, and 10 percent critical level. 


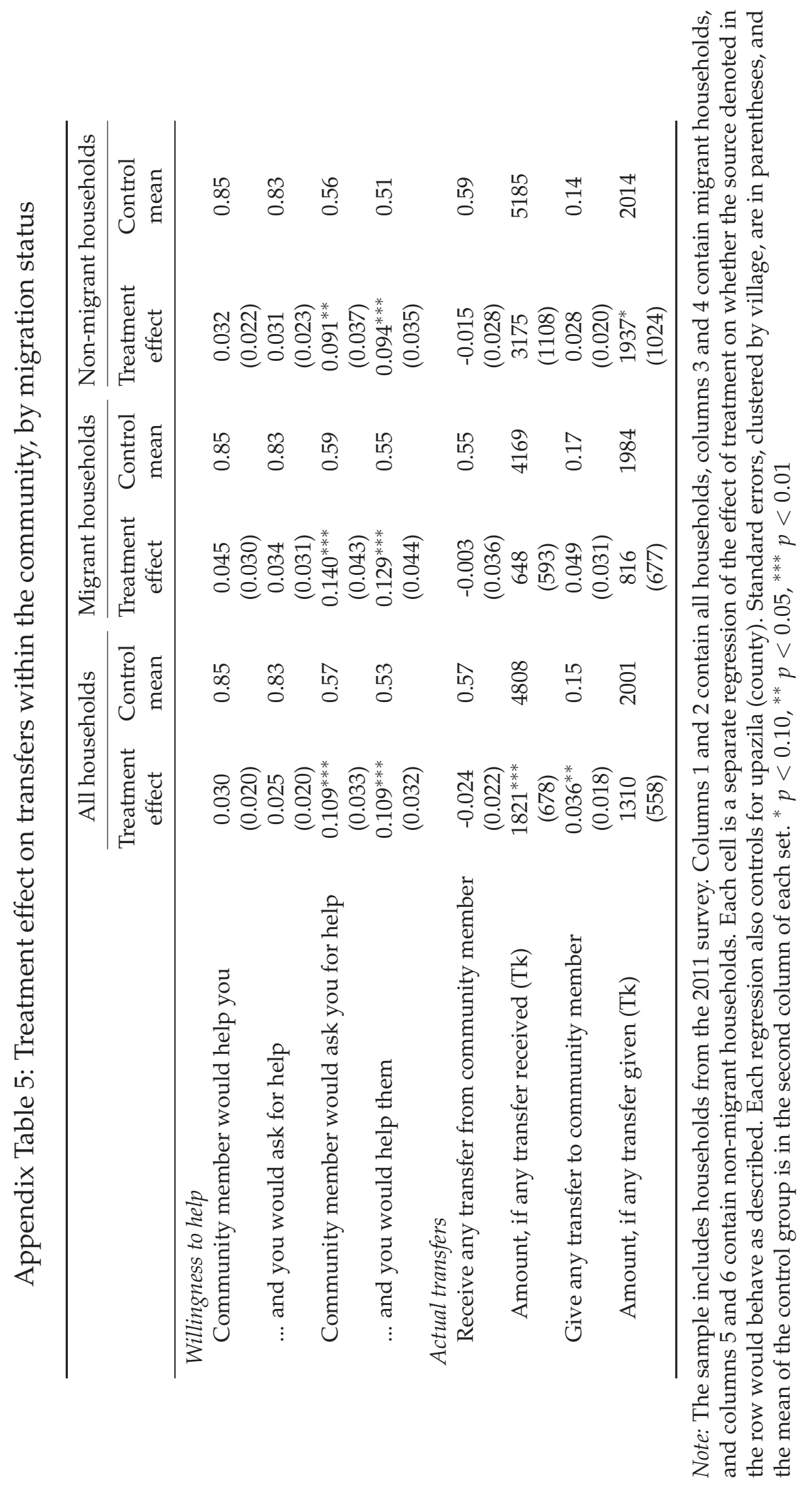


Appendix Table 6: Effect of migration incentives on exposure of consumption to income, cross-treatments

\begin{tabular}{|c|c|c|c|}
\hline & \multicolumn{3}{|c|}{ Log total consumption } \\
\hline & (1) & (2) & (3) \\
\hline Log income & $\begin{array}{c}0.157^{* * *} \\
(0.027)\end{array}$ & $\begin{array}{c}0.156^{* * *} \\
(0.027)\end{array}$ & $\begin{array}{c}0.158^{* * *} \\
(0.028)\end{array}$ \\
\hline Log income $x$ treatment & $\begin{array}{c}-0.073^{* * *} \\
(0.027)\end{array}$ & & \\
\hline \multicolumn{4}{|l|}{ Treatment group restrictions } \\
\hline Log income $x$ unassigned group & & $\begin{array}{c}-0.085^{* *} \\
(0.035)\end{array}$ & \\
\hline Log income $x$ self-formed group & & $\begin{array}{l}-0.018 \\
(0.033)\end{array}$ & \\
\hline Log income $\mathrm{x}$ assigned group & & $\begin{array}{c}-0.106^{* * *} \\
(0.037)\end{array}$ & \\
\hline \multicolumn{4}{|l|}{ Treatment destination restrictions } \\
\hline Log income $\mathrm{x}$ unassigned destination & & & $\begin{array}{c}-0.065^{* *} \\
(0.030)\end{array}$ \\
\hline Log income $\mathrm{x}$ assigned destination & & & $\begin{array}{c}-0.082^{* *} \\
(0.032)\end{array}$ \\
\hline unconditional credit $\times \log y$ & $\begin{array}{l}-0.020 \\
(0.038)\end{array}$ & $\begin{array}{l}-0.020 \\
(0.039)\end{array}$ & $\begin{array}{l}-0.021 \\
(0.039)\end{array}$ \\
\hline Observations & 1857 & 1857 & 1857 \\
\hline R-squared & 0.186 & 0.188 & 0.187 \\
\hline
\end{tabular}

Note: The sample includes households from the 2011 survey. The dependent variable is log annual percapita total consumption. The main independent variable is log annual per-capita income, interacted with the respective treatment variable. All models control for village fixed effects and log income interacted with 2011 treatment arms. Standard errors, clustered by village, are in parentheses. ${ }^{*} p<0.10,{ }^{* *} p<0.05,{ }^{* * *}$ $p<0.01$ 


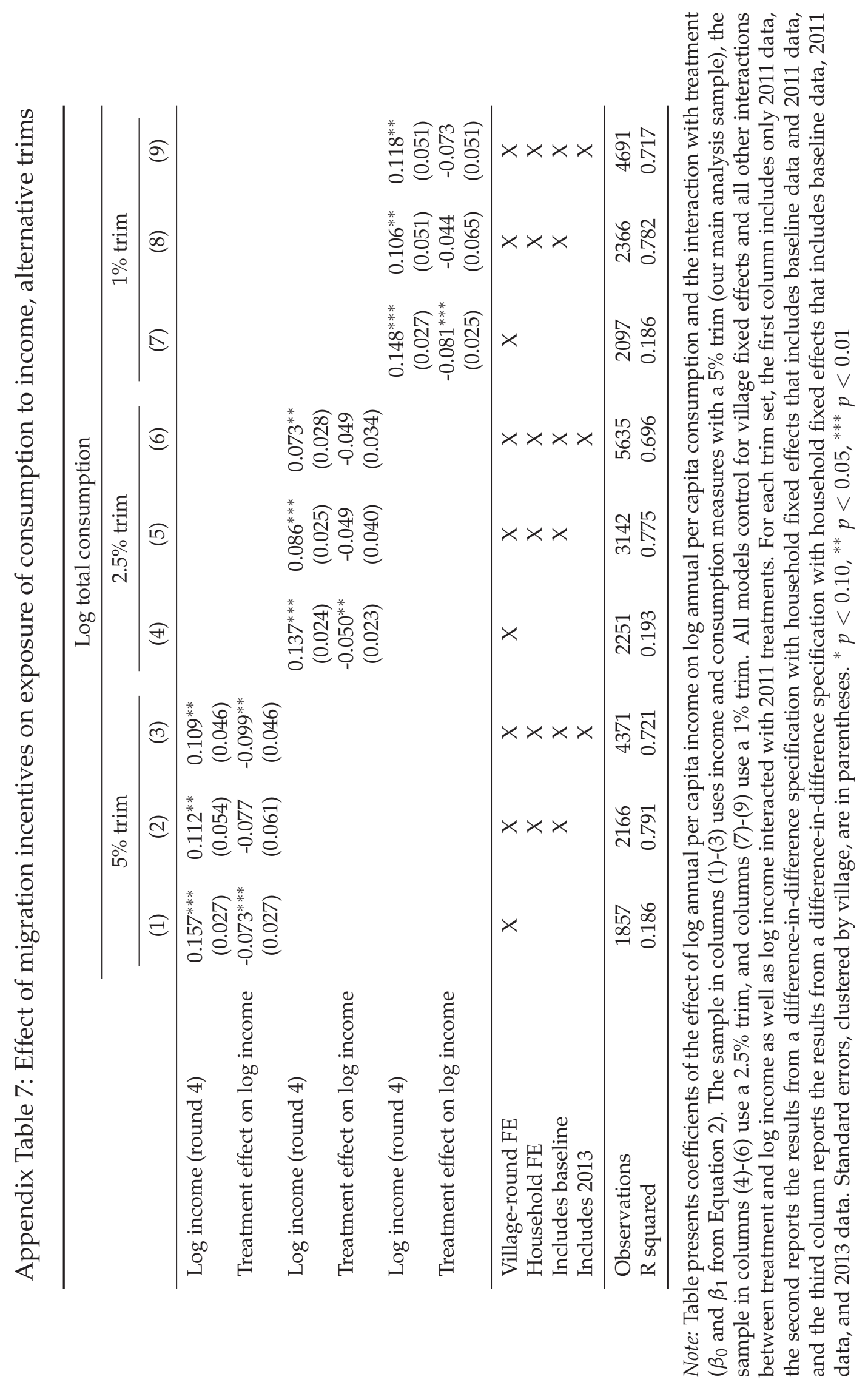




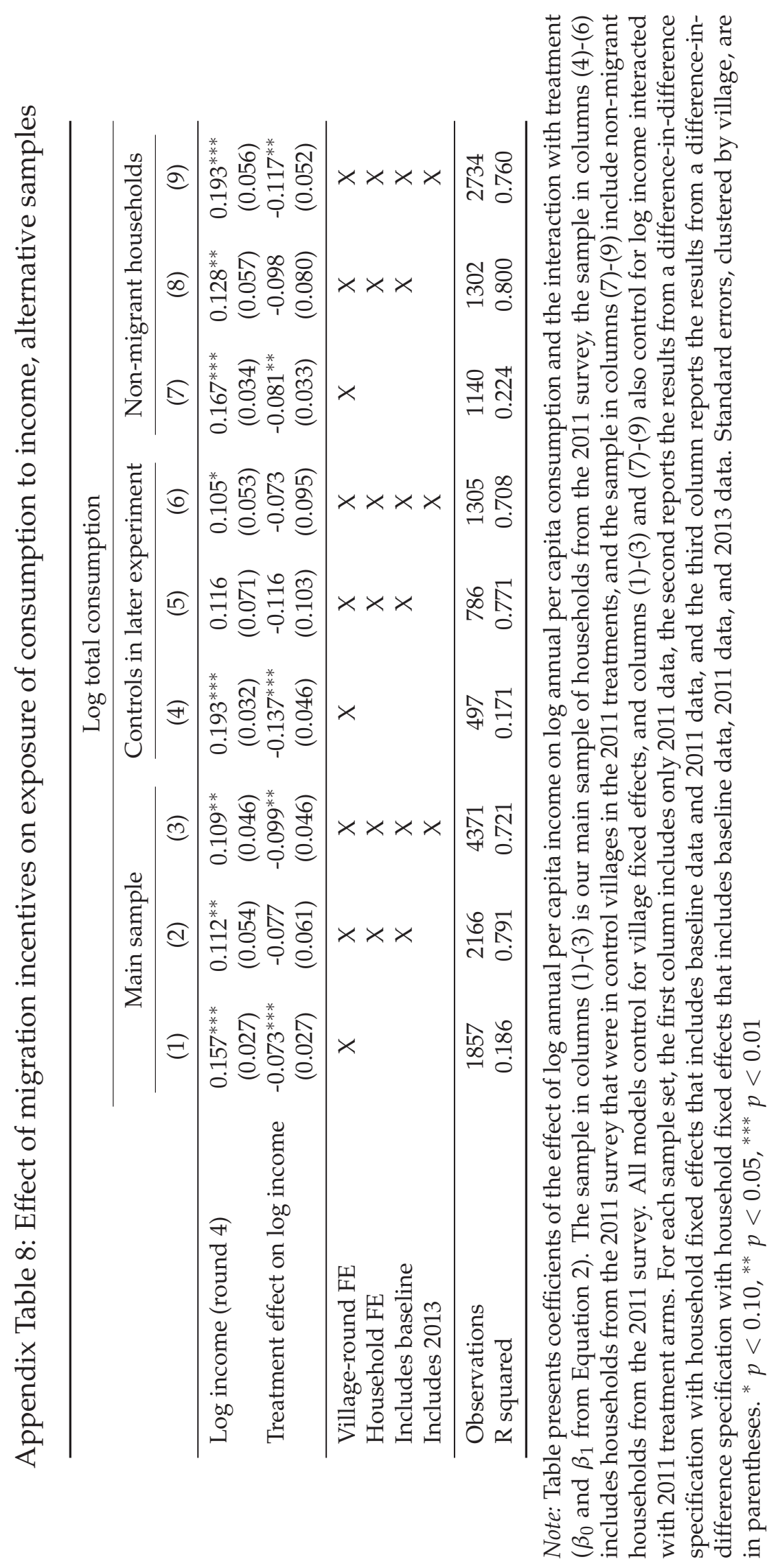


Appendix Table 9: Effect of migration incentives on exposure of consumption to income, different household size assumptions

\begin{tabular}{|c|c|c|c|c|c|}
\hline \multirow[b]{2}{*}{ Size: } & \multicolumn{5}{|c|}{ Log total consumption } \\
\hline & $\begin{array}{c}\text { past } 7 \text { days } \\
\text { (main spec.) } \\
\text { (1) }\end{array}$ & $\begin{array}{c}\text { current } \\
\text { (2) }\end{array}$ & $\begin{array}{c}\text { past } 14 \text { days } \\
\text { (3) }\end{array}$ & $\begin{array}{l}\text { equiv. scale } \\
\text { (4) }\end{array}$ & $\begin{array}{c}7 \text { days }+ \text { mig } \\
\text { (5) }\end{array}$ \\
\hline Log income $x$ treat, size: past 7 days & $\begin{array}{c}-0.073^{* * *} \\
(0.027)\end{array}$ & & & & \\
\hline Log income $x$ treat, size: current & & $\begin{array}{l}-0.046^{*} \\
(0.026)\end{array}$ & & & \\
\hline Log income $x$ treat, size: past 14 days & & & $\begin{array}{c}-0.077^{* * *} \\
(0.026)\end{array}$ & & \\
\hline Log income $x$ treat, size: equiv. scale & & & & $\begin{array}{c}-0.080^{* * *} \\
(0.026)\end{array}$ & \\
\hline Log income $x$ treat, size: 7 days + migrants & & & & & $\begin{array}{c}-0.069^{* *} \\
(0.027)\end{array}$ \\
\hline Observations & 1857 & 1854 & 1860 & 1854 & 1858 \\
\hline R-squared & 0.186 & 0.183 & 0.191 & 0.221 & 0.184 \\
\hline
\end{tabular}

Note: The sample includes households from the 2011 survey. The dependent variable is log of annual percapita total consumption. The main independent variable is log of annual per capita income, interacted with treatment. The definition of household size used to calculate per capita terms is the total number of household members present in at least the past 7 days at the time of the interview in column (1), the total number of household members currently present at the time of the interview in column (2), the total number of household members present in at least the past 14 days at the time of the interview in column (3), an equivalence scale in column (4), and the total number of household members present in the past 7 days plus any migrants who have not yet returned in column (5). We use Townsend's equivalence scale in which the weights are: 1.0 for adult males, 0.9 for adult females, 0.94 for males $13-18,0.83$ for females $13-18$, 0.67 for children 7-12, 0.52 for children 4-6, 0.32 for children 1-3, and 0.05 for infants. All models control for log of income interacted with 2011 treatment arms and village fixed effects. Standard errors, clustered by village, are in parentheses. ${ }^{*} p<0.10,{ }^{* *} p<0.05,{ }^{* * *} p<0.01$ 
Appendix Table 10: Effect of migration incentives on exposure of consumption to income, reverse regression

\begin{tabular}{lcc}
\hline & $(1)$ & $(2)$ \\
& Log consumption (fwd) & Log income (rev) \\
\hline Log income x control & $0.204^{* * *}$ & \\
& $(0.045)$ & \\
Log income x treatment & $0.131^{* * *}$ & \\
& $(0.043)$ & $0.567^{* * *}$ \\
Log consumption x control & & $(0.118)$ \\
& & $0.385^{* * *}$ \\
Log consumption x treatment & & $(0.120)$ \\
& & 0.360 \\
Fwd/Rev ratio, control & 1857 & 0.342 \\
Fwd/Rev ratio, treat & 0.186 & 1857 \\
Observations & 0.166 \\
R-squared & & \\
\hline
\end{tabular}

Note: The sample includes households from the 2011 survey. In column (1) the dependent variable is log of annual per-capita total consumption and the main independent variable is log of annual per-capita income, interacted with the respective treatment variable. In column (2) the dependent and independent variables are reversed. All models control for village fixed effects and the independent variable interacted with 2011 treatment arms. Standard errors, clustered by village, are in parentheses. ${ }^{*} p<0.10,{ }^{* *} p<0.05$, ${ }^{* * *}$ $p<0.01$ 
Appendix Table 11: Effect of migration incentives on exposure of consumption to income, by income components

\begin{tabular}{lccc}
\hline & \multicolumn{3}{c}{ Log total consumption } \\
\cline { 2 - 4 } & $(1)$ & $(2)$ & $(3)$ \\
\hline Log income $x$ treatment & $-0.073^{* * *}$ & & \\
& $(0.027)$ & & \\
Log village income $x$ treatment & & $-0.069^{* * *}$ & \\
& & $(0.024)$ & -0.048 \\
Log migration income x treatment & & & $0.036)$ \\
\hline Observations & & & 792 \\
R-squared & 1857 & 1857 & 792 \\
\hline
\end{tabular}

Note: The sample includes households from the 2011 survey. The dependent variable is log of annual percapita total consumption and the main independent variable is log of annual per-capita income, interacted with the respective treatment variable. Income is defined as total income in column (1), village income in column (2), and migration income (among migrants) in column (3). All models control for village fixed effects and the independent variable interacted with 2011 treatment arms. Standard errors, clustered by village, are in parentheses. ${ }^{*} p<0.10,{ }^{* *} p<0.05,{ }^{* * *} p<0.01$

Appendix Table 12: Savings compared to income

\begin{tabular}{lccc}
\hline & Round 1 & Round 2 & Round 4 \\
\hline Liquid assets & & & \\
$\quad$ Mean liquid assets & 91 & 148 & 296 \\
$\quad$ Mean liquid assets saved recently* & 2 & 3 & 32 \\
Cash savings & 228 & 215 & 163 \\
$\quad$ Mean cash savings & & & 155 \\
$\quad$ Mean cash saved in past 12 months & & & \\
Income & 6185 & 3999 & 8770 \\
$\quad$ Mean village income & & 2760 & 1959 \\
$\quad$ Mean migration income (migrants) & & 4819 & 9502 \\
$\quad$ Mean total income & 3366 & 3085 & 4721 \\
$\quad$ SD village income & & 2178 & 1304 \\
$\quad$ SD migration income (migrants) & & 3455 & 4728 \\
$\quad$ SD total income & &
\end{tabular}

Note: Table reports data from control villages only. All numerical values are in per capita terms. ${ }^{*}$ Liquid assets saved recently corresponds to the last 4 months for round 2 and the last 12 months for rounds 1 and 4. 


\section{Appendix Table 13: Robustness over dynamics and utility shock}

\begin{tabular}{|c|c|c|c|c|}
\hline & $\begin{array}{l}(1) \\
\text { Data }\end{array}$ & $\begin{array}{c}(2) \\
\text { Full model }\end{array}$ & $\begin{array}{c}\text { (3) } \\
\text { No utility shock }\end{array}$ & $\begin{array}{c}(4) \\
\text { No utility shock and no mig asset }\end{array}$ \\
\hline \multicolumn{5}{|l|}{ Targeted moments } \\
\hline Risk sharing (control) & 0.16 & 0.16 & -0.00054 & -0.0016 \\
\hline Risk sharing (treatment effect) & -0.073 & -0.055 & 0.000055 & 0.00027 \\
\hline Mean migration rate & 0.39 & 0.45 & 0.47 & 0.40 \\
\hline Mig. treatment effect (during RCT) & 0.22 & 0.35 & 0.13 & 0.20 \\
\hline Mig. treatment effect (after RCT) & 0.094 & 0.15 & 0.12 & 0.13 \\
\hline Migrate neither during/after RCT (control) & 0.49 & 0.32 & 0.31 & 0.37 \\
\hline Migrate during and after RCT (control) & 0.23 & 0.22 & 0.25 & 0.16 \\
\hline Migrate neither during/after RCT (treatment effect) & -0.17 & -0.16 & -0.15 & -0.14 \\
\hline Migrate during and after RCT (treatment effect) & 0.15 & 0.14 & 0.11 & 0.12 \\
\hline Mean log home income (migrant) & 1.80 & 1.57 & 1.15 & 0.87 \\
\hline Std. log home income (migrant) & 0.67 & 0.29 & 0.46 & 0.44 \\
\hline Mean log home income (nonmigrant) & 2.13 & 2.63 & 2.72 & 2.80 \\
\hline Std. log home income (nonmigrant) & 0.56 & 0.33 & 0.49 & 0.59 \\
\hline Log std. mig. income (migrant) & 0.27 & 0.23 & 0.28 & 0.28 \\
\hline Log mean mig. income (nonmigrant prior pd.) & 0.60 & 0.39 & 0.57 & 0.80 \\
\hline Log mean mig. income (migrant prior pd.) & 0.73 & 0.51 & 0.62 & 0.80 \\
\hline \multicolumn{5}{|l|}{ Estimated parameters } \\
\hline CRRA parameter & & 1.88 & 1.80 & 1.73 \\
\hline Opportunity cost of migration & & 0.15 & 0.19 & 0.25 \\
\hline Utility cost of migrating & & 0.075 & 0.13 & 0.088 \\
\hline Utility subsidy & & 0.075 & & \\
\hline Decay rate of utility subsidy & & 0.15 & & \\
\hline Mean home income & & 2.23 & 2.08 & 2.15 \\
\hline Std. home income & & 0.58 & 0.88 & 1.02 \\
\hline Mean city income with contact & & 0.38 & 0.37 & 0.61 \\
\hline Std. city income with contact & & 0.78 & 0.85 & 0.71 \\
\hline Prob. get contact & & 0.79 & 0.93 & \\
\hline Prob. lose contact if migrate & & 0.44 & 0.32 & \\
\hline Prob. lose contact if don't migrate & & 0.66 & 0.74 & \\
\hline Discount factor & & 0.70 & 0.70 & 0.70 \\
\hline \multicolumn{5}{|l|}{ Model criterion } \\
\hline Model criterion & & 1.72 & 2.91 & 3.01 \\
\hline
\end{tabular}

Notes: Utility shock, if estimated, decays over 3 periods. Financial variables measured in annual log (thousands of Taka). 
Appendix Table 14: Robustness over discount factor and subsistence

\begin{tabular}{|c|c|c|c|c|}
\hline & $\begin{array}{c}(1) \\
\text { Data }\end{array}$ & $\begin{array}{c}(2) \\
\beta=0.7\end{array}$ & $\begin{array}{c}(3) \\
\beta=0.8\end{array}$ & $\begin{array}{c}(4) \\
\beta=0.9\end{array}$ \\
\hline Risk sharing (control) & 0.16 & 0.16 & 0.082 & -0.0054 \\
\hline Risk sharing (treatment effect) & -0.073 & -0.055 & -0.045 & 0.00037 \\
\hline Mean migration rate & 0.39 & 0.45 & 0.45 & 0.44 \\
\hline Mig. treatment effect (during RCT) & 0.22 & 0.35 & 0.35 & 0.16 \\
\hline Mig. treatment effect (after RCT) & 0.094 & 0.15 & 0.15 & 0.12 \\
\hline Migrate neither during/after RCT (control) & 0.49 & 0.32 & 0.33 & 0.34 \\
\hline Migrate during and after RCT (control) & 0.23 & 0.22 & 0.22 & 0.22 \\
\hline Migrate neither during/after RCT (treatment effect) & -0.17 & -0.16 & -0.15 & -0.14 \\
\hline Migrate during and after RCT (treatment effect) & 0.15 & 0.14 & 0.13 & 0.11 \\
\hline Mean log home income (migrant) & 1.80 & 1.57 & 1.61 & 1.34 \\
\hline Std. log home income (migrant) & 0.67 & 0.29 & 0.30 & 0.51 \\
\hline Mean log home income (nonmigrant) & 2.13 & 2.63 & 2.67 & 3.06 \\
\hline Std. log home income (nonmigrant) & 0.56 & 0.33 & 0.33 & 0.61 \\
\hline Log std. mig. income (migrant) & 0.27 & 0.23 & 0.25 & 0.27 \\
\hline Log mean mig. income (nonmigrant prior pd.) & 0.60 & 0.39 & 0.39 & 0.64 \\
\hline Log mean mig. income (migrant prior pd.) & 0.73 & 0.51 & 0.51 & 0.68 \\
\hline \multicolumn{5}{|l|}{ Estimated parameters } \\
\hline CRRA parameter & & 1.88 & 1.94 & 1.75 \\
\hline Opportunity cost of migration & & 0.15 & 0.14 & 0.16 \\
\hline Utility cost of migrating & & 0.075 & 0.072 & 0.11 \\
\hline Utility subsidy & & 0.075 & 0.076 & 0.058 \\
\hline Decay rate of utility subsidy & & 0.15 & 0.13 & 0.41 \\
\hline Mean home income & & 2.23 & 2.26 & 2.38 \\
\hline Std. home income & & 0.58 & 0.58 & 1.01 \\
\hline Mean city income with contact & & 0.38 & 0.37 & 0.48 \\
\hline Std. city income with contact & & 0.78 & 0.80 & 0.78 \\
\hline Prob. get contact & & 0.79 & 0.78 & 0.94 \\
\hline Prob. lose contact if migrate & & 0.44 & 0.44 & 0.42 \\
\hline Prob. lose contact if don't migrate & & 0.66 & 0.66 & 0.68 \\
\hline Discount factor & & 0.70 & 0.80 & 0.90 \\
\hline \multicolumn{5}{|l|}{ Model criterion } \\
\hline Model criterion & & 1.72 & 2.09 & 2.80 \\
\hline
\end{tabular}

Notes: The cost to consume a subsistence level of consumption, estimated to be 600 calories per day, is estimated to be 250 Taka/month (3000 Taka annually). Because the model is measured in income, not consumption, units, we set the subsistence level to 1000 Taka instead of 3000 Taka to match the proportion of people below subsistence as measured by income with the proportion of people below subsistence as measured by consumption. 


\section{B.3 Appendix Figures}

Appendix Figure 4: Distributions of baseline annual village income and consumption, by treatment
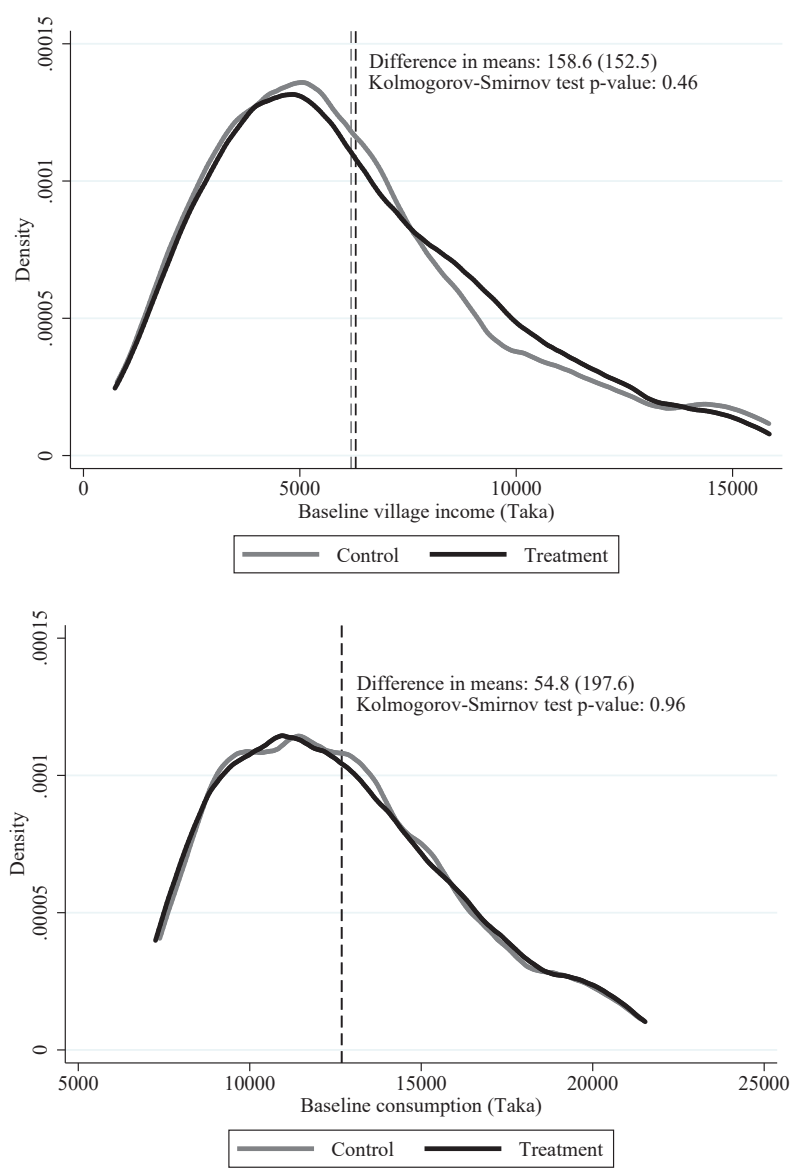

Notes: Top figure is baseline annual village income and the bottom figure is baseline annual consumption, in Taka. Black lines are treatment households and gray lines are control households. The dotted vertical lines are the means of the distributions. 
Appendix Figure 5: Dynamics of migration subsidy: Robustness

(a) Mig asset $\checkmark$; utility sub. $\checkmark$

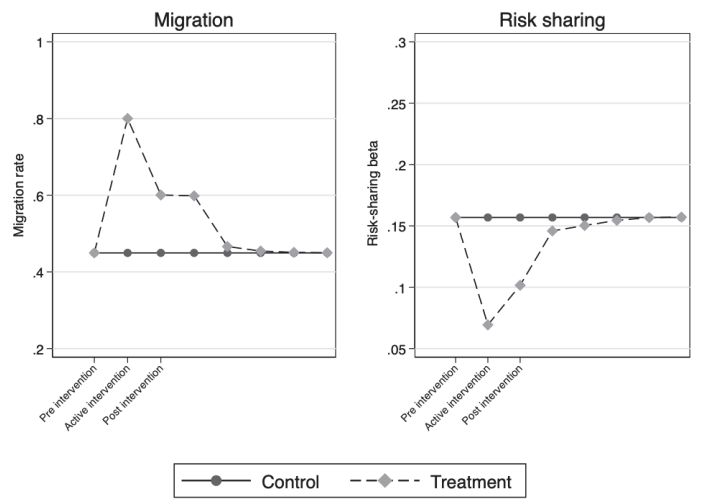

(b) Mig asset $\checkmark$; utility sub. X

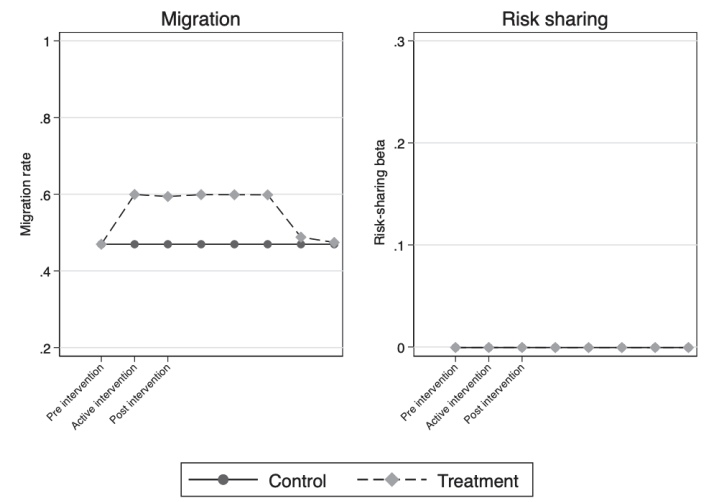

(c) Mig asset X; utility sub. X
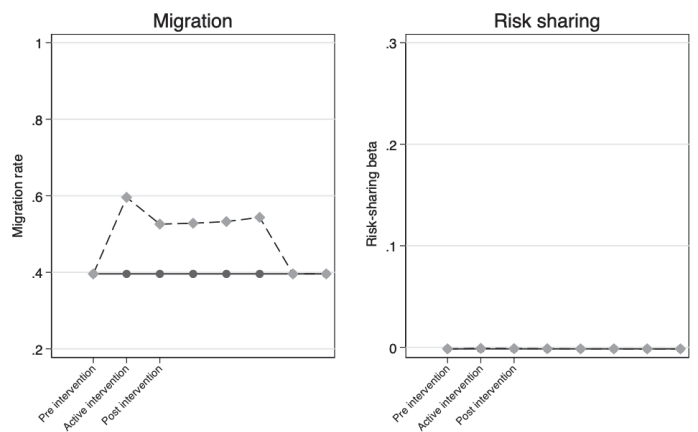

$\longrightarrow$ Control $\quad--\bullet-$ - Treatment 


\section{Appendix Figure 6: Decomposition of permanent shock}

(a) Temporary: financial shock only
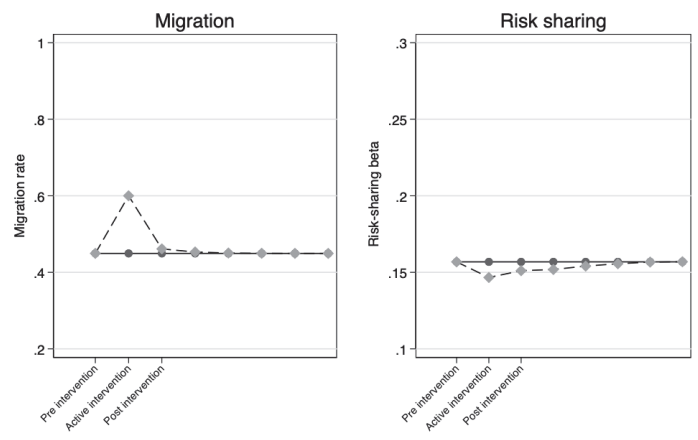

$\longrightarrow$ Control $\quad----$ Treatment

(c) Temporary: utility shock only

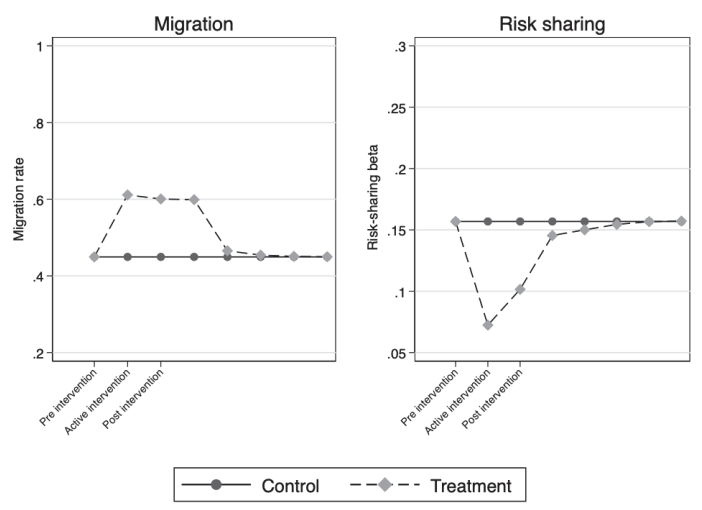

(e) Temporary: combined shock

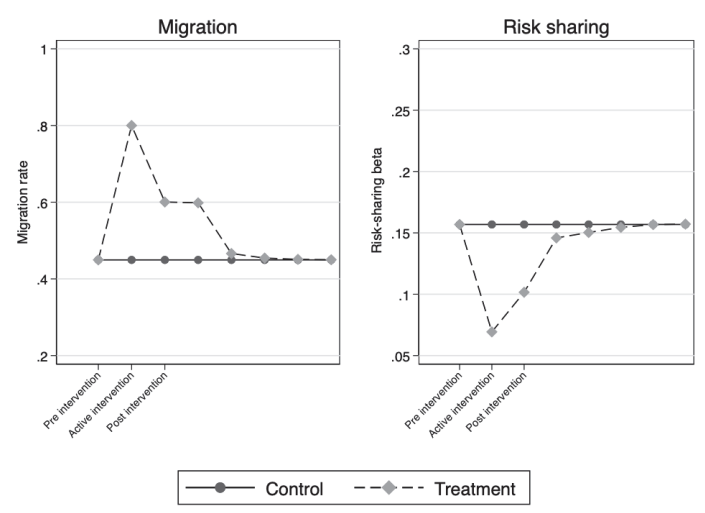

(b) Permanent: financial shock only

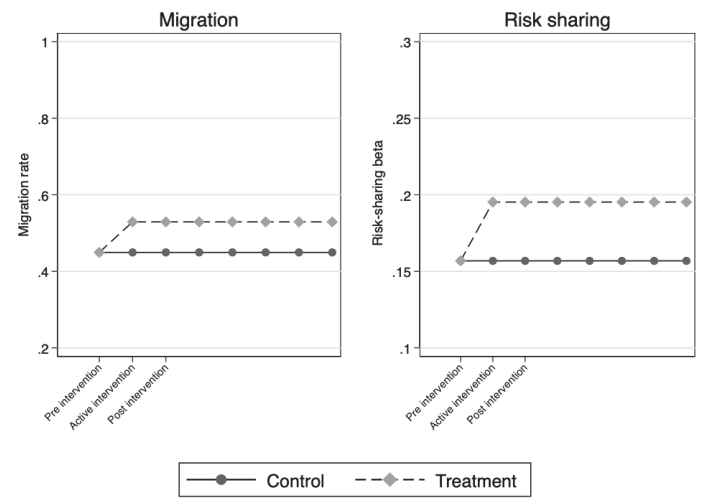

(d) Permanent: utility shock only

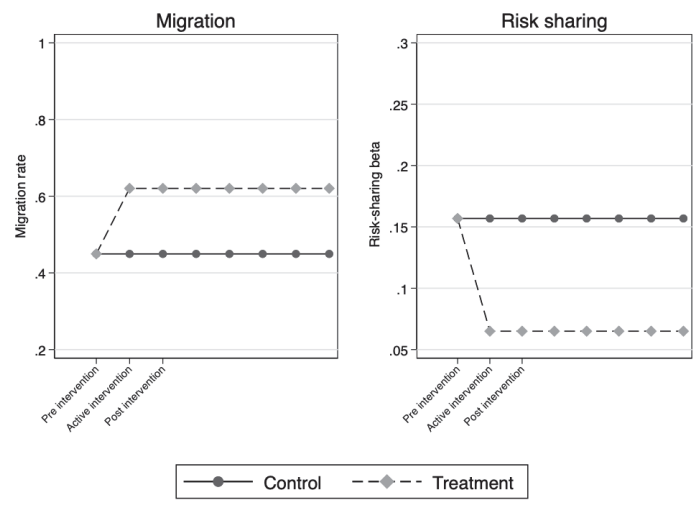

(f) Permanent: combined shock

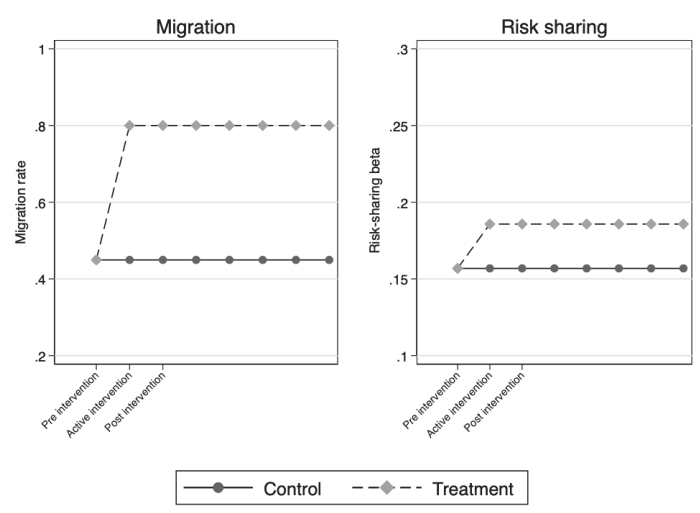

